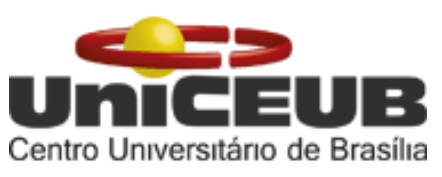

CENTRO UNIVERSITÁRIO DE BRASÍLIA - UniCEUB

FACULDADE DE TECNOLOGIA E CIÊNCIAS SOCIAIS APLICADAS - FATECS

PROGRAMA DE INICIAÇÃO CIENTÍFICA

MATHEUS SOARES NASCIMENTO

NATHALIA SALOMÃO DAMIÃO

DISPOSITIVO PORTÁTIL PARA DIAGNÓSTICO DE DOENÇAS DO CORAÇÃo

BRASÍLIA-DF

2018 


\title{
DISPOSITIVO PORTÁTIL PARA DIAGNÓSTICO DE DOENÇAS DO CORAÇÃO
}

\author{
Relatório final de pesquisa de Iniciação Científica \\ apresentado à Assessoria de Pós-Graduação e \\ Pesquisa pela Faculdade de Tecnologia e Ciências \\ Sociais Aplicadas - FATECS
}

Orientação: Prof. MSc. Luciano Henrique Duque 


\title{
DISPOSITIVO PORTÁTIL PARA DIAGNÓSTICO DE DOENÇAS DO CORAÇÃo
}

\author{
Matheus Soares Nascimento - UniCEUB, PIC voluntário \\ matheus.msn99@sempreceub.com
}

\author{
Natália Salomão Damião - UniCEUB, PIC voluntário \\ nathalia.damiao@sempreceub.com
}

\author{
Msc. Luciano Henrique Duque - UniCEUB, professor orientador \\ luciano.duque@ceub.edu.br
}

Com a oportunidade provida pelo Centro Universitário de Brasília - UniCEUB e apoio do Conselho Nacional de Desenvolvimento Científico e Tecnológico - CNPQ, foi possível elaborar uma pesquisa e o desenvolvimento de um dispositivo, que reuni duas grandes áreas da ciência, a medicina e a engenharia, com a necessidade de realizar exames cardiológicos e o envio dos resultados, em comunidades desprovidas de recursos, como comunidades indígenas, ribeirinhas e algumas até próximas de grandes centros urbanos. O equipamento desenvolvido para sanar essas dificuldades, é um dispositivo portátil e de baixo custo, capaz de realizar a captação, o tratamento e o envio dos sinais cardíacos, para um médico cardiologista analisar e diagnosticar o paciente, mesmo estando distante do local de atendimento. 0 exame realizado pelo dispositivo não é invasivo, utiliza-se eletrodos de superfície, que são posicionados em volta e sobre o peito do paciente. Os eletrodos são distribuídos em um posicionamento específico sobre tronco, que pode ser realizado por um especialista ou leigo, que apenas precisa seguir as instruções que acompanham o equipamento, essa é uma das maiores vantagens do dispositivo, de poder ser utilizado por qualquer pessoa. 0 equipamento conta com luzes indicadoras de funcionamento, duas baterias, chave interruptora de alimentação, aplicativos para smartfone e computador, uma placa de circuito controladora e uma de amplificadores e filtros. A placa de amplificadores e filtros, recebe os sinais cardíacos por meio do cabo que é ligado aos eletrodos, amplifica esse sinal por meio de amplificadores de instrumentação e filtra utilizando filtros de primeira ordem passivos e filtros de segunda ordem ativos, 
sendo todos analógicos, o sinal entra na placa com a tensão máxima de pico a pico de um milivolt e sai da mesma com uma tensão entre zero a cinco volts, tornando o sinal aplicacional. A placa controladora, gerencia as luzes de funcionamento, a comunicação e amostra em frequências especificas o sinal tratado pela placa dos amplificadores e filtros. Enviando em seguida para o aplicativo, que recebe via bluetooth o sinal cardíaco e aplica a um filtro digital, feito com a transformada de Wavelet, para aproveitar sua característica de multiresolução, que permite decompor um sinal em diversas faixas de frequências. Após o filtro digital o sinal é armazenado e imprimido na tela do aplicativo, permitindo ao usuário analisar pontos específicos. 0 envio ocorre no fim da utilização, ou durante o processo de utilização caso for solicitado pelo usuário, e o meio de comunicação é o email. 0 equipamento foi submetido a testes, que avaliaram seu desempenho de captação e tratamento dos sinais cardíacos, para a comparação foi utilizado um eletrocardiógrafo profissional e para que os sinais sejam iguais em ambos dispositivos um equipamento simulador de sinais cardíacos é utilizado. Nos testes de envio, foi utilizado um smartfone e um computador, ambos conectados à internet e que continham o mesmo aplicativo do projeto. Com os testes concluídos, foi possível analisar e concluir, que os resultados foram satisfatórios, atingindo a meta inicialmente proposta, ou seja, a realização dos exames nas condições mencionadas.

Palavras-Chave: Aplicativo. Microcontrolador. Transformada Wavelet. Sinais cardíacos. 


\section{LISTA DE FIGURAS}

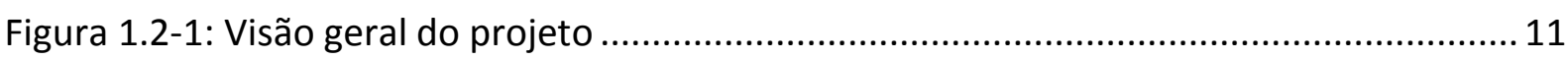

Figura 2.1-1: Esquema do sistema de condução intracardíaco............................................. 16

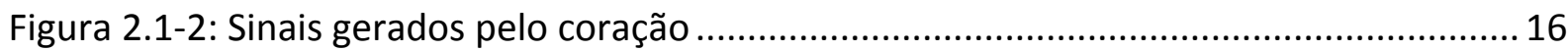

Figura 2.1-3: Áreas do coração onde são geradas as ondas .............................................. 17

Figura 2.1-4: Derivações eletrocardiográficas ...................................................................... 18

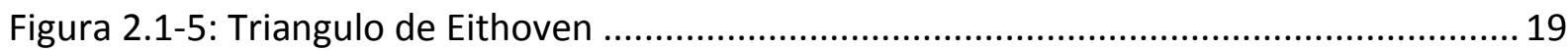

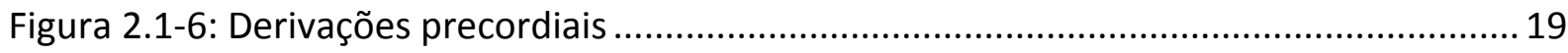

Figura 2.1-7: Derivações e seus respectivos sinais .............................................................. 20

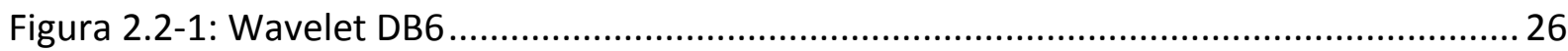

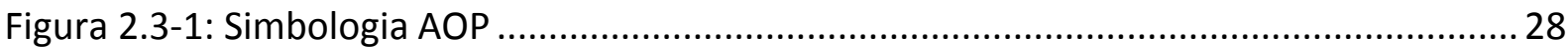

Figura 2.3-2: Sistema com realimentação do sinal............................................................... 29

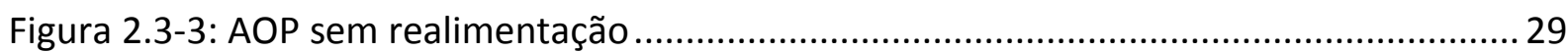

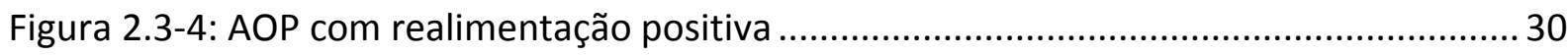

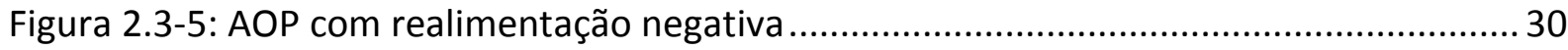

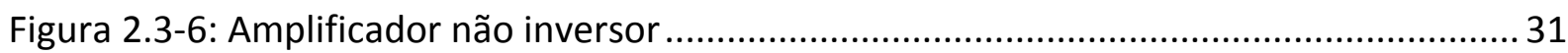

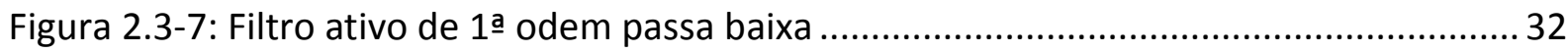

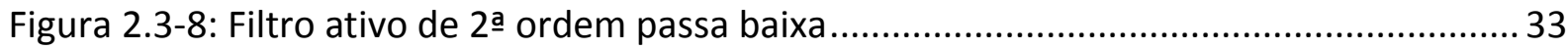

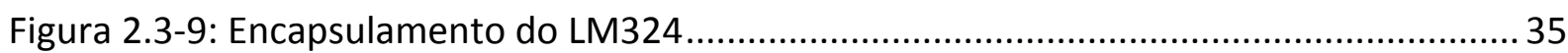

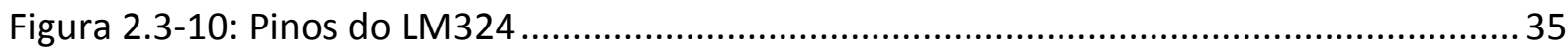

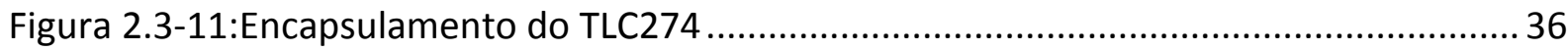

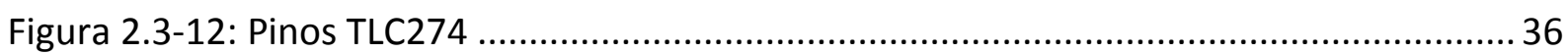

Figura 2.4-1: Arquitetura básica de um Microcontrolador ................................................... 37

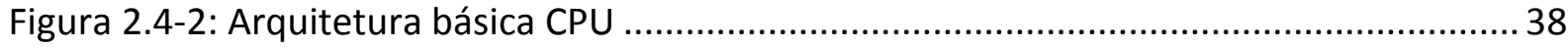

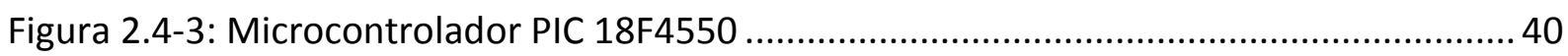

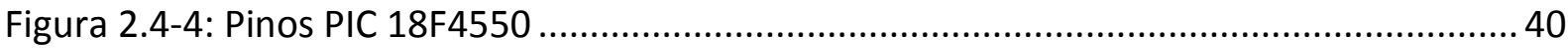

Figura 3.1-1: Diagrama de blocos do Projeto ....................................................................... 42

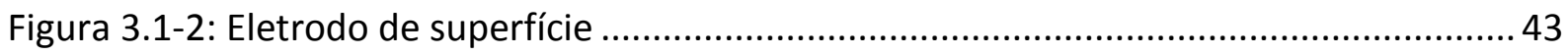

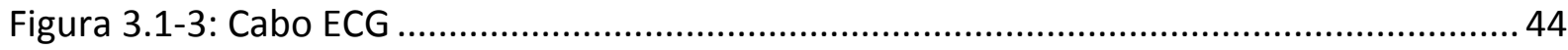

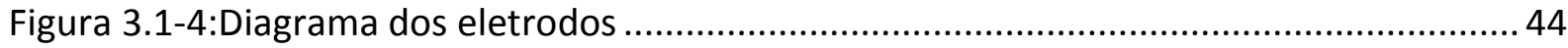

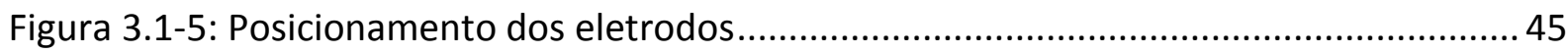




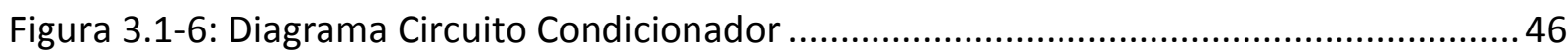

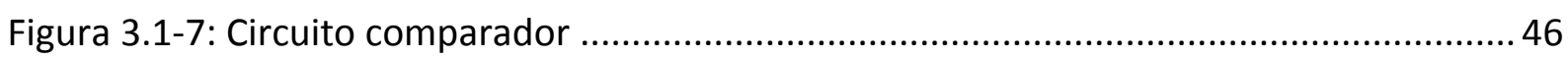

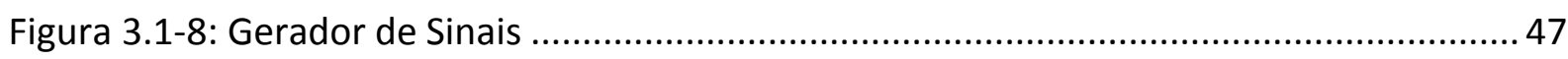

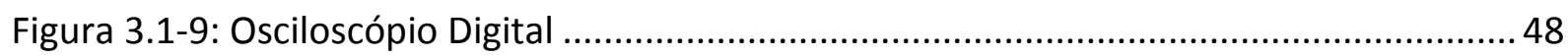

Figura 3.1-10: Tela do osciloscópio sem o ajuste do CMRR ................................................. 48

Figura 3.1-11: Tela do osciloscópio com o ajuste do CMRR................................................. 49

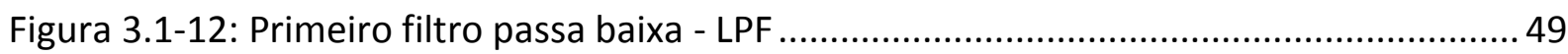

Figura 3.1-13: Segundo filtro passa baixa - LPF .............................................................. 50

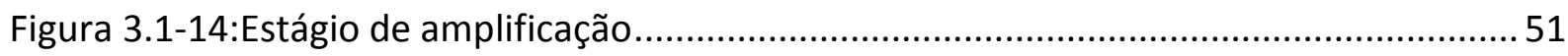

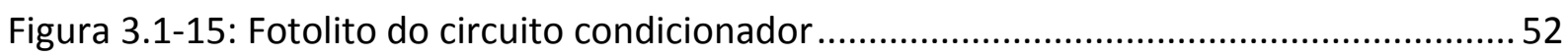

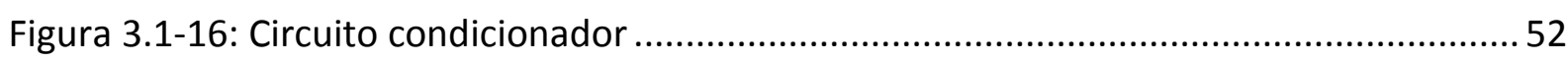

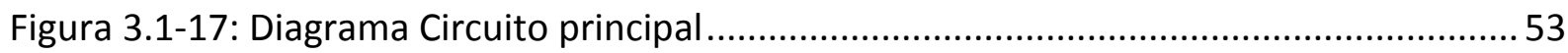

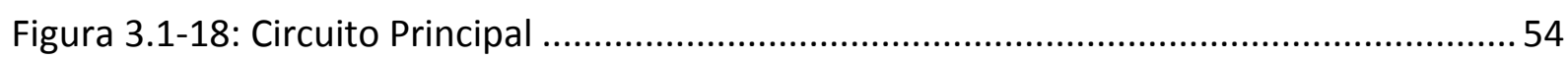

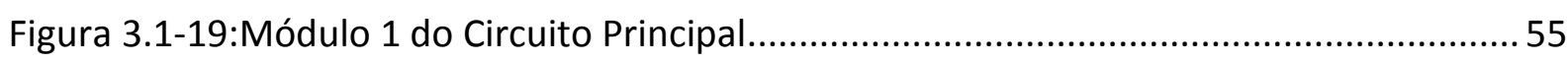

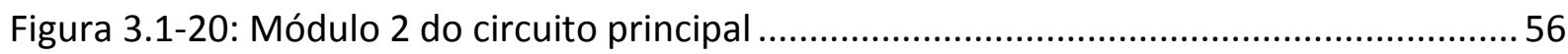

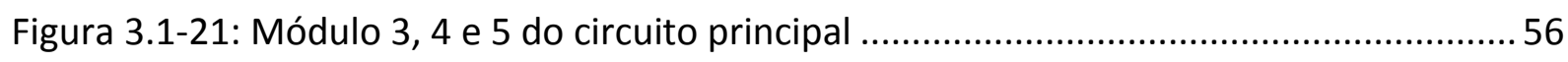

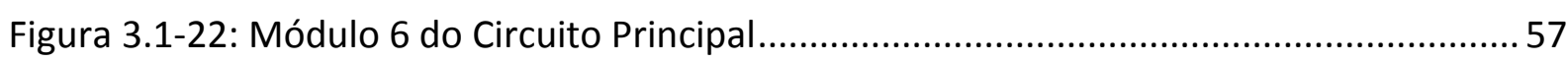

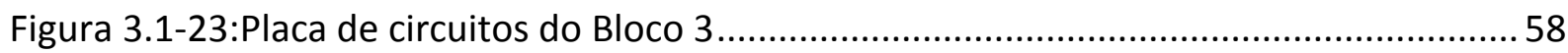

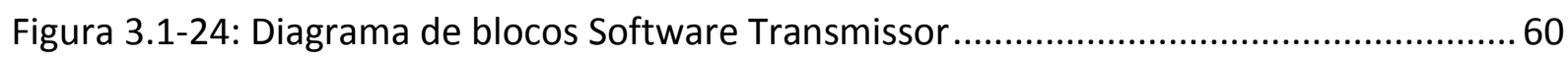

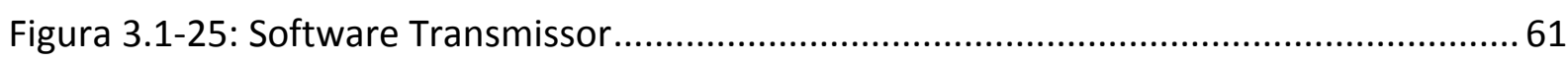

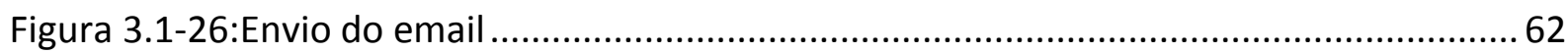

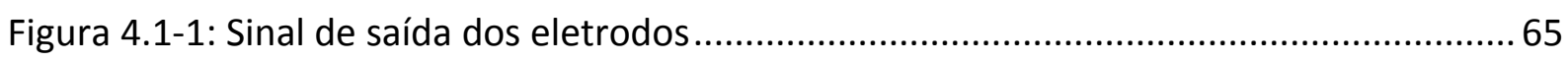

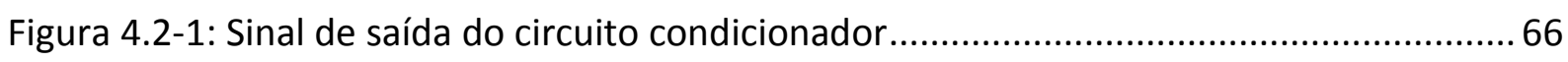

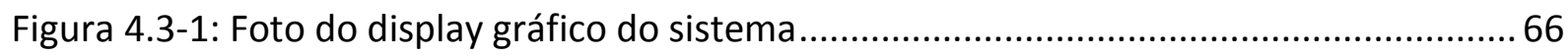

Figura 4.3-2: Comparativo sinal mostrado e arquivo gravado .............................................. 67

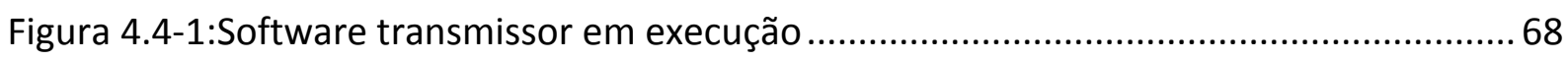

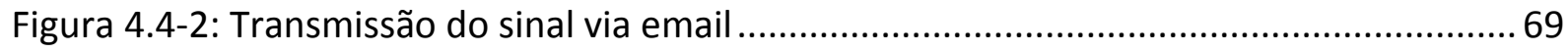

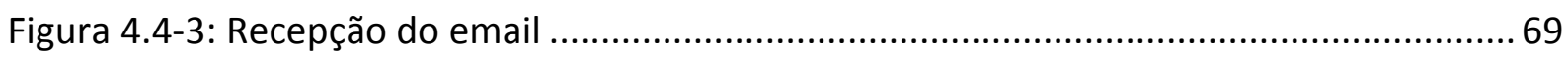

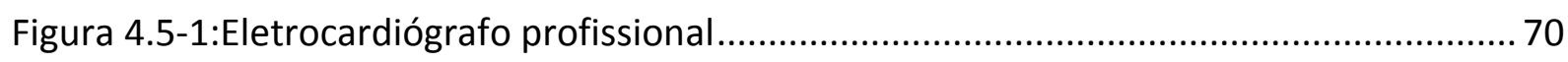

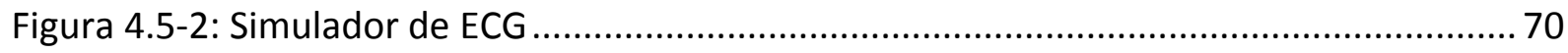

Figura 4.5-3: Comparativo Eletrocardiógrafo profissional x Dispositivo proposto .................. 71 


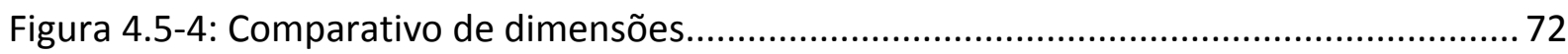




\section{SUMÁRIO}

CAPÍTULO 1 - INTRODUÇÃO

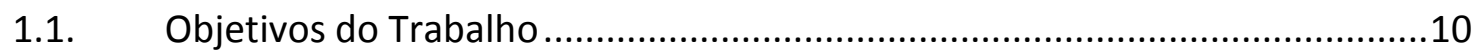

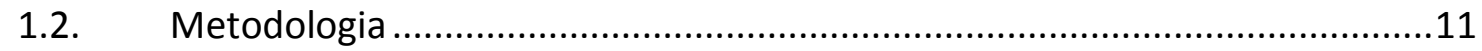

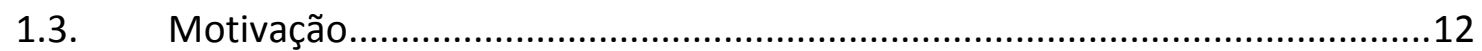

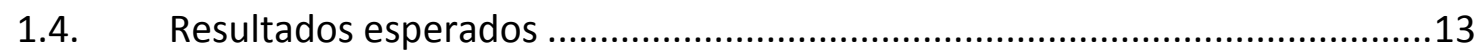

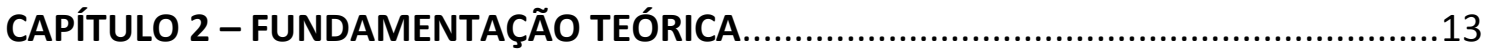

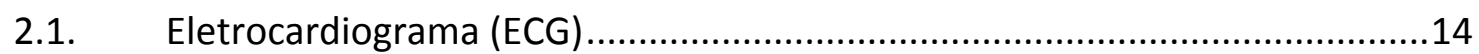

2.1.1. Morfologia do Sinal Eletrocardiográfico .....................................................15

2.1.2. Derivações Eletrocardiográficas................................................................18

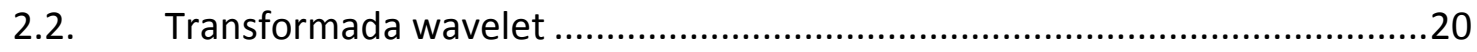

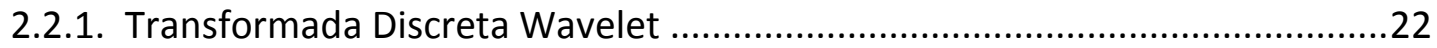

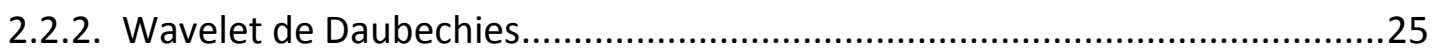

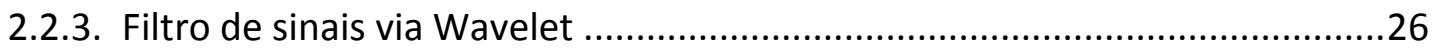

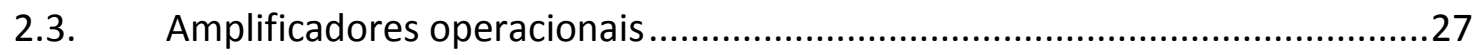

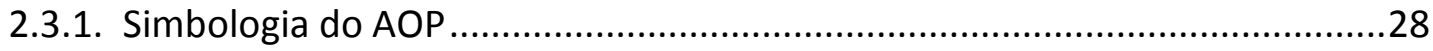

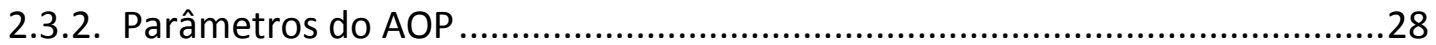

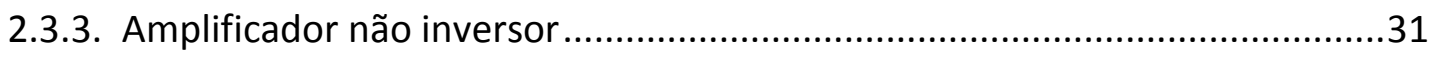

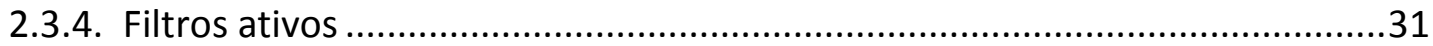

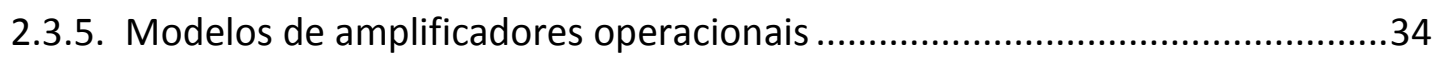

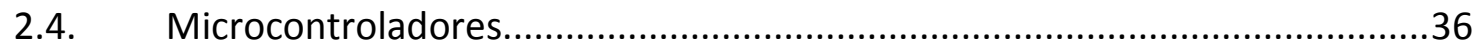

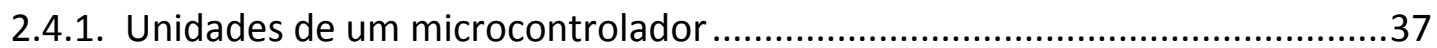

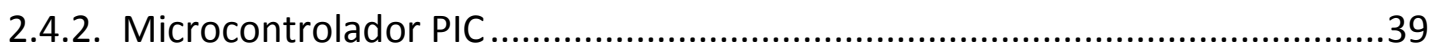


CAPÍTULO 3 - DESENVOLVIMENTO DO PROTÓTIPO

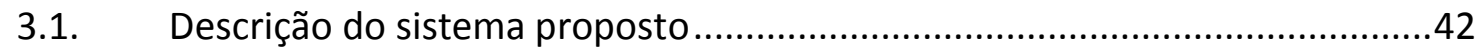

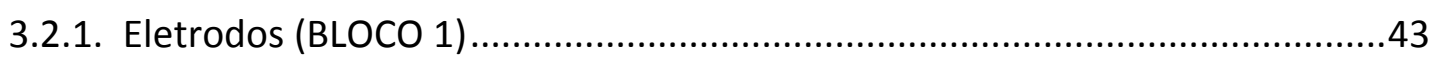

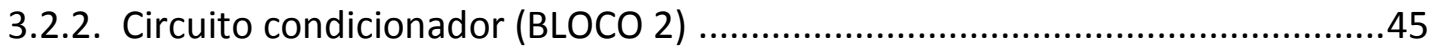

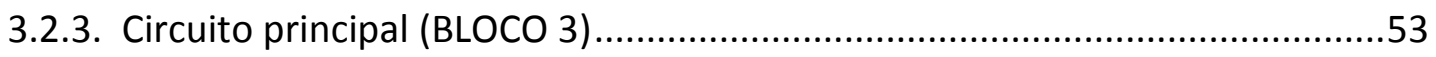

3.2.4. Software Transmissor (BLOCO 4) ............................................................60

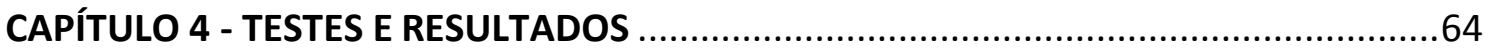

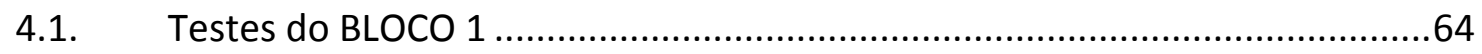

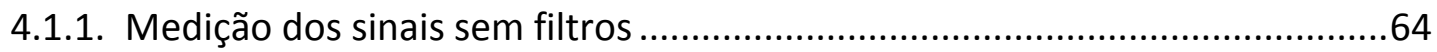

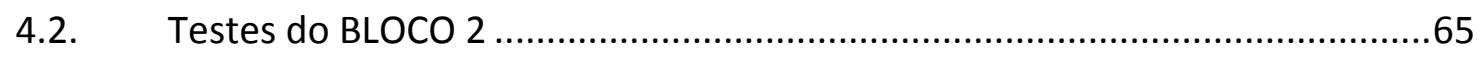

4.2.1. Medição dos sinais com filtros analógicos e amplificador..............................65

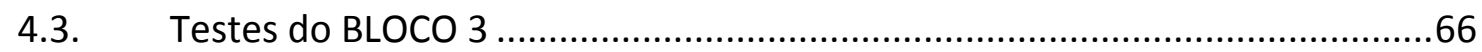

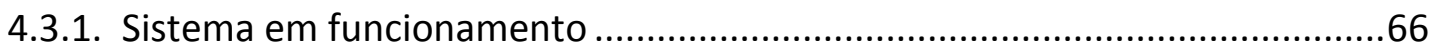

4.3.2. Teste de gravação do arquivo ..................................................................67

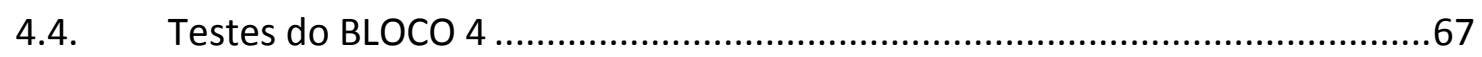

4.4.1. Software em funcionamento ..................................................................68

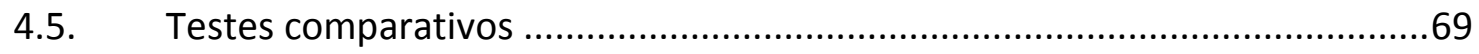

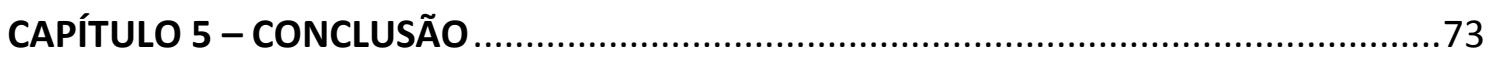

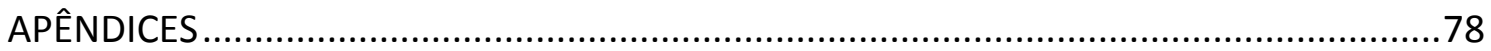

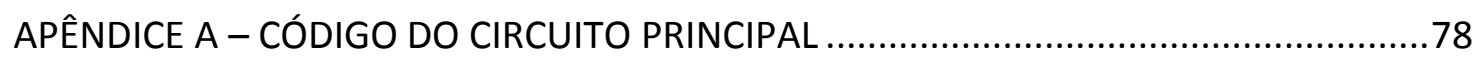

APÊNDICE B - CÓDIGO DO SOFTWARE TRANSMISSOR …............................................83 


\section{CAPÍTULO 1 - INTRODUÇÃO}

A medicina utiliza a tecnologia para auxiliar o diagnóstico de doenças, assim, através de equipamentos eletrônicos e software, propicia uma mais rápida identificação e análise de problemas. Um exemplo de tecnologia desenvolvida é o eletrocardiógrafo, que compreende como um equipamento eletrônico que faz o registro extracelular das variações do potencial elétrico do músculo cardíaco em um ambiente hospitalar ou clínicas. Além disso, obtém como principal objetivo a possibilidade de descoberta de anomalias no coração ao avaliar os sinais cardíacos.

Dessa forma, dispondo de um eletrocardiógrafo que possibilite a sua portabilidade, permite uma acessibilidade a locais remotos que não possuem condições estruturais para o atendimento de pessoas. Com isso, exames poderão ser realizados em indivíduos que somente serão manejados para um hospital em caso de real necessidade. A partir desse entendimento, verifica-se um caráter social de tal equipamento, que garante, como exemplo, um alcance a comunidades indígenas e ribeirinhas.

Sabe-se que o músculo cardíaco (miocárdio) se contrai ritmicamente de 60 a 90 vezes por minuto e sustenta, como se fosse uma bomba, a circulação sanguínea nos vasos. (COTRIM, 2009) A existência de inconformidade no batimento e na geração dos sinais cardíacos pode representar problemas e, que podem ser monitorados e avaliados pelo dispositivo portátil proposto, porém realizado por médicos ou enfermeiros não especialistas.

Os impulsos elétricos gerados pelo coração, são sinais de tensões inferiores a 0,001 volts (pico a pico), que exige do dispositivo uma amplificação, filtros de alto desempenho e processamento digital. O processamento digital de sinais permite que os ruídos e interferências sejam eliminados dos sinais cardíacos. (DINIZ, DA SILVA, \& NETTO, 2004) 


\subsection{Objetivos do Trabalho}

O objetivo geral deste trabalho é desenvolver um dispositivo portátil capaz de coletar, tratar e enviar as medições dos sinais cardíacos via internet para análise de especialistas da área e ainda possibilitar que qualquer médico ou agente de saúde possa realizar o exame. $O$ projeto visa reduzir as distâncias e diagnosticar doenças cardíacas em pacientes localizados em regiões desprovidas de equipamentos e médicos especialistas.

\section{Objetivos específicos:}

- Realizar uma revisão bibliográfica sobre o funcionamento do coração, filtros digitais, amplificadores operacionais e arquitetura do microcontrolador PIC;

- Desenvolver um dispositivo (hardware) para captação de sinais cardíacos, filtragem e amplificação em seu formato analógico em segunda ordem;

- Elaborar um hardware utilizando microcontrolador PIC e seus periféricos;

- Implementar um software capaz de realizar a filtragem em formato digital;

- Salvar o sinal apresentado para a transmissão do sinal via internet;

- Efetuar testes de desempenho no protótipo e realizar ajustes conforme a necessidade;

- Construir uma placa de circuito para montagem do protótipo final e efetuar testes em placa com o protótipo montado;

- Comparar os sinais medidos pelo protótipo com o eletrocardiograma profissional existente no Uniceub e realizar ajustes, sempre que necessário;

- Montar uma caixa para o protótipo. 


\subsection{Metodologia}

O projeto é dividido em módulos de funcionamento, onde cada módulo é responsável por uma determinada ação do projeto proposto. A Figura 1.2-1 ilustra o modelo do projeto de forma simples, com o intuito de facilitar seu entendimento.

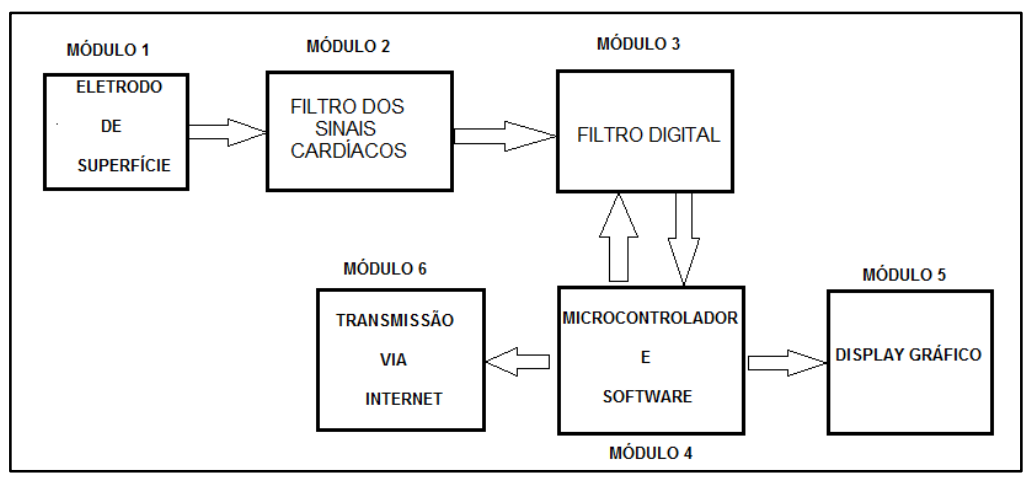

Figura 1.2-1: Visão geral do projeto

Fonte: Elaborada pelo autor

Inicialmente é feita uma pesquisa sobre sinais analógicos e sinais mioéletricos. Em seguida, uma pesquisa sobre componentes eletrônicos necessários e suas funções, tais como: capacitores, resistores, indutores, amplificadores operacionais, filtros ativos e passivos. Após um estudo sobre os elementos envolvidos na amplificação e filtragem de sinais analógicos, é iniciado o desenvolvimento do circuito para coletar, amplificar e filtrar o sinal. Posteriormente é criado o hardware para a exibição e transmissão do sinal. O projeto é dividido nas seguintes etapas:

- Etapa 1 - Revisão da bibliografia: Os documentos selecionados serão estudados a fundo. Nessa etapa será realizada uma leitura crítica e comparativa dos documentos e elaboração da fundamentação teórica para cada aspecto do dispositivo proposto. A proposta do dispositivo deve seguir a filosofia do acesso aberto ao conhecimento e, pela natureza do projeto, acesso aberto ao projeto do hardware e do software necessários para o funcionamento do dispositivo proposto;

- Etapa 2 - Captação de sinais: Desenvolver o sistema de captação dos sinais 
cardíacos, baseado em eletrodos de superfície não invasivos;

- Etapa 3-Circuito condicionador: Desenvolver um circuito de amplificação e filtro analógico capaz de filtrar os sinais vindos dos eletrodos e eliminar parte dos ruídos existentes;

- Etapa 4-Processamento do sinal: Implementar um software capaz de processar o sinal já amplificado e filtrado, afim de retirar os possíveis ruídos ainda existentes no sinal.

- Etapa 5 - Exibição do sinal: Inserir um display gráfico no sistema proposto para a visualização do sinal, onde será possível a identificação dos batimentos cardíacos.

- Etapa 6 - Transmissão dos resultados: Construir um módulo capaz de realizar a transmissão do dispositivo, para a internet.

- Etapa 7 - Testes: Realizar testes com outros equipamentos de eletrocardiograma, verificando se os sinais recebidos estão corretos.

- Etapa 8 - Aperfeiçoamento: Inserir os sistemas criados em uma caixa plástica, para ser utilizado em campo.

\subsection{Motivação}

Os sistemas utilizados na medição dos sinais cardíacos portáteis foram lançados no ano de 2012, custando ainda muito caro por sua tecnologia ser importada. A utilização do sistema proposto visa atender programas de saúde do governo, como por exemplo, o programa "Mais Médico" do Ministério da Saúde. A portabilidade e a facilidade na realização dos exames pelo dispositivo proposto, agiliza o processo de deteç̧ão de doenças cardíacas e podem ser aplicados principalmente em localidades desprovidas de recursos e enviar os resultados remotamente a um especialista para diagnosticar o paciente.

Sua principal vantagem é permitir que qualquer profissional de saúde possa manusear e realizar os exames, e enviar os resultados via internet. A facilidade e o envio 
dos resultados podem salvar vidas, principalmente em localidades distantes. O exame realizado pode ser lido por um especialista e o mesmo sugerir que um determinado paciente tenha que deslocar a um centro médico, evitando maiores danos ao paciente analisado.

\subsection{Resultados esperados}

Espera-se alcançar o desenvolvimento de um sistema capaz de realizar as medições das frequências cardíacas e possibilitar diagnosticar doenças do coração, por especialista da área. Espera-se aprimorar o circuito de condicionamento (circuito coletor dos sinais cardíacos) e melhorar a qualidade dos sinais na filtragem. Por fim, espera-se desenvolver um sistema de coleta das frequências cardíacas e mostrar em um display de cristal líquido. O sistema deve ser portátil, com capacidade de guardar e enviar exames realizados por qualquer profissional da área de saúde. É esperado que o sistema apresente um comportamento eficiente em relação aos ruídos externos, que podem interferir no sistema de medição com uma precisão de $2 \%$ em relação à um equipamento profissional.

\section{CAPÍTULO 2 - FUNDAMENTAÇÕA TEÓRICA}


Este ítem trata sobre os conceitos teóricos abordados para o desenvolvimento do projeto proposto, abordando a importância do registro da atividade elétrica cardíaca utilizando um eletrocardiograma. Além disso, terá uma breve descrição dos materiais utilizados.

\subsection{Eletrocardiograma (ECG)}

O eletrocardiograma é um exame que permite a avaliação elétrica da atividade cardíaca (potenciais elétricos) e da sua condução, registrada em gráficos que são comparados com gráficos padrão e que indicam, assim, o estado de normalidade ou de alteração dos músculos e nervos do coração. A atividade elétrica cardíaca é dada pela variação da quantidade de íons dentro e fora das células musculares cardíacas, a qual gera diferenças de concentrações desses íons na periferia do corpo. São essas diferenças, captadas por eletrodos sensíveis colocados em pontos específicos do corpo, que são registradas nos gráficos do eletrocardiograma. Apesar de ser de execução muito simples, o eletrocardiograma é um exame muito importante na cardiologia, pois ele permite diagnosticar desde condições ligeiras até outras muito graves, como os infartos do miocárdio (ABC.MED.BR, 2013).

Os eletrocardiogramas devem ser interpretados por cardiologistas, clínicos gerais e médicos que trabalham com urgências. Os profissionais devem ter a habilidade de reconhecer e compreender as bases fisiopatológicas de algumas anormalidades eletrocardiográficas. Os programas de ensino devem estimular os médicos a reconhecer, além dos diagnósticos habituais (arritmias, sobrecargas, áreas eletricamente inativas, alterações da repolarização e marcapassos), outros diagnósticos clínicos que podem se manifestar com alterações eletrocardiográficas típicas (SOCIEDADE BRASILEIRA DE CARDIOLOGIA, 2003).

Sabe-se que o músculo cardíaco (miocárdio) se contrai ritmicamente de 60 a 90 vezes por minuto e sustenta, como se fosse uma bomba, a circulação sanguínea nos vasos. 
A contração da fibra muscular é estimulada por impulsos elétricos provenientes do nódulo sinoatrial (NSA), situado na parte superior do átrio direito, e é um gerador biológico de impulsos elétricos que comanda o coração. Por meio de tecidos específicos de condução (feixe de His e rede de Purkinje), os impulsos de comando provenientes do nódulo sinoatrial são transmitidos às fibras musculares da parede do ventrículo do coração. (COTRIM, 2009)

\subsubsection{Morfologia do Sinal Eletrocardiográfico}

O ciclo cardíaco consiste em um período de contração ventricular denominado de sístole, que expele o sangue dos ventrículos, seguido de um período de relaxamento ventricular denominado de diástole, no qual os átrios voltam a se encher de sangue (RANGAYYAN, 2002).

Uma onda de despolarização elétrica que se propaga por todo o coração precede e desencadeia cada contração mecânica. A despolarização começa no nódulo sinusal, ou nódulo sinoatrial de Keith Flack, depois se propaga pelo miocárdio de ambos os átrios, para atingir o nódulo atrioventricular de Tawara, localizado na região inferior do

septo interatrial. Após ligeiro atraso no nódulo átrio-ventricular, a onda de despolarização se transmite através do feixe átrio-ventricular (feixe de HIS), e de seus ramos esquerdo e direito para as fibras de Purkinje, situadas abaixo do endocárdio, continuando com as fibras miocárdicas comuns. (RANGAYYAN, 2002) (GESELOWITZ, 1989).

A despolarização ventricular se segue a contração ventricular e, após um intervalo de 100 a 200 ms, os ventrículos retornam a seu estado original devido à repolarização elétrica.

Os processos de despolarização e repolarização geram correntes elétricas que circundam as membranas das células miocárdicas. Essas correntes elétricas dentro do coração se fecham no volume condutor do tórax gerando um campo elétrico detectável na superfície corporal. Assim, o eletrocardiograma é um registro do potencial elétrico na superfície corporal causado pelas correntes do volume condutor torácico que foram geradas pelas correntes elétricas do coração. (WOLF, 2004) 
Os nódulos e os feixes de HIS, bem como seus ramos, podem ser vistos na Figura 2.1-1 a seguir.

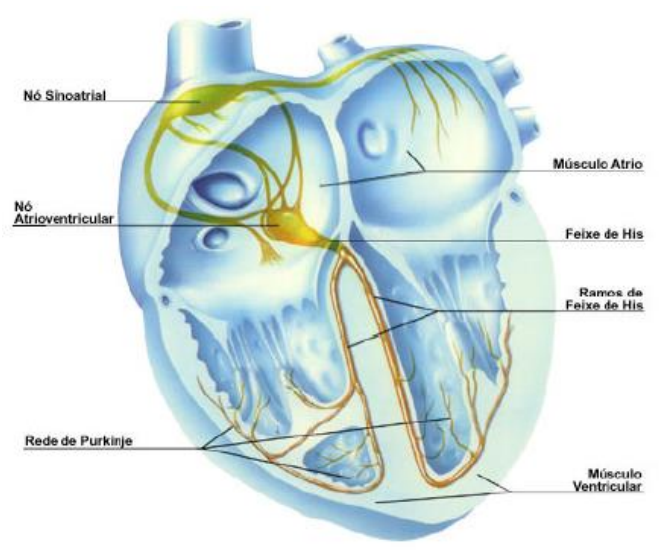

Figura 2.1-1: Esquema do sistema de condução intracardíaco

Fonte: Cheida, Luiz Eduardo. Medicina Integrada. São Paulo, 1997

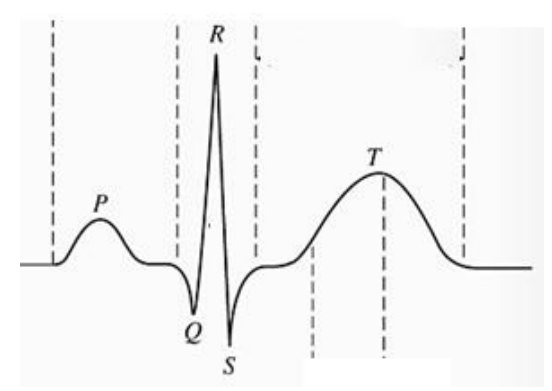

Figura 2.1-2: Sinais gerados pelo coração

Fonte: (COTRIM, 2009)

Os sinais cardíacos são compostos pelas ondas $\mathrm{P}, \mathrm{Q}, \mathrm{R}, \mathrm{S}$ e $\mathrm{T}$, conforme é ilustrado na Figura 2.1-2.

A onda $\mathbf{P}$ representa a despolarização atrial. A primeira parte da onda corresponde à despolarização do átrio direito e a parte final à despolarização do átrio esquerdo. $\mathrm{A}$ função da contração atrial é o enchimento final dos ventrículos com o sangue armazenado em seu interior. A repolarização atrial, porém, não é registrada no ECG pois ocorre simultaneamente à despolarização ventricular, que possui maior amplitude devido à superior massa muscular dos ventrículos, sendo, portanto, um processo elétrico mais potente (KILPATRICK \& JOHNSTON, 1994) (WOLF, 2004). 
O complexo QRS corresponde à despolarização total dos ventrículos, representando a maior onda do eletrocardiograma. Após a despolarização ventricular, o coração bombeia o sangue para a circulação sistêmica (ventrículo esquerdo, maior e com paredes mais reforçadas) e para a circulação pulmonar (ventrículo direito) (KILPATRICK \& JOHNSTON, 1994) (WOLF, 2004).

A onda $\mathbf{T}$ reflete a repolarização ventricular ou o relaxamento do músculo ventricular. É comum a ela ser positiva nas derivações em que a onda R for positiva, além de ter formato arredondado e ligeiramente assimétrico, com inclinação mais suave na primeira metade da onda (COTRIM, 2009) (KILPATRICK \& JOHNSTON, 1994). A Figura 2.1-3 ilustra o coração e os pontos onde as ondas são geradas através de impulsos elétricos e serão analisados pelo dispositivo portátil.

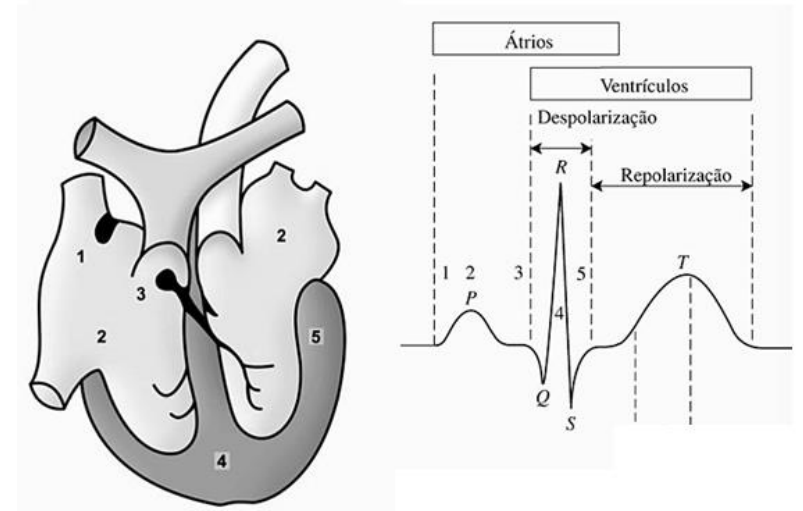

Figura 2.1-3: Áreas do coração onde são geradas as ondas

Fonte: (COTRIM, 2009)

A Figura 2.1-3 mostra as ondas características dos sinais cardíacos e a sua relação direta com os as áreas do coração e a sua função de polarização ou despolarização.

Várias doenças cardíacas podem ser localizadas utilizando um eletrocardiograma, Segundo (GOLDMAN, 1973), com o progresso da eletrocardiografia, a precisão do diagnóstico eletrocardiográfico tornou-se mais elevada. Tendo particular valor nas seguintes condições clínicas:

- Hipertrofia atrial e ventricular

- Infarto do miocárdio 
- Arritmias

- Pericardite

- Distúrbios no metabolismo eletrolítico, sobretudo as alterações de potássio

\subsubsection{Derivações Eletrocardiográficas}

O ECG registra a diferença de potencial elétrico entre as regiões das quais foram conectados os eletrodos. Cada uma dessas regiões possui variações diferentes de potenciais aos sinais elétricos gerados pelo coração. Existem 12 derivações básicas que os eletrodos podem ser conectados e estas podem ser chamadas de precordiais ou periféricas, dependendo do posicionamento dos sensores. A Figura 2.1-4 representa a localização das derivações precordiais e periféricas conectadas ao paciente (RANGAYYAN, 2002).

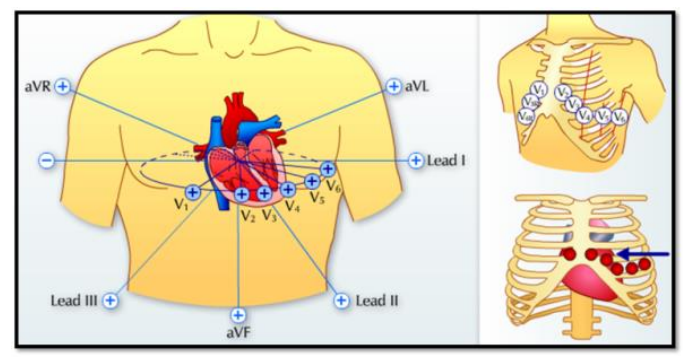

Figura 2.1-4: Derivações eletrocardiográficas

Fonte: www.webcardio.net.br

Os posicionamentos ilustrados na figura 5 mostram as derivações precordiais e periféricas, sendo que cada uma delas possui 6 sensores para a aquisição dos dados.

As derivações periféricas são chamadas de DI, DII e DIII, das quais para defini-las são conectados eletrodos sobre o braço esquerdo (aVL), sobre o braço direito (aVR) e sobre a perna esquerda (aVF), formando assim um triângulo, chamado de Triângulo de Eithoven (RANGAYYAN, 2002). 
A Figura 2.1-5 ilustra o triangulo de Eithoven.

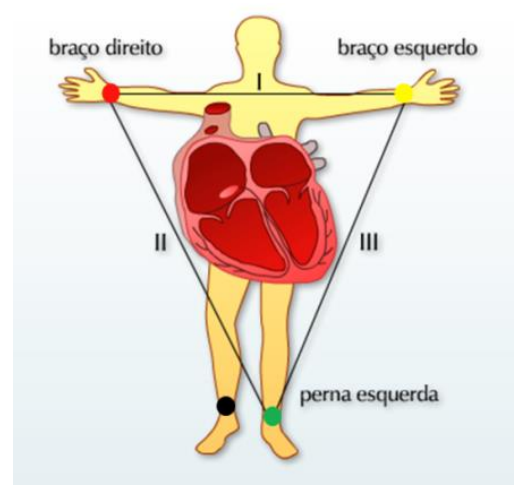

Figura 2.1-5: Triangulo de Eithoven

Fonte: www.webcardio.net.br

As derivações periféricas DI, DII e DIII são formadas a partir dos eletrodos conectados nos membros do paciente, onde DI é a diferença de potencial entre aVL (braço esquerdo) e aVR (braço direito), DII é a diferença de potencial entre aVF (perna esquerda) e aVR (braço direito) e DIII é a diferença de potencial entre aVF (perna esquerda) e aVL (braço esquerdo) (RANGAYYAN, 2002).

As derivações precordiais são representadas por V1 a V6 e situam-se nas paredes anterior e lateral do tórax, dando a vista do coração e da onda de despolarização no plano horizontal. A Figura 2.1-6 ilustra as derivações citadas conectadas ao paciente.

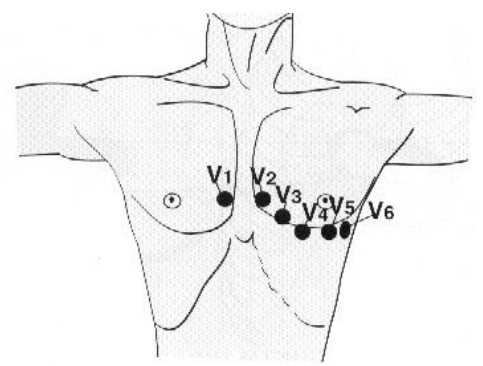

Figura 2.1-6: Derivações precordiais

Fonte: bibliomed.com.br

A Figura 2.1-6 ilustra a localização das 6 derivações precordiais. As derivações V1 e V2 estão localizadas sobre o lado direito do coração e são chamadas de derivações precordiais direitas, as derivações V4 e V5 se localizam sobre o septo interventricular, 
que é uma parede comum ao ventrículo direito e ao ventrículo esquerdo, já as derivações V5 e V6 estão localizadas no lado esquerdo do coração e são chamadas de derivações precordiais esquerdas (RANGAYYAN, 2002).

É possível realizar um exame utilizando uma modificação das derivações precordiais e periféricas. Esta modificação é indicada para desempenhar leituras por longos períodos de tempo, adquirindo sinais do paciente enquanto ele realiza atividades cotidianas. A Figura 2.1-7 ilustra o posicionamento dos eletrodos para esta modificação. (WOLF, 2004)

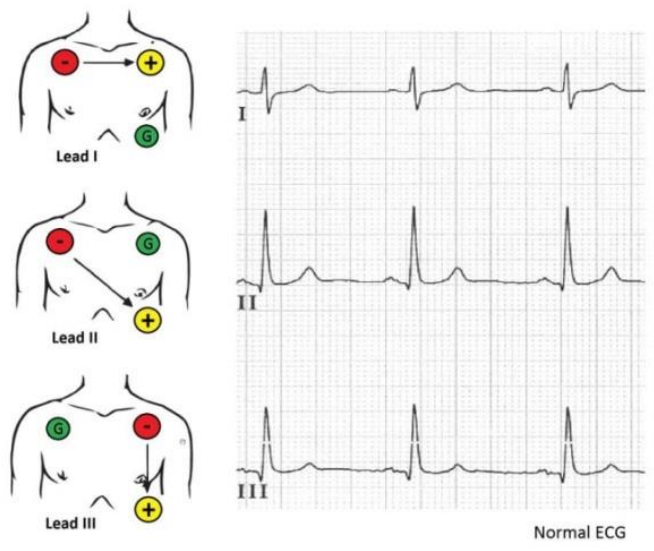

Figura 2.1-7: Derivações e seus respectivos sinais Fonte: hrwproject.com

A figura 8 ilustra o posicionamento dos eletrodos para se adquirir os sinais I, II e III. As derivações, nomeadas na figura por "lead", são adquiridas por 3 eletrodos conectados no paciente e estes eletrodos são conectados de forma a se obter um dos 3 sinais cardíacos ilustrados na figura.

A lead II é uma derivação bipolar paralela à derivação DII padrão, em que seu posicionamento é feito com um eletrodo colocado na crista ilíaca esquerda e o outro posicionado na fossa infraclavicular. Esta apresenta características típicas da derivação DIl padrão (WOLF, 2004).

\subsection{Transformada wavelet}

A análise de sinais constitui uma das mais importantes ferramentas no 
processamento digital de sinais. Essa análise pode ser feita por meio das transformadas de Fourier, porém ela se torna ineficaz para determinadas situações em que o sinal não é estacionário, tendo variação de suas características estatísticas com o tempo (OLIVEIRA, 2007).

A transformada wavelet é muito utilizada para análise de sinais digitais e compressão de dados, e representam a decomposição de uma função no domínio do tempo em um conjunto de coeficientes que descrevem as suas componentes de frequência em determinados instantes de tempo.

Neste sentido, a transformada wavelet se torna de extrema importância, pois é utilizada como uma das principais ferramentas para o processamento do sinal de um ECG para extração do complexo QRS, sendo utilizado como uma espécie de filtro de sinal (OLIVEIRA, 2007).

Tendo a transformada wavelet $W_{(a, b)}$ definida como (OLIVEIRA, 2007):

$$
W(a, b)=\int_{-\infty}^{\infty} f(t) \frac{1}{\sqrt{|a|}} \psi\left(\frac{t-b}{a}\right) d t
$$

e definindo $\psi_{a, b}(t)$ como:

$$
\psi_{a, b}=\frac{1}{\sqrt{|a|}} \cdot \psi\left(\frac{t-b}{a}\right)
$$

Pode-se reescrever a transformada como um produto das funções $f(t)$ e $\psi_{a, b}(t)$ :

$$
W(a, b)=\left\langle f(t), \psi_{a, b}(t)\right\rangle=\int_{-\infty}^{\infty} f(t) \psi_{a, b}(t) d t
$$

A função $\psi_{1,0}(t)$ de $\psi(t)$ é chamada de wavelet mãe enquanto as outras funções são chamadas de wavelet filhas. A variável $a \in \mathbb{N}$ é o parâmetro de dilatação da função, que aumenta ou diminui a sua escala. A variável $b \in \mathbb{R}$ é o parâmetro de translação da 
função, o qual significa que a função $\psi(t)$ foi transladada no eixo $t$ a uma distância equivalente $a b$. (KAISER, 2004). O termo $\frac{1}{\sqrt{|a|}}$ é um fator de normalização, tendo como objetivo garantir que a energia de $\psi_{a, b}(t)$ seja independente de $a$ e $b$.

Para a reconstrução do sinal no domínio do tempo, a partir da sua decomposição, é necessária uma transformada inversa, onde $\widehat{\psi}(\omega)$ é chamada de a transformada de Fourier da equação $\psi(t)$. A equação de $\widehat{\psi}(\omega)$ é mostrada abaixo (MALLAT, 1999):

$$
\widehat{\psi}(\omega)=\int_{-\infty}^{\infty} \psi(t) e^{-i \omega t} d t
$$

Sendo $W(a, b)$ a transformada wavelet da função $f(t)$, utilizando a wavelet $\psi(t)$, então a transformada inversa será dada por (MALLAT, 1999):

$$
f(t)=\frac{1}{C} \int_{-\infty}^{\infty} \int_{-\infty}^{\infty} \frac{1}{|a|^{2}} W(a, b) \psi_{a, b}(a, b, t) d a d b
$$

onde:

$$
C=\int_{-\infty}^{\infty} \frac{|\widehat{\psi}(\omega)|^{2}}{|\omega|} d \omega
$$

Dessa forma torna-se possível a recomposição de um sinal decomposto aplicando a Transformada Inversa de Wavelet.

\subsubsection{Transformada Discreta Wavelet}

As versões discretas da transformada podem ser obtidas discretizando-se as dilatações e as translações. Assumindo dilatações binárias e translações unitárias, as funções de base wavelet são mudadas, onde $a=2^{-m}$ e $b=n 2^{-m}$ (KAISER, 2004). 


$$
\psi_{m, n}(t)=2^{-\frac{m}{2}} \psi\left(2^{m} t-n\right)
$$

A transformada wavelet discreta será então definida como

$$
f(t)=\sum_{m=-\infty}^{\infty} \sum_{n=-\infty}^{\infty}\left(f, \psi_{m, n}\right) \psi_{m, n}(t)
$$

Através do conceito de análise em multiresolução, pode-se construir famílias de wavelet discretas e desenvolver algoritmos rápidos para o cálculo da transformada. A análise em multiresolução parte da existência de duas funções básicas, uma função wavelet mãe $\psi(t)$ e uma função de escala mãe $\varphi(t)$, ortogonais entre si e tais que, ao longo dos diversos níveis de resolução, as diversas funções de escala $\psi_{m, n}(t)$ e wavelet $\psi_{m, n}(t)$ estão relacionadas às respectivas funções mãe por meio da seguintes equações (MALLAT, 1999).

$$
\begin{aligned}
& \varphi_{m, n}(t)=2^{-\frac{m}{2}} \varphi\left(2^{m} t-n\right) \\
& \psi_{m, n}(t)=2^{-\frac{m}{2}} \psi\left(2^{m} t-n\right)
\end{aligned}
$$

A relação entre os níveis de resolução pode ser descrita sob a forma de um alinhamento dos espaços de função, em que cada espaço de maior resolução contém os espaços de menor resolução, isto é (MALLAT, 1999):

$$
\ldots \subset V_{-2} \subset V_{-1} \subset V_{-0} \subset V_{1} \subset V_{2}
$$

Cada espaço $V_{m}$ é coberto pela família de funções de base $\varphi_{m, n}(t)$ correspondente. As funções wavelet $\psi_{m, n}(t)$ estão contidas nos espaços $W_{m}$, sendo cada espaço deste o complemento ortogonal de $V_{m}$ em relação ao espaço $V_{m+1}$. Desta forma, pode-se escrever a relação entre dois níveis adjacentes de resolução como 
(STRANG \& NGUYEN, 1996)

$$
V_{m+1}=V_{m} \oplus W_{m}
$$

em que o símbolo $\bigoplus$ representa a operação de soma direta de dois subespaços vetoriais quando sua interjeição é nula. Uma vez que $V_{m}$ e $W_{m}$ estão contidas em $V_{m+1}$, então ambos conjuntos de funções de base podem ser expressos como combinação linear das funções base de $V_{m+1}$, sendo cada uma delas ponderada pelos coeficientes $h_{0}[n]$ e $h_{1}[n]$, responsáveis pela relação de ortogonalidade entre as funções e definido como:

$$
h[n]=\left\langle\varphi_{0,0}, \varphi_{1, n}\right\rangle
$$

Portanto (MALLAT, 1999)

$$
\begin{aligned}
& \varphi_{m, n}(t)=\sum_{k} h_{0}[k-2 n] \cdot \varphi_{m+1, k}(t) \\
& \psi_{m, n}(t)=\sum_{k} h_{1}[k-2 n] \cdot \varphi_{m+1, k}(t)
\end{aligned}
$$

Estando a função $f$ contida no espaço $V_{m+1}$, então $f$ pode ser expressa como combinação linear das funções de base $\varphi_{m+1, n}(t)$. De forma similar, projetando $f$ em $V_{m}$ e $W_{m}$ e escrevendo estas projeções em função das bases $V_{m}$ e $W_{m}$, é possível relacionar as projeções de $f$ e os diversos níveis de refinamento de acordo com a equação 16. (MALLAT, 1999)

$$
a_{m+1, k}=\left\langle f, \varphi_{m+1, k}\right\rangle a_{m n}=\left\langle f, \psi_{m, n}\right\rangle
$$

Então aplicando as equações 14 e 15 na equação 16, obtém-se: 


$$
\begin{gathered}
a_{m, n}=\left\langle f, \varphi_{m+n}\right\rangle=\sum_{k} h_{0}[k-2 n] \cdot\left\langle f, \varphi_{m+1, k}\right\rangle \\
=\sum_{k} h_{0}[k-2 n] \cdot a_{m+1, k}
\end{gathered}
$$

Dado que $V_{m+1}$ é a soma direta dos espaços $V_{m}$ e $W_{m}$. Pode-se expressar a base de $V_{m+1}$ como combinação linear das bases $V_{m}$ e $W_{m}$, em que cada uma delas está ponderada pelos coeficientes $g_{0}[n]$ e $g_{1}[n]$, responsáveis pela relação de ortogonalidade entre as funções. Definido como:

$$
g_{n}=\left\langle\psi_{0,0}, \varphi_{1, n}\right\rangle
$$

Então de acordo com (MALLAT, 1999) :

$$
\varphi_{m+1, k}(t)=\sum_{n} g_{0}[k-2 n] . \varphi_{m, n}(t)=\sum_{n} g_{1}[k-2 n] . \psi_{m, n}(t)
$$

Estes processos de síntese/composição e análise/decomposição podem ser entendidos como a aplicação de filtros passa baixas e passa altas seguidos por uma subamostragem na análise ou por uma superamostragem na síntese, em que os coeficientes $\left\{h_{0}[n], h_{1}[n]\right\}$ e $\left\{g_{0}[n], g_{1}[n]\right\}$ formam os bancos de filtros utilizados por estes métodos, correspondendo aos bancos de filtros de análise e síntese respectivamente (STRANG \& NGUYEN, 1996) (DAUBECHIES, 1992).

\subsubsection{Wavelet de Daubechies}

Baseado na análise de multiresolução que estabelece os princípios básicos para a determinação de uma wavelet, diversos pesquisadores desenvolveram estudos e criaram sua própria família de wavelet para resolução dos mais variados problemas 
(OLIVEIRA, 2007).

Apesar da grande quantidade de famílias de wavelet existentes, nesse trabalho é abordada apenas a família de wavelet de Daubechies. As wavelets de Daubechies são uma família de wavelets ortogonais, correspondendo a uma transformada discreta wavelet e caracterizada pelo máximo número de momentos nulos para um dado suporte, ou seja, momentos em que a função é nula. Com cada tipo de wavelet dessa classe há uma função base, chamada wavelet-mãe, que gera uma análise de multiresolução ortogonal (OLIVEIRA, 2007).

A Figura 2.2-1 mostra a wavelet de Daubechies de ordem 6.

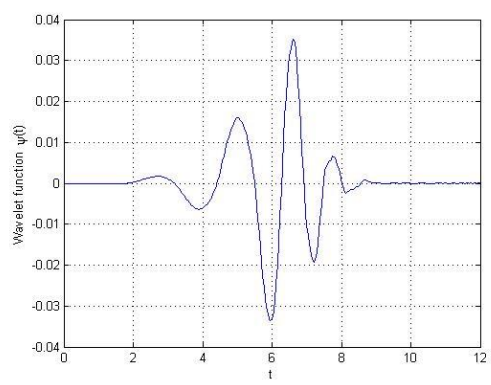

Figura 2.2-1: Wavelet DB6

Para a análise de sinais através de transformadas wavelet, a wavelet de Daubechies número 6 se aproxima muito a forma do sinal cardíaco e por isso se torna muito utilizada para análises e filtros em sinais cardíacos.

\subsubsection{Filtro de sinais via Wavelet}

Sabe-se que todo sinal captado em um mundo real existe ruído. Esse ruído faz com que a interpretação de sinais se torne muito difícil, sendo necessário a aplicação de filtros digitais com o propósito de limpar o sinal.

Existem diferentes métodos para filtrar um sinal, onde um meio para tal tarefa é a descontaminação de sinais através de transformadas wavelets, chamado de wavelet shrinkage (OLIVEIRA, 2007).

A descontaminação de um sinal visa remover qualquer ruído presente e manter 
o sinal sem alteração, não retirando informações por eliminação de uma determinada faixa de frequência (TASWELL, 2000). Essa descontaminação envolve a compressão do sinal no domínio das transformadas wavelet e é composto basicamente por 3 etapas, onde a primeira é decompor o sinal por meio da transformada, a segunda é descontaminar o sinal e a terceira é reconstruir o sinal por meio da transformada inversa.

Uma vez tendo um sinal com ruídos, deve-se decompor o mesmo por meio de transformadas wavelets. O sinal decomposto em seus diversos níveis é submetido a aplicação de um limiar de corte, abrupto ou suave que vai eliminar os coeficientes que estejam abaixo do mesmo. Com os coeficientes indesejados retirados, por meio da aplicação do limiar, a transformada wavelet inversa deve ser aplicada aos dados restantes para reconstrução do sinal sem o ruído.

\subsection{Amplificadores operacionais}

Os AOPs (Amplificadores operacionais) foram desenvolvidos na década de 40 e eram construídos com válvulas. Evidentemente as características desses primitivos amplificadores eram bastante precárias. Com o advento do transistor no final da década de 40, foi possível a construção de amplificadores operacionais com características razoáveis. (JÚNIOR, 2003)

O AOP é um amplificador de corrente contínua multiestágio com entrada diferencial cujas características se aproximam de um amplificador ideal. Seu nome, deriva do conceito de um amplificador DC (amplificador acoplado em corrente contínua) com uma entrada diferencial e ganho extremamente alto, cujas caraterísticas de operação estavam determinadas pelos elementos de realimentação utilizados. Mudando os tipos e a disposição dos elementos de realimentação, podiam ser implementados diferentes operações analógicas. Em grande parte, as caraterísticas globais do circuito estavam determinadas só por estes elementos de realimentação. Dessa forma, o mesmo amplificador era capaz de realizar diversas operações, onde o desenvolvimento gradual dos amplificadores operacionais deu local ao surgimento de 
uma nova era nos conceitos de desenhos de circuitos. (JOHNSON, 1991)

\subsubsection{Simbologia do AOP}

Um AOP possui duas entradas e uma saída, em que esta obtém valor múltiplo da diferença entre as duas entradas. O fator A é o ganho de tensão do amplificador operacional, ou seja, a relação entre a tensão de entrada diferencial e a de saída do dispositivo. (INSTITUTO FEDERAL DO ESPÍRITO SANTO)

A simbologia básica de um AOP pode ser vista na figura a seguir.

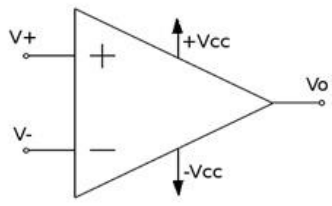

Figura 2.3-1: Simbologia AOP

Fonte: Amplificadores operacionais I-10

Na Figura 2.3-1 percebe-se que existem 5 pinos no AOP, onde $(V+)$ é a entrada não inversora, (V-) a entrada inversora, (Vo) a saída do sinal e (+Vcc e -Vcc) é a alimentação do AOP. (JÚNIOR, 2003)

\subsubsection{Parâmetros do AOP}

Todo AOP possui uma tensão de offset de saída, sendo esta a amplificação da diferença entre os sinais de sua entrada. Em um amplificador ideal, caso suas entradas fossem iguais, a saída deveria ser igual à 0 , porém em um amplificador real essa saída não apresenta esse comportamento, gerando assim uma tensão de offset em seu resultado.

A alimentação do AOP é realizada com fontes de corrente contínua para sua polarização e normalmente se utiliza fontes simétricas.

Existem várias formas de se utilizar os amplificadores operacionais, podendo ser 
sem realimentação do sinal, com realimentação positiva e com realimentação negativa. A Figura 2.3-1 mostra, de forma básica, um sistema com realimentação do sinal

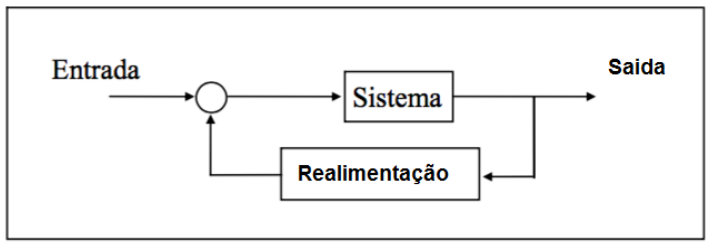

Figura 2.3-2: Sistema com realimentação do sinal Fonte: Autor

Um AOP sem realimentação de sinal também pode ser caracterizado como operação em malha aberta e é muito comum quando se utiliza o amplificador somente como modo comparador, onde não se tem o controle do AOP (JÚNIOR, 2003). A Figura 2.3-3 representa a ligação de um AOP sem a realimentação do sinal.

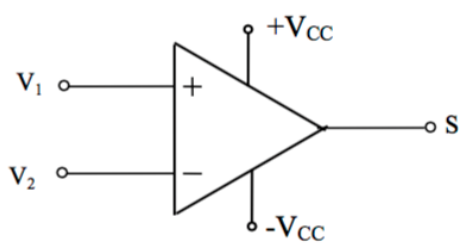

Figura 2.3-3: AOP sem realimentação Fonte: Instituto Federal do Espírito Santo

Um AOP pode ser configurado com a realimentação do sinal, caracterizado como operação em malha fechada. Esta realimentação pode ser feita de duas formas distintas. A realimentação positiva do sinal é comumente utilizada em osciladores e comparadores com histerese, porém nesse modo não é possível o controle sobre a saída do circuito. A Figura 2.3-4 exemplifica um AOP na nesta configuração. (JÚNIOR, 2003) 


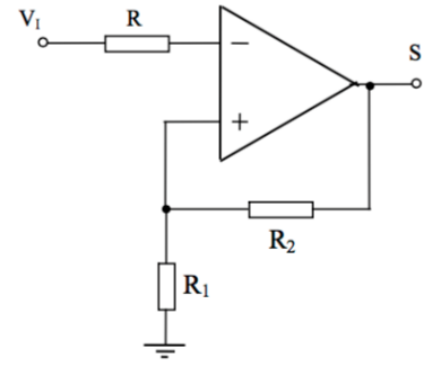

Figura 2.3-4: AOP com realimentação positiva Fonte: Instituto Federal do Espírito Santo

A realimentação negativa do sinal é o modo mais utilizado de amplificadores operacionais. A grande vantagem da utilização desse tipo é a possibilidade de se conseguir o controle externo do ganho para uma dada configuração. A Figura 2.3-5 mostra um AOP com realimentação negativa. (JÚNIOR, 2003)

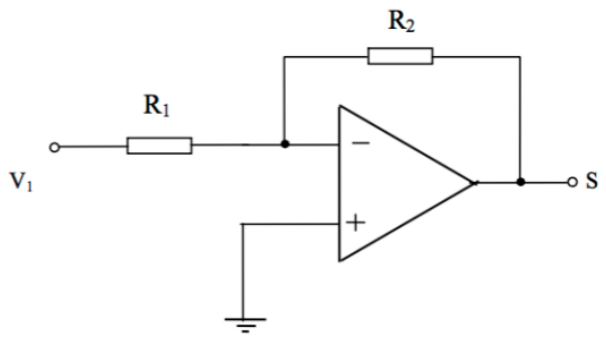

Figura 2.3-5: AOP com realimentação negativa Fonte: Instituto Federal do Espírito Santo

Essa realimentação é utilizada em diversas configurações, entre elas podem-se citar:

- Amplificador inversor

- Amplificador não inversor

- Amplificador somador inversor

- Amplificador subtrator

- Amplificador integrador inversor

- Amplificador diferenciador inversor

Como neste trabalho será utilizado apenas o amplificador em modo não inversor, 
este será o único a ser descrito neste trabalho.

\subsubsection{Amplificador não inversor}

O amplificador não inversor não apresenta diferença de fase entre o sinal de entrada e o de saída e esta realimentação é realizada através da alimentação da entrada inversora por uma fração da tensão de saída, sendo essa realimentação obtida através do divisor de tensão mostrado na Figura 2.3-6 (JÚNIOR, 2003).

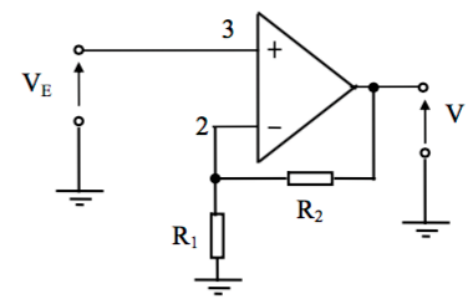

Figura 2.3-6: Amplificador não inversor Fonte: Instituto Federal do Espírito Santo

Nessa configuração pode-se chegar a uma relação entre os resistores R1, R2 e entrada e saída Ve e Vs. Essa relação é mostrada em (20).

$$
\frac{V s}{V e}=1+\frac{R 2}{R 1}
$$

\subsubsection{Filtros ativos}

Um filtro eletrônico é um circuito que, na presença de um sinal elétrico, em qualquer frequência, só permite que uma determinada faixa de frequência passe por ele, eliminando todas as outras. Os filtros podem ser classificados como ativos ou passivos, onde o primeiro é caracterizado pela utilização de resistores e capacitores. Já o segundo é assim determinado por utilizar transistores e circuitos integrados, como os amplificadores operacionais.

Outro tipo de agrupamento direcionado aos filtros é em relação à quantidade de 
elementos reativos presentes no circuito, separando-se em ordens, em que a ordem é determinada pela quantidade de elementos reativos existentes. Assim, a título exemplificativo, um filtro de primeira ordem possui somente um elemento reativo, já no caso do filtro de segunda ordem possui dois elementos reativos e assim sucessivamente.

Da mesma forma, conceitua-se também os filtros pela faixa de frequência desejável, dividindo-se em filtro passa baixa (LPF - Low Pass Filter), filtro passa alta (HPF - High Pass Filter), filtro passa faixa (BPF - Band Pass Filter) e filtro rejeita faixa (BRF Band Reject Filter), onde cada um deles deve ser aplicado conforme o tipo de frequência que deseja que se passe. (JÚNIOR, 2003)

Neste trabalho é utilizado o filtro passa baixa, que corresponde por ser um filtro que só permite passar sinais que estejam abaixo de uma determinada frequência de corte (cut-off frequency) e bloqueia todas as outras acima desta. O filtro ativo passa baixa é composto por um filtro RC conectado a um amplificador operacional. A Figura 2.3-7 mostra o funcionamento desse tipo de filtro.

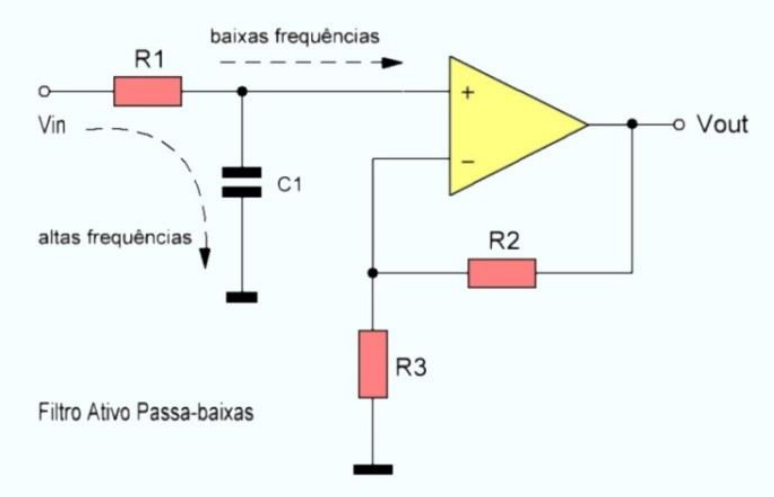

Figura 2.3-7: Filtro ativo de $1^{\underline{a}}$ odem passa baixa Fonte: ordemnatural.com.br

A Figura 2.3-7 anterior mostra um filtro passa baixa, onde (Vin) indica a entrada de sinal no filtro e (Vout) a saída do sinal. Como dito anteriormente, esse filtro apresenta somente um componente reativo indicado na figura pelo capacitor (C1), classificando este como de primeira ordem. (JÚNIOR, 2003)

É possível determinar a frequência de corte de um filtro passa baixa de primeira ordem através de sua equação característica mostrada em (21). 


$$
F c=\frac{1}{(2 \pi R 1 C 1)}
$$

Na equação 21, Fc determina a frequência de corte dada em Hertz, a variável R1 é o valor em Ohms do resistor e C1 o valor em Farad do capacitor utilizado.

O ganho deste filtro pode ser calculado através da equação mostrada em (22).

$$
G=1+\frac{R 2}{R 1}
$$

Em (22), G determina o ganho do filtro, a variável R2 e R1 é o valor em Ohm dos resistores utilizados no circuito.

Para se conseguir uma melhor seletividade destes filtros, é possível conectar 2 estágios destes filtros em série, formando um filtro de segunda ordem. A Figura 2.3-8, mostra um filtro ativo de segunda ordem passa baixa.

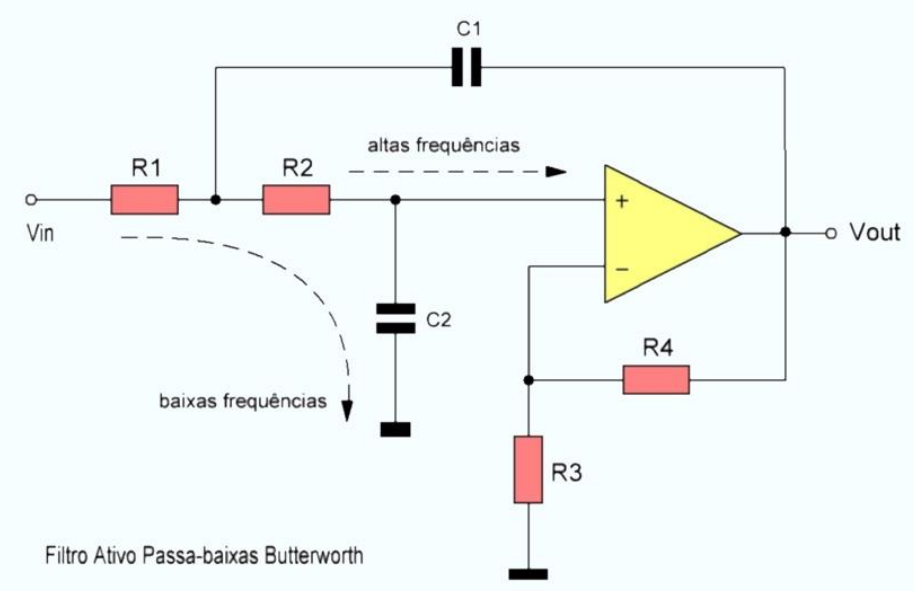

Figura 2.3-8: Filtro ativo de $2^{a}$ ordem passa baixa Fonte: ordemnatural.com.br

A Figura 2.3-8 mostra um filtro de 2ª ordem passa baixa. A classificação como segunda ordem deve-se ao fato deste possuir dois componentes reativos em seu circuito, estes podem ser visualizados na imagem pelos dois capacitores nomeados por 
C1 e C2.

Para os filtros de 2 a ordem a equação que determina a frequência de corte pode ser visualizada em (23) (JÚNIOR, 2003).

$$
F C=\frac{1}{(2 \pi \sqrt{R 1 R 2 C 1 C 2})}
$$

Na equação anterior Fc indica a frequência de corte dada em Hertz, as variáveis $\mathrm{R} 1, \mathrm{R} 2, \mathrm{C} 1 \mathrm{e} \mathrm{C2}$, indicam os valores em Ohm dos resistores e os valores em Farad dos capacitores.

\subsubsection{Modelos de amplificadores operacionais}

Existem no mercado vários modelos de amplificadores operacionais diferentes, contudo, alguns possuem algumas características específicas. Neste trabalho serão utilizados dois modelos, o LM324 e o TLC274.

\subsubsection{LM324}

O LM324 consiste em quatro amplificadores independentes de alto ganho e foram criados para funcionar a partir de uma única fonte de alimentação através de uma ampla gama de tensões. A operação de fornecimento de energia de divisão também é possível e o baixo fornecimento de energia de drenagem de corrente é independente da amplitude da tensão da fonte de alimentação. A Figura 2.3-9 e a Figura 2.3-10 mostram este modelo de AOP (TEXAS INSTRUMENTS, 2015). 


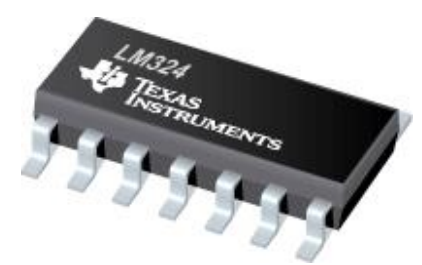

Figura 2.3-9: Encapsulamento do LM324

Fonte: Texas Instruments

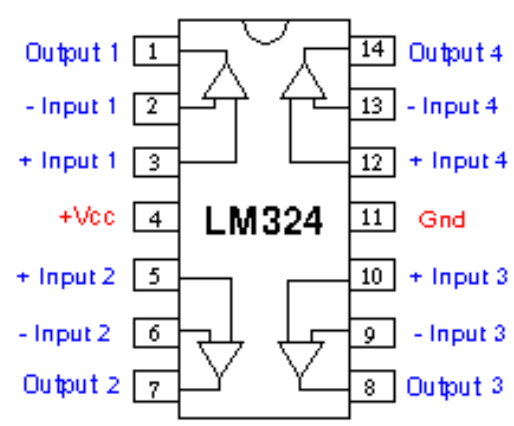

Figura 2.3-10: Pinos do LM324

Fonte: Texas Instruments

A Figura 2.3-10 mostra os pinos do amplificador LM 324, este circuito integrado possui 4 amplificadores internos, o primeiro formado pelos pinos 1, 2 e 3, o segundo pelos pinos 5, 6 e 7, o terceiro pelos pinos 8, 9 e 10 e o último pelos pinos 12, 13 e 14 . Os pinos 4 e 11 são utilizados para a alimentação dos 4 amplificadores internos ao circuito.

\subsubsection{TLC274}

Os amplificadores operacionais TLC274 combinam uma ampla gama de compensação de entrada de tensão e alta impedância de entrada, fazendo deste um amplificador de baixo ruído, ideal para aplicações onde se deseja extrema definição do sinal (TEXAS INSTRUMENTS, 2001).

Esse dispositivo utiliza a tecnologia "Texas Instruments LinCMOS", que proporciona uma estabilidade de tensão muito superior aos outros amplificadores. A 
Figura 2.3-11 e a Figura 2.3-12 mostram o AOP em questão.

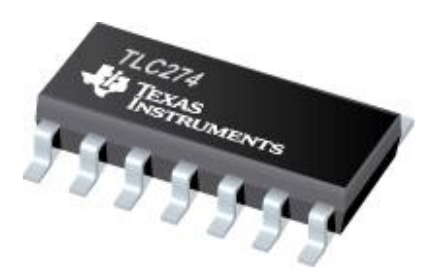

Figura 2.3-11:Encapsulamento do TLC274 Fonte: Texas Instruments

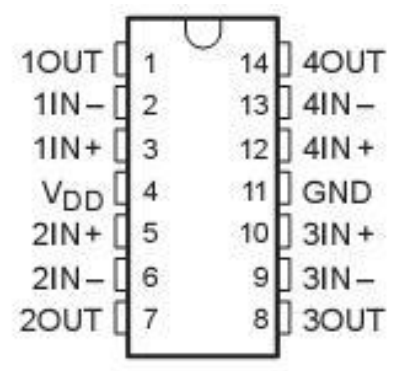

Figura 2.3-12: Pinos TLC274

Fonte: Texas Intruments

A Figura 2.3-12 mostra os pinos do amplificador TLC 274. Este amplificador é composto por 14 pinos e possui 4 amplificadores internos ao circuito. O primeiro é formado pelos pinos 1, 2 e 3, o segundo pelos pinos 5,6 e 7, o terceiro pelos pinos 8,9 e 10 e o quarto amplificador pelos pinos 12,13 e 14 . A alimentação de todos os amplificadores operacionais internos ao circuito é feita pelos pinos 4 e 5 , onde o primeiro é a alimentação positiva e o segundo a alimentação negativa.

\subsection{Microcontroladores}

Microcontrolador é um computador completo construído em um único circuito integrado. Eles são compostos de uma unidade de processamento central, memória e unidade de entrada e saída integradas a um único microchip. (MALVINO, 1985)

Dessa forma, compreende-se que os microcontroladores são utilizados para aplicações específicas, sendo destinados para o desenvolvimento de projetos singulares. 
Diferentemente, porém, pode-se falar dos microprocessadores, que correspondem como um tipo de componente voltado para incidências de uso geral, trazendo a possibilidade de subdividi-los em outros programas.

A aplicação individual dos microcontroladores é enfatizada por possuir um conjunto de instruções que são programadas diretamente em seu chip, normalmente denominadas como "Firmware", limitando a sua função para aquela que foi programada. Visto a redução dos microcontroladores, um de seus benefícios é o custo envolvido para o seu propósito, sendo claramente menor que o exigido para a realização de um projeto com microprocessador. A Figura 2.4-1 ilustra de forma básica as unidades de um Microcontrolador.

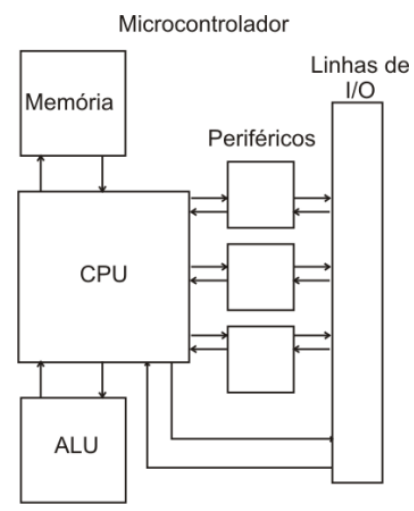

Figura 2.4-1: Arquitetura básica de um Microcontrolador Fonte: arnerobotics.com.br

A Figura 2.4-1 ilustra de forma básica, os componentes internos de um microcontrolador. Esses componentes são a CPU com a unidade de lógica e aritmética, denominada ALU, a memória e os periféricos com as linhas de conexão de entradas e saídas, denominadas 10.

\subsubsection{Unidades de um microcontrolador}

A CPU do inglês, "Central Processing Unit" é a parte mais importante de qualquer computador e é a responsável por todo o processamento de dados do Microcontrolador. Inicialmente era composta de vários componentes integrados, mas com o passar do tempo evoluiu para um único circuito integrado. A CPU é composta por 
três componentes principais, unidade lógica e aritmética, unidade de controle e registradores. Os componentes básicos de uma CPU são os registradores, a unidade de controle e a unidade de lógica e aritmética, como mostra a Figura 2.4-2.

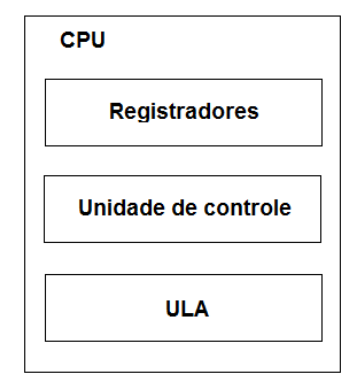

Figura 2.4-2: Arquitetura básica CPU

Fonte: Autor

A unidade lógica e aritmética também chamada de ULA ou ALU no inglês, é responsável pelas operações aritméticas lógicas como adição, subtração e todos os cálculos que envolvam registros e lógica para a tomada de decisões. (MALVINO, 1985)

A unidade de controle também denominada UC, é responsável por extrair as instruções da memória, decodificar e executar as ações. A UC gera todos os sinais que controlam as operações as operações da CPU. Ela deve garantir a correta execução dos dados manipulados.

A CPU possui internamente uma memória de alta velocidade e permitem o armazenamento de valores intermediários e informações de comando. Essa memória é composta por registradores e cada registrador possui uma função própria. Os registradores são construídos com flip-flops que são capazes de armazenar dados. 0 principal registrador é o acumulador que contém um dos dados usados na operação que se deseja e guarda o resultado da operação. (MALVINO, 1985)

A memória é o componente do sistema capaz de armazenar os dados e informações a serem manipulados pelo sistema. Existem vários tipos de memória, algumas delas permanentes ou não voláteis, que não perdem os dados quando desligadas e outras temporárias ou voláteis, onde os dados permanecem apenas quando estão energizadas.

Existem vários tipos de memórias, em que a memória RAM, do inglês "Randomic 
Access Memory", é uma memória do tipo volátil e é compreendida apenas como um espaço temporário de trabalho. Os dados permanecem nesta memória quando estão sendo utilizados pelo Microcontrolador. Já a memória PROM do inglês "Programmable Read Only Memory" é uma memória do tipo não volátil e podem ser escritas, mas não podem ser apagadas.

A memória EPROM, do inglês "Erasable Programmable Read Only Memory", são iguais a memória PROM, porém podem ser apagadas com o uso de radiação ultravioleta, permitindo sua reutilização. Já a memória EEPROM do inglês "Eletrically Erasable Programmable Read Only Memory" é uma evolução da EPROM, que também permite a escrita e apagamento dos dados, sendo o que difere estas memórias é o fato de que esta última pode ser apagada de forma elétrica por comando da CPU, não precisando assim da radiação ultravioleta para este trabalho.

A memória flash é uma memória do tipo EEPROM e esta possui uma maior velocidade e um menor custo se comparado com a EEPROM padrão.

O último componente do microcontrolador é a unidade de entrada e saída, conhecida por IO do inglês "IN/OUT". Esta unidade é responsável por todas as conexões de entradas e saídas do Microcontrolador, comandada pela unidade de controle. Ela permite que o Microcontrolador receba e envie sinais externos, funcionando assim para que o sistema possa interagir com os sinais externos a ele.

Nesta unidade existem vários periféricos que permitem uma maior flexibilidade ao microcontrolador como entradas e saídas seriais, I2C, SPI entre outras.

\subsubsection{Microcontrolador PIC}

Existem no mercado vários modelos e marcas de microcontroladores e neste trabalho será abordado os Microcontroladores fabricados pela empresa Microchip Technology.

Os microcontroladores PIC compreendem como uma família de controladores da 
arquitetura Harvard e conjunto de instruções RISC, em que sua sigla é uma derivação do inglês "Peripheral Interface Controller", hoje conhecido apenas pela sigla PIC. Existem vários modelos destes microcontroladores, os quais cada um deles possui uma determinada particularidade.

Neste trabalho será abordado o Microcontrolador PIC 18F4550, que é um microcontrolador da série 18f, produzida pela Microchip Technology, que possui um baixo custo e atende completamente às configurações necessárias para o desenvolvimento do sistema proposto.

\subsubsection{PIC $18 \mathrm{~F} 4550$}

Este Microcontrolador apresenta 40 pinos de conexões com uma memória flash de $32 \mathrm{kB}$, memória RAM de $2 \mathrm{kB}$ e memória EEPROM de $256 \mathrm{kB}$. Sua velocidade de operação pode chegar até $48 \mathrm{MHz}$ e possui 35 portas de entrada e saída, além de um conversor de sinal analógico para digital com resolução de 10 bits. A Figura 2.4-3 mostra o encapsulamento deste PIC e a Figura 2.4-4 mostra todos os pinos do microcontrolador.

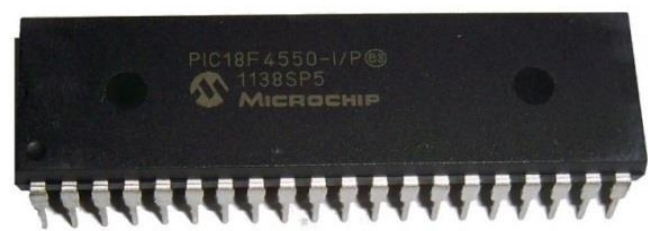

Figura 2.4-3: Microcontrolador PIC $18 F 4550$ Fonte: Microchip

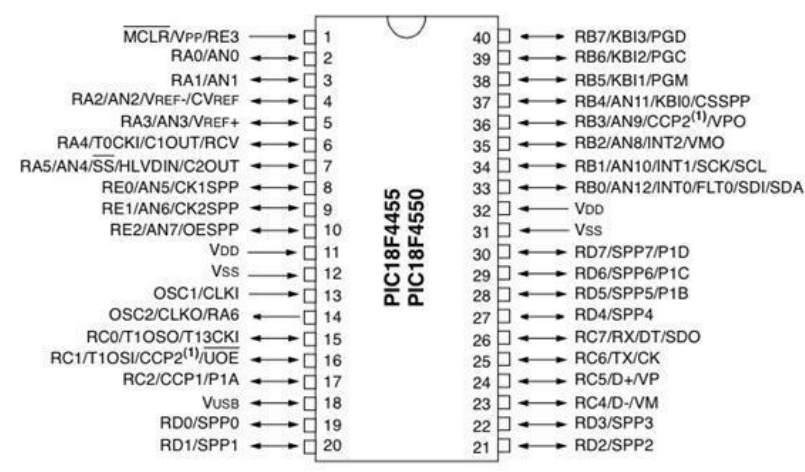

Figura 2.4-4: Pinos PIC 18F4550 
Fonte: Microchip

As entradas e saídas deste microcontrolador são divididas em grupos, e cada porta tem uma determinada função. O microcontrolador PIC 18 F4550 possui 4 grupos de portas, chamados PORT A, PORT B, PORT C e PORT D. O registrador que controla se estes pinos serão entradas de sinal ou saídas de sinal é o "TRIS". Esse registrador deve ser configurado de acordo com a necessidade dos pinos que serão utilizados.

O grupo de portas deste microcontrolador possui entradas analógicas que também devem ser configuradas quanto a ativação da porta e resolução de trabalho dela. Três registradores internos são responsáveis por esta configuração, o ADCONO, ADCON1 e ADCON2.

Para este microcontrolador funcionar é necessário utilizar um oscilador externo conectados nos pinos 13 e 14 e este oscilador é responsável pelo relógio, clock, de trabalho do microcontrolador.

A alimentação do circuito é feita pelos pinos 11 e 12 ou 32 e 31, nos pinos denominados VDD e VSS, onde o primeiro é conectado o polo positivo e o segundo o polo negativo ou terra. A tensão de alimentação máxima do circuito é 5,5 Volts e a mínima é 2,0 Volts.

Para a programação dos microcontroladores é gerado um código fonte contendo as instruções que serão executadas por um determinado controlador.

Com o fim de se inserir os dados dentro deste microcontrolador é necessário um hardware externo, que recebe o código em hexadecimal e converte para binário. 0 código construído permanece gravado na memória flash do PIC.

\section{CAPÍTULO 3 - DESENVOLVIMENTO DO PROTÓTIPO}

Este capítulo apresenta o desenvolvimento do circuito condicionador, responsável por filtrar e amplificar os sinais vindos dos eletrodos, e do circuito principal, 
que receberá o sinal previamente tratado para mostrar em um display e gerar um arquivo que será importado por um software para ser transmitido. Estes circuitos são necessários para a construção do produto final.

\subsection{Descrição do sistema proposto}

O sistema proposto, através de eletrodos conectados ao usuário, visa receber sinais elétricos provenientes do coração, filtrando e amplificando-os, para então mostralos em uma tela para uma futura análise do sinal cardíaco. O circuito condicionador consiste na preparação do sinal através de filtros e amplificadores para serem então enviados ao circuito principal. O circuito principal compreende na captação do sinal do circuito condicionador e seu tratamento para a visualização na tela e gravação do sinal através de um botão. O software transmissor receberá um arquivo criado e fará a transmissão do arquivo por email. A Figura 3.1-1 apresenta o diagrama de blocos do sistema.

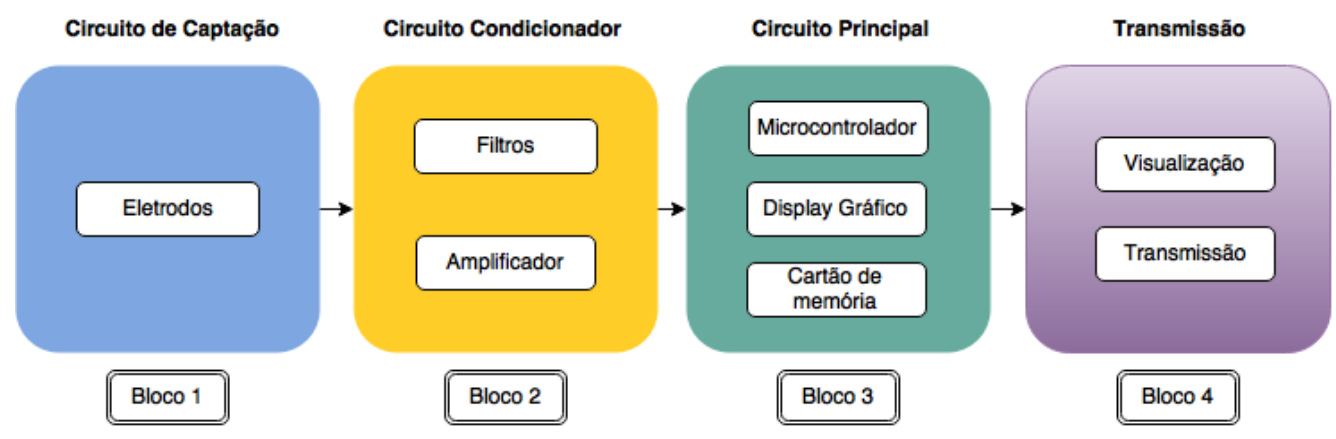

Figura 3.1-1: Diagrama de blocos do Projeto

Fonte: Elaborada pelo autor, utilizado ferramenta Flow Chart Maker: www.draw.io

O bloco 1 representa os três eletrodos conectados ao usuário. Esses eletrodos são de uso próprio para exames de eletrocardiograma e são eletrodos descartáveis e não invasivos. O bloco 2 refere-se ao circuito condicionador, responsável por filtrar e amplificar o sinal através de filtros ativos. O bloco 3 consiste na captação dos sinais, exibindo-os no display gráfico e, por fim, salvando-os em um arquivo. 0 bloco 4 
compreende a leitura do arquivo gerado pelo circuito principal e a transmissão do sinal via internet.

\subsubsection{Eletrodos (BLOCO 1)}

Os eletrodos são responsáveis pela captação dos sinais cardíacos gerados pelo coração do usuário. O eletrodo utilizado no sistema é classificado como não invasivo, ficando apenas colado sobre a pele. Cada eletrodo é composto de uma parte metálica que está inserido em um material autoadesivo utilizado para a fixação na pele do usuário. Na parte de dentro existe uma esponja contendo um gel condutor que é utilizado para a condução do estímulo elétrico até a parte metálica externa. A Figura 3.1-2 mostra o eletrodo de superfície.

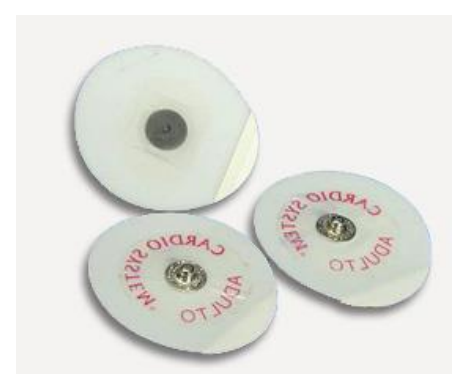

Figura 3.1-2: Eletrodo de superfície Fonte: allbiz.com

A figura mostra um eletrodo para ECG visto pela parte superior e inferior. $\mathrm{Na}$ parte inferior existe o material autoadesivo e a esponja com o gel condutor, esta parte fica colada sobre a pele do usuário. Na parte superior existe apenas a parte metálica, que será conectada aos cabos que levarão o sinal ao circuito condicionador.

No projeto, são utilizados 3 eletrodos conectados ao usuário através de um cabo típico para exames de eletrocardiogramas. A Figura 3.1-3 mostra o cabo utilizado. 


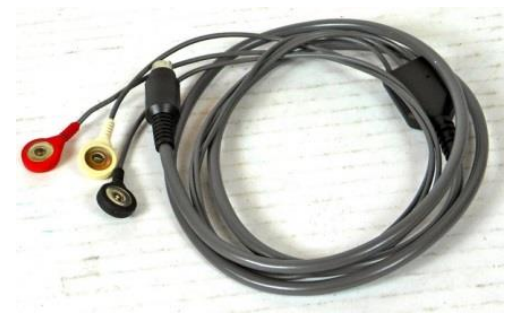

Figura 3.1-3: Cabo ECG

Fonte: http://www.labx.com

A Figura 3.1-3 mostra o cabo utilizado para exames de ECG. O cabo possui conexão para 3 eletrodos e na saída é acoplado um conector DB09 para melhor conexão deste cabo, nos circuitos.

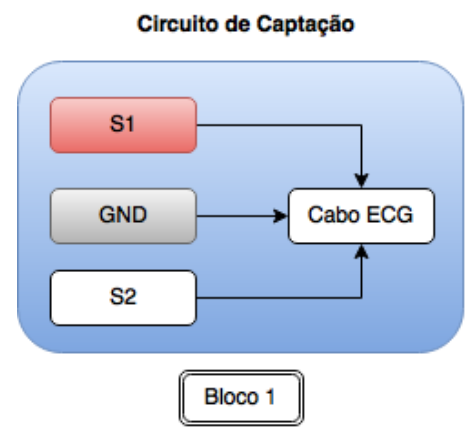

Figura 3.1-4:Diagrama dos eletrodos

Fonte: Elaborada pelo autor, utilizado ferramenta Flow Chart Maker: www.draw.io

A Figura 3.1-4 mostra o diagrama dos eletrodos. Na figura, S1, S2 e GND representam os eletrodos conectados ao paciente através do cabo de ECG. O eletrodo S1 representa o cabo de cor vermelha, S2 o cabo de cor branca e GND o cabo de cor preta. Os eletrodos são colados no usuário de acordo com a Figura 3.1-5. 


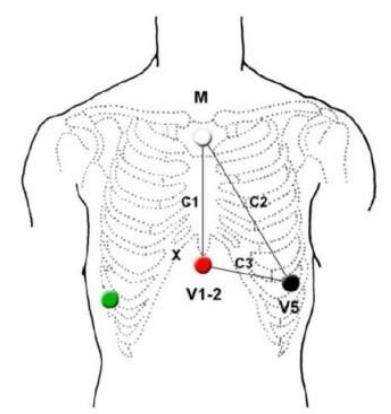

Figura 3.1-5: Posicionamento dos eletrodos Fonte: adaptada de cardios.com.br

Na Figura 3.1-5 o eletrodo S1 é conectado ao ponto vermelho indicado por V1-2, o S2 é conectado ao ponto M e o GND é conectado ao ponto V5 ilustrado na figura.

\subsubsection{Circuito condicionador (BLOCO 2)}

O circuito condicionador é responsável por receber os sinais dos eletrodos, além de filtrar e amplificar os sinais.

O corpo humano gera vários tipos de sinais elétricos e junto a eles uma série de ruídos. Por isso, para captar somente os sinais provenientes do coração é necessário a aplicação de filtros que eliminarão parte desses ruídos e somente deixarão passar o sinal elétrico a ser captado. Como estes sinais estão na ordem de $0 \mathrm{mV}$ à $1 \mathrm{mV}$, também é necessário o uso de amplificadores que elevarão o nível de tensão dos sinais que serão analisados. O circuito condicionador pode ser separado em 4 estágios. A Figura 3.1-6 mostra, de forma simples, o diagrama de montagem do circuito condicionador. 


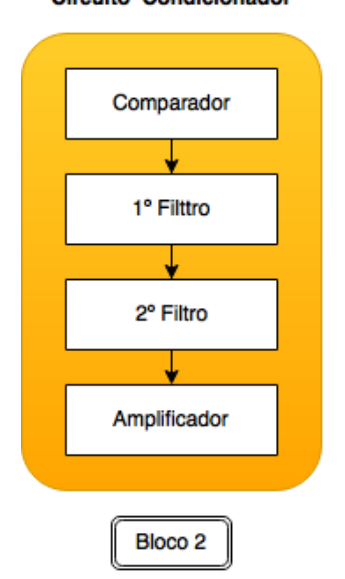

Figura 3.1-6: Diagrama Circuito Condicionador

Fonte: Elaborada pelo autor, utilizado ferramenta Flow Chart Maker: www.draw.io

O primeiro estágio do circuito condicionador faz uma comparação entre os sinais vindos dos eletrodos S1 e S2. Todos os ruídos comuns aos dois eletrodos são descartados no estágio do comparador. Para a criação dessa etapa é utilizado o amplificador operacional TLC274. A Figura 3.1-7 mostra o circuito elétrico do comparador.

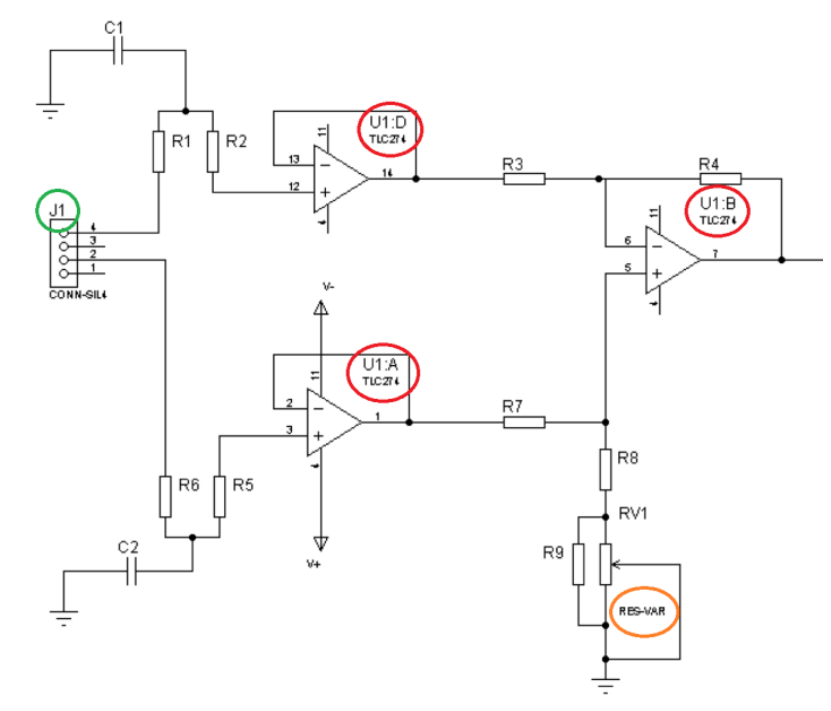

Figura 3.1-7: Circuito comparador

Fonte: Elaborada pelo autor no software Proteus

Na Figura 3.1-7, a indicação "U1" nos círculos em vermelho evidenciam os amplificadores operacionais TLC274. Como esse microchip possui 4 amplificadores no mesmo encapsulamento, cada um deles é seguido por uma letra, "U1:A", “U1:B", "U1:C" 
e "U1:D". Os sinais chegam dos eletrodos através do conector representado na figura por "J1" indicado pelo círculo verde. O sinal do eletrodo "S1", de cor vermelha, chega ao circuito condicionador pelo pino 2 do conector "J1" e é conectado ao primeiro AO definido por "U1:A". O sinal do eletrodo "S2", de cor branca, chega ao circuito pelo pino 4 de "J1" e é conectado ao AO definido por "U1:D". As saídas desses amplificadores é conectada a outro AO definido na figura por "U1:B", formando assim o circuito comparador. Para o cancelamento dos sinais comuns às duas entradas é utilizada uma característica dos amplificadores operacionais chamada de CMRR (Common Mode Reject Ratio), onde é possível ter o controle de rejeição comum as duas entradas de um amplificador diferencial, evitando, assim, a entrada de sinais indesejados, comuns a ambos os condutores de entrada. A rejeição pode ser controlada por um potenciômetro mostrado por RV1 na figura.

Para o correto cancelamento de sinais, o potenciômetro RV1, indicado na figura pelo círculo laranja, tem que ser calibrado utilizando um osciloscópio e um gerador de sinais. Utilizando um gerador de sinais, configurado para gerar uma senoide na frequência de $1 \mathrm{kHz}$ e amplitude de $1 \mathrm{~V}$ de pico a pico, é injetado dois sinais idênticos em S1 e S2, e é conectado um osciloscópio na saída do amplificador diferencial definido por U1:B. O potenciômetro tem que ser ajustado até que apareça uma linha reta no osciloscópio, mostrando que se ambas as entradas forem iguais, a saída é igual a 0v. A Figura 3.1-8 mostra imagem do gerador de sinais bem como sua configuração.

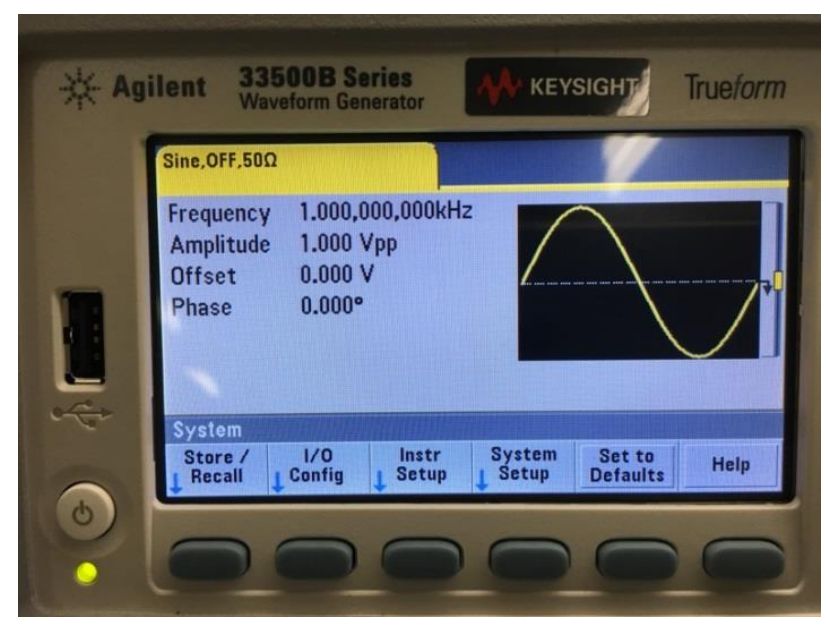

Figura 3.1-8: Gerador de Sinais Fonte: Elaborada pelo autor

Na Figura 3.1-8 é possível visualizar a tela do gerador de sinais, gerando uma 
onda senoidal com frequência de $1 \mathrm{kHz}$ e amplitude de $1 \mathrm{Vpp}$. Para visualizar a saída dos sinais, é utilizado um osciloscópio digital que pode ser visualizado na Figura 3.1-9.

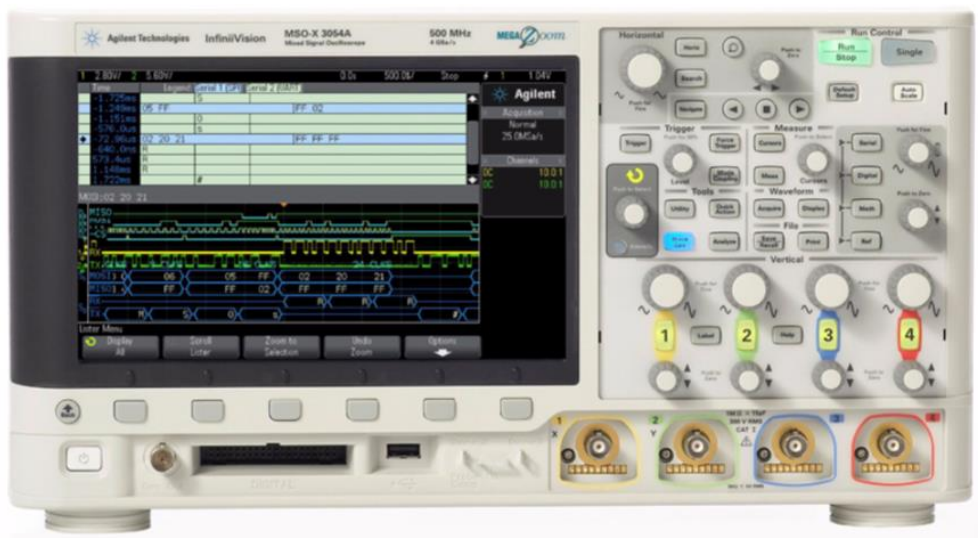

Figura 3.1-9: Osciloscópio Digital Fonte: agilent.com

Após a conexão do gerador de sinais aos eletrodos S1 e S2, é conectado o osciloscópio na saída do amplificador operacional. A Figura 3.1-10 mostra a saída do sinal sem o ajuste do potenciômetro RV1.

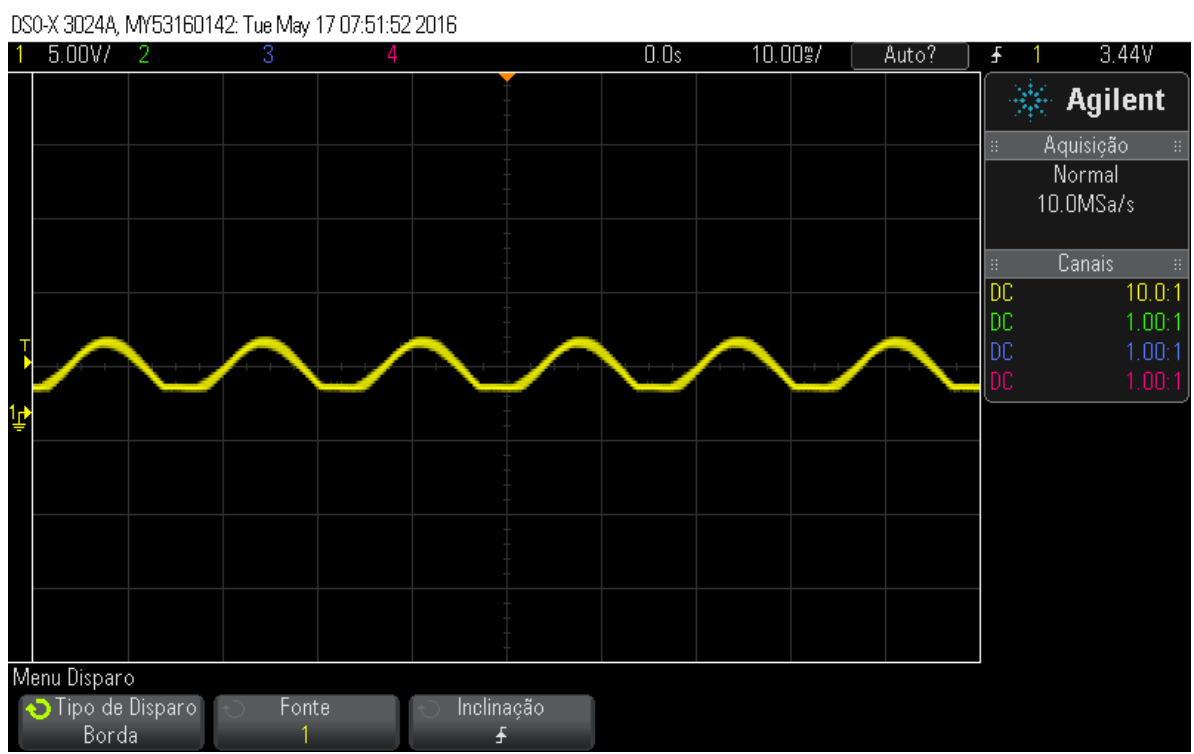

Figura 3.1-10: Tela do osciloscópio sem o ajuste do CMRR Fonte: Elaborada pelo autor

Na Figura 3.1-10 é possível perceber que existe um sinal de saída mostrado no 
osciloscópio. Em seguida é feito o ajuste do CMRR, através do potenciômetro RV1, até que apareça uma linha reta na tela do osciloscópio, mostrando que não existe nenhuma saída quando os eletrodos possuem o mesmo sinal. A Figura 3.1-11mostra a saída do amplificador após o ajuste do CMRR.

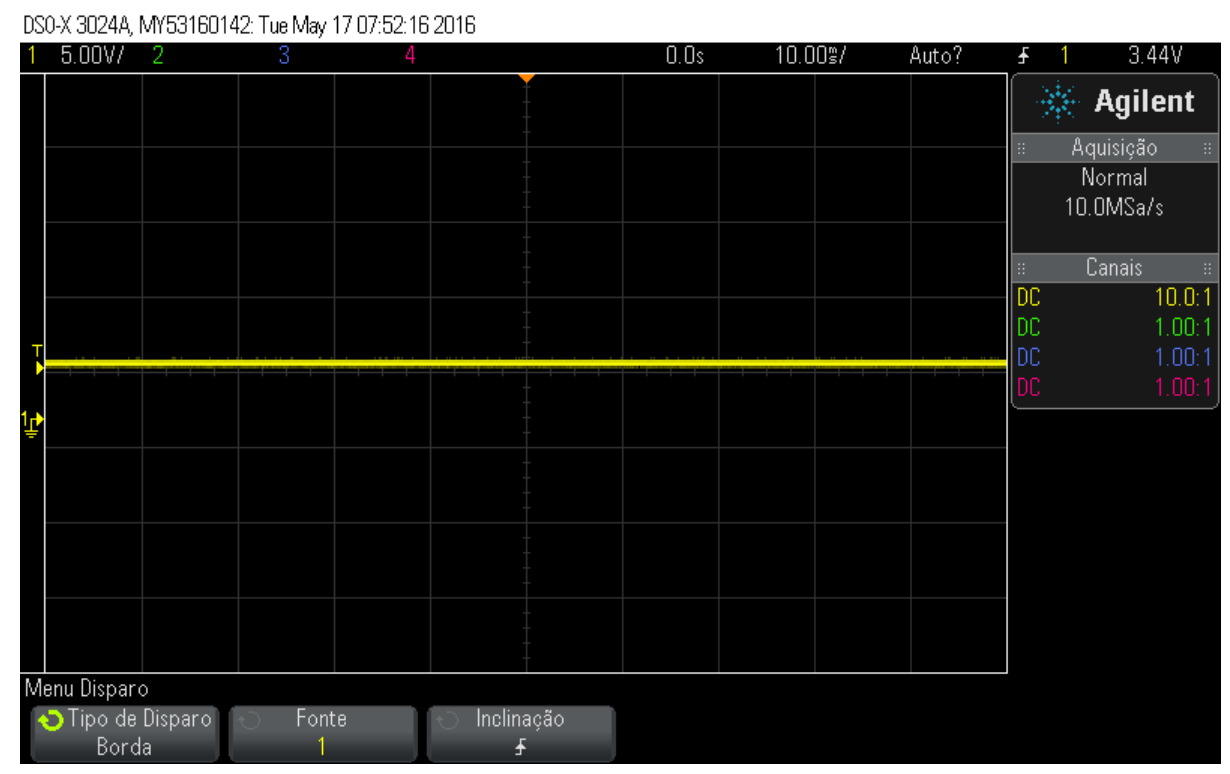

Figura 3.1-11: Tela do osciloscópio com o ajuste do CMRR Fonte: Elaborada pelo autor

Após o ajuste do CMRR para cancelar os sinais, o sinal passa para o segundo estágio do circuito, que é o primeiro filtro passa baixa. A Figura 3.1-12 mostra a parte do circuito responsável por este filtro.

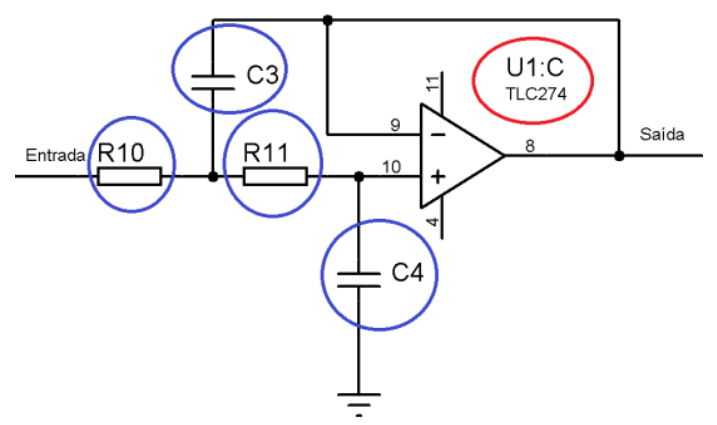

Figura 3.1-12: Primeiro filtro passa baixa - LPF Fonte: Elaborada pelo autor utilizado software proteus

A Figura 3.1-12 mostra o circuito responsável pelo primeiro filtro de segunda 
ordem passa baixa. Para a montagem deste filtro é utilizado o microchip TLC274, indicado na Figura 3.1-12 por U1:C no círculo vermelho. A frequência de corte é determinada pelos resistores (R10) e (R11) e os capacitores (C3) e (C4), indicados nos círculos azuis, onde foram utilizados resistores de $68 \mathrm{k} \Omega$ e capacitores de $100 \mathrm{nF}$. A equação (24) mostra a fórmula matemática para a determinação da frequência de corte de um filtro de 2aㅡ ordem passa baixa, conforme apresentada no capítulo 2.

$$
F c=\frac{1}{(2 \pi \sqrt{R 1 R 2 C 1 C 2})}
$$

Na equação anterior, Fc é a frequência de corte do filtro, a variável R é o valor do resistor e a variável C é o valor da capacitância do capacitor utilizado. A equação a seguir mostra os valores já substituídos na fórmula.

$$
\begin{gathered}
F C=\frac{1}{2 * \pi * \sqrt{68 * 10^{3} * 68 * 10^{3} * 100 * 10^{-9} * 100 * 10^{-9}}} \\
F C \sim 23 \mathrm{~Hz}
\end{gathered}
$$

A equação anterior mostra o cálculo realizado para determinação da frequência de corte. $\mathrm{O}$ valor de aproximadamente $23 \mathrm{~Hz}$ deve-se ao fato de que qualquer frequência cardíaca, independente do paciente, terá medida menor que esta.

Para uma melhor filtragem do sinal, é construído um segundo filtro passa baixa. Na saída do primeiro filtro o sinal é conduzido para um segundo filtro passa baixa que pode ser visualizado na Figura 3.1-13.

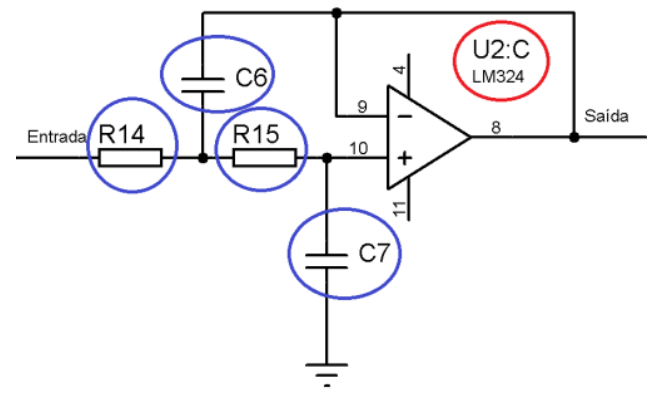

Figura 3.1-13: Segundo filtro passa baixa- LPF Fonte: Elaborado pelo autor utilizando software Proteus 
Para a construção do segundo filtro passa baixa, é utilizado um microchip LM324, indicado na figura por U2:C no círculo vermelho. Na imagem, os resistores "R14", "R15" e os capacitores " $C 6$ " e "C7" determinam a frequência de corte deste filtro. Como este segundo filtro também possui a mesma frequência de corte do primeiro filtro, foram utilizados os mesmos valores de resistores e capacitores do primeiro filtro, no caso, os resistores de $68 \mathrm{k} \Omega$ e os capacitores de $100 \mathrm{nF}$, gerando novamente uma frequência de corte em aproximadamente $23 \mathrm{~Hz}$.

Após todos os estágios de filtragem o sinal é passado para um outro amplificador operacional para gerar um ganho maior no sinal. O circuito responsável por este estágio pode ser visualizado na Figura 3.1-14.

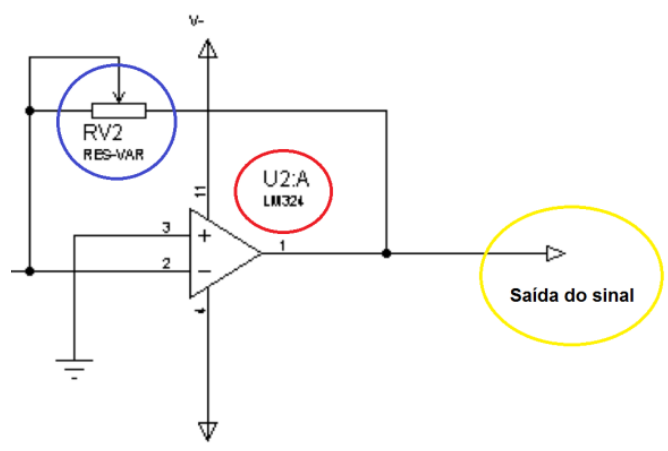

Figura 3.1-14:Estágio de amplificação

Fonte: Elaborado pelo autor utilizando software Proteus

A Figura 3.1-14 mostra o circuito responsável pela última amplificação do sinal previamente filtrado. Para esta amplificação do sinal é utilizado um amplificador operacional LM324, indicado na figura por U2:A no círculo vermelho. O ganho dessa amplificação pode ser controlado através de um potenciômetro indicado na figura por RV2 no círculo azul. A saída deste último estágio do circuito condicionador pode ser visualizada no círculo amarelo que é conectada diretamente ao circuito principal do protótipo.

Todos os estágios do circuito condicionador foram acoplados em uma única placa de circuitos impressos, onde são conectados os eletrodos e é gerada uma saída do circuito condicionador. Para realizar a impressão de todos os circuitos contidos nessa placa, é gerado um fotolito contendo apenas as trilhas e as ilhas onde os componentes 
eletrônicos são soldados. A Figura 3.1-15 mostra o fotolito gerado.

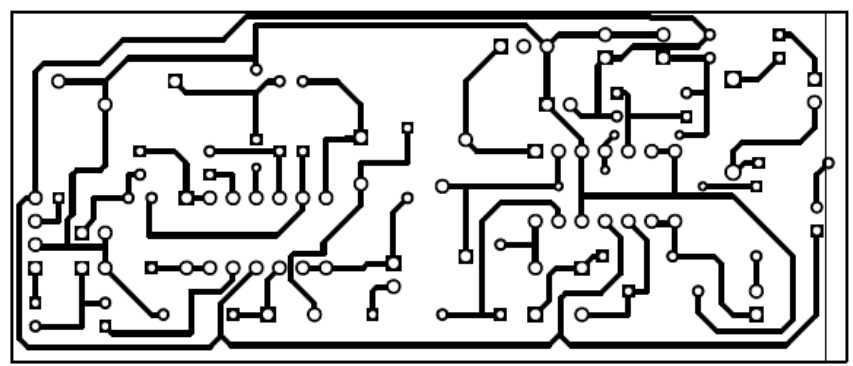

Figura 3.1-15: Fotolito do circuito condicionador Fonte: Elaborado pelo autor utilizando software Proteus

Na figura anterior é possível visualizar todas as trilhas de conexão dos circuitos da placa, indicado pelas linhas pretas. Os círculos pretos são chamados de ilhas e delimitam onde os componentes eletrônicos serão soldados na placa de circuito impresso.

Depois da placa ser impressa os componentes eletrônicos são soldados na placa, finalizando, assim, todo o circuito condicionador de sinais do protótipo. A figura a seguir mostra a placa de circuitos já finalizada.

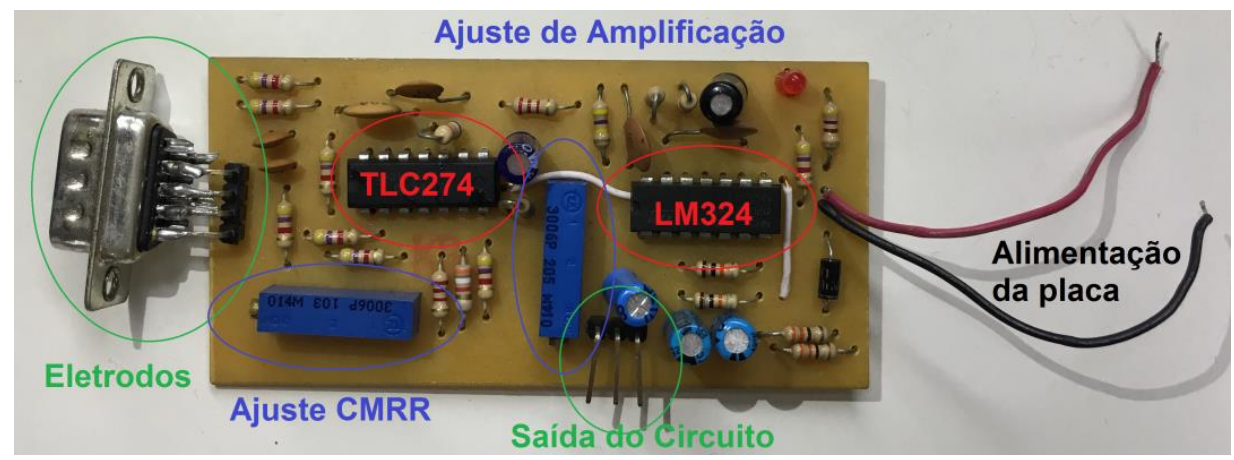

Figura 3.1-16: Circuito condicionador Fonte: Autor

A Figura 3.1-16 mostra a placa confeccionada responsável pelo circuito condicionador. Os círculos em vermelho mostram os 2 blocos de amplificadores operacionais utilizados, referentes ao TLC274 e ao LM324, já os círculos em verde 
mostram os conectores de entrada e saída de sinais, referentes a entrada dos eletrodos e a saída para o circuito principal do protótipo, e os círculos em azul mostram os dois potenciômetros de ajuste da placa do condicionador, referentes ao ajuste do CMRR e a amplificação final da placa.

\subsubsection{Circuito principal (BLOCO 3)}

O circuito principal é responsável por receber os sinais previamente tratados pelo condicionador, mostra-los em um display gráfico e por fim gravar estes sinais em um arquivo. A Figura 3.1-17 mostra de forma simples os passos do circuito principal.

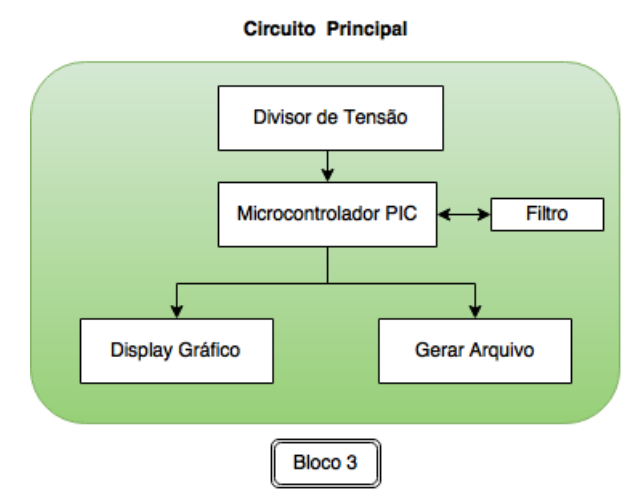

Figura 3.1-17: Diagrama Circuito principal Fonte: Elaborada pelo autor

Os sinais recebidos pelo circuito principal são conectados ao microcontrolador PIC através de um divisor de tensão. O microcontrolador é o componente responsável por fazer todo o gerenciamento das funções do circuito principal. A primeira função deste circuito é aplicar um filtro que, por meio de software, retirará qualquer resquício de ruído do sinal. Sua segunda atribuição é exibir o sinal em um display gráfico para a visualização pelo operador do sistema. A terceira e última atividade é gerar um arquivo em um cartão de memória contendo as informações do sinal para ser passado ao software transmissor. O diagrama elétrico do circuito principal é dividido em 6 módulos para facilitar o entendimento e estes podem ser visualizados na Figura 3.1-18 a seguir. 


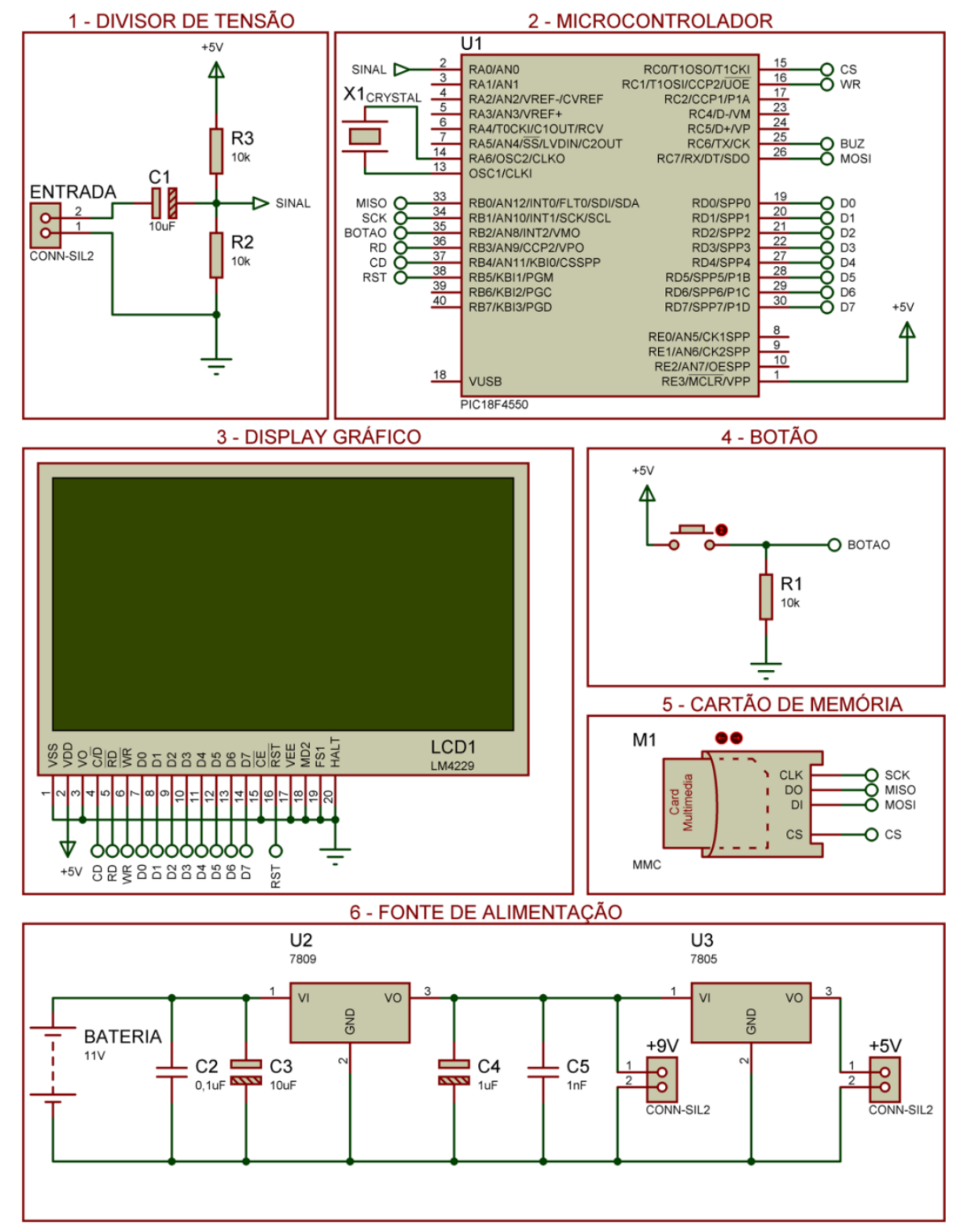

Figura 3.1-18: Circuito Principal

Fonte: Elaborada pelo autor com o software proteus

A Figura 3.1-18 mostra os 6 módulos, indicados pelos retângulos, que constituem o circuito principal. O primeiro módulo é o divisor de tensão e é responsável por receber o sinal do circuito condicionador e colocar este sinal em um valor aceitável pelo microcontrolador. O segundo módulo constitui o microcontrolador, sendo este encarregado de fazer todo o controle dos módulos seguintes. O módulo 3 refere-se ao display gráfico que possui a função de apresentar em sua tela informações enviadas pelo módulo anterior. O módulo 4 trata do botão do circuito principal, encarregado de enviar um sinal ao módulo 2 quando for pressionado. O módulo 5 concerne ao cartão de 
memória, que armazena o arquivo gerado pelo segundo módulo. Por fim, o módulo 6 é a fonte de alimentação do sistema, que energiza todos os componentes eletrônicos em sua correta tensão de funcionamento.

O circuito condicionador gera em sua saída um sinal alternado que varia de $-4,5 \mathrm{~V}$ a $+4,5 \mathrm{~V}$, porém o microcontrolador trabalha apenas com valores de $0 \mathrm{~V}$ a $5 \mathrm{~V}$. O módulo 1 é encarregado de pegar o sinal do circuito condicionador e converter para um valor de Ov a $5 \mathrm{v}$ para ser lido pelo microcontrolador.

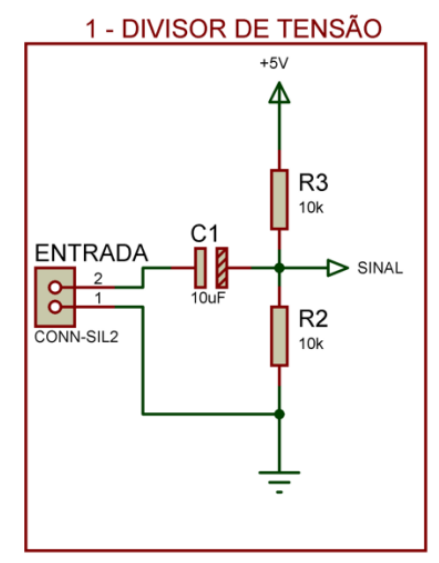

Figura 3.1-19:Módulo 1 do Circuito Principal Fonte: Elaborada pelo autor

A Figura 3.1-19 mostra os componentes eletrônicos responsáveis por adequar o sinal a um valor de tensão de admissível pelo microcontrolador. O capacitor e os resistores, indicados por $\mathrm{C} 1, \mathrm{R} 2, \mathrm{R} 3$, fazem um divisor de tensão, onde uma tensão de OV na entrada, representa um valor de $2,5 \mathrm{~V}$ na saída, assim como um valor de $-4,5 \mathrm{~V}$ na entrada, denota um valor de $0 \mathrm{~V}$ na saída e um valor de 4,5V na entrada representa $5 \mathrm{~V}$ na saída. Desta forma, os valores na saída do divisor de tensão possuem valor mínimo OV e valor máximo de $5 \mathrm{~V}$, podendo, então, ser conectado ao microcontrolador.

O módulo 2 é o microcontrolador do circuito principal, e tem por função passar o sinal de entrada por um último filtro e controlar os demais módulos. A Figura 3.1-20 mostra o diagrama elétrico deste módulo, com todas as suas conexões simbolizadas pelos círculos. 


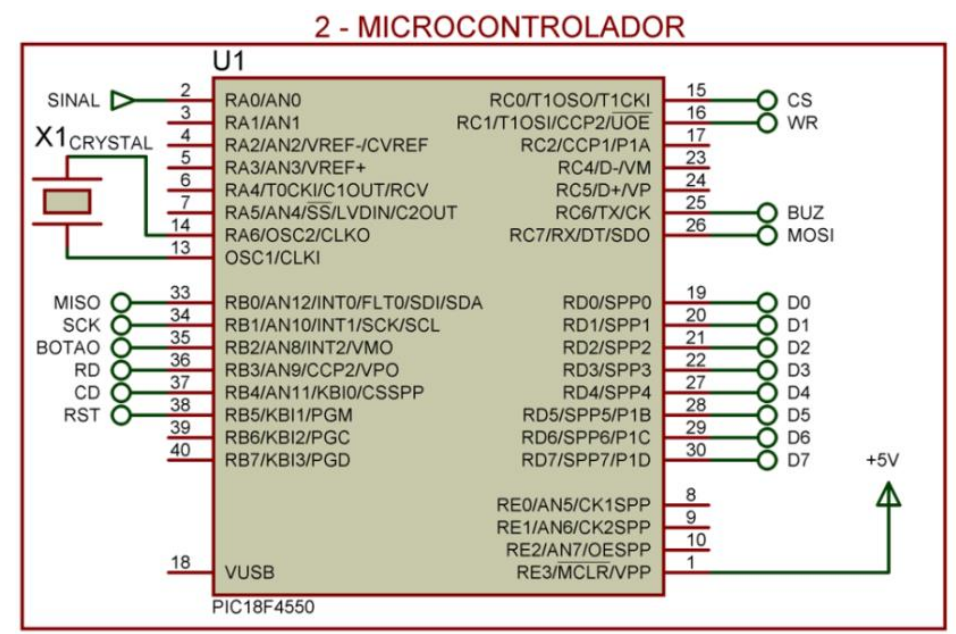

Figura 3.1-20: Módulo 2 do circuito principal Fonte: Elaborada pelo autor

A saída de sinal do módulo 1 é conectada ao pino 2 do microcontrolador, que corresponde como uma entrada analógica. A utilização de uma entrada analógica devese ao fato deste sinal variar de 0 a 5 Volts.

A figura a seguir apresenta os módulos 3, 4 e 5, que são todos os periféricos conectados ao módulo 2.
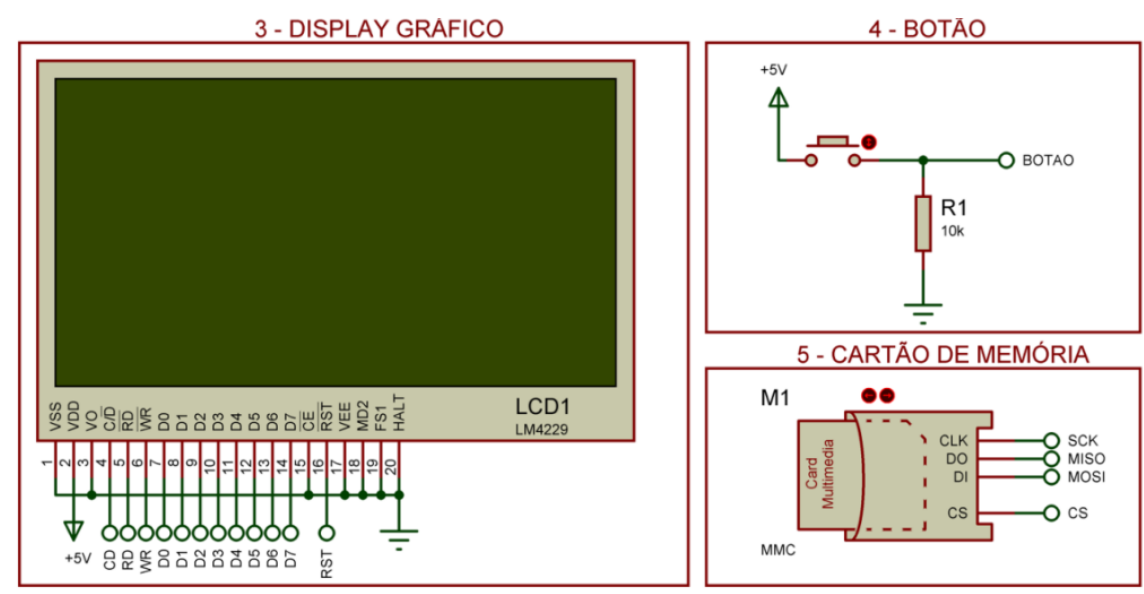

Figura 3.1-21: Módulo 3, 4 e 5 do circuito principal Fonte: Elaborada pelo autor

Na Figura 3.1-21, o módulo 3 é o display gráfico, este é conectado ao microcontrolador através de 14 conexões. Os pinos (1) e (2) deste display são apenas para alimentação, já os pinos (4), (5), (6) e (16) são os pinos responsáveis pelo controle e os pinos de (7) ao (14) são para a comunicação do microcontrolador para o display. 
O módulo 4 é o botão do sistema, este é conectado a porta 35 do microcontrolador, simbolizado na figura por (BOTAO). Ele consiste como um pino digital de interrupção interna ao microcontrolador. A utilização do botão em um pino de interrupção possui como justificativa o fato de otimizar o funcionamento geral do sistema, já que o sistema não terá que ficar verificando periodicamente se o botão foi pressionado. Ao ser pressionado, o botão possibilita a passagem de $5 \mathrm{~V}$ ao microcontrolador, gerando a interrupção. Quando não está pressionado, o resistor, indicado na figura por R1, coloca a tensão em $0 \mathrm{~V}$, indicando ao microcontrolador que o botão não está pressionado.

O módulo 5 é o cartão de memória SD, o qual pode ser removido e possui seis pinos, onde dois são de alimentação, dois são de controle e 2 são de comunicação. A comunicação entre o microcontrolador e o cartão de memória é feita através do protocolo SPI (Serial Peripheral Interface) que é um protocolo de dados seriais síncronos utilizado em microcontroladores. Os pinos apresentados na figura são apenas os de controle e comunicação onde os pinos de controle são indicados na figura por (SCK) e (CS), onde o primeiro é o clock de sincronização da comunicação e o segundo é o ChipSelect, que seleciona o chip da comunicação. Os pinos de comunicação são indicados na figura por (MISO) e (MOSI), onde o primeiro é saída de dados do cartão para o microcontrolador e o a saída de dados do microcontrolador para o cartão SD.

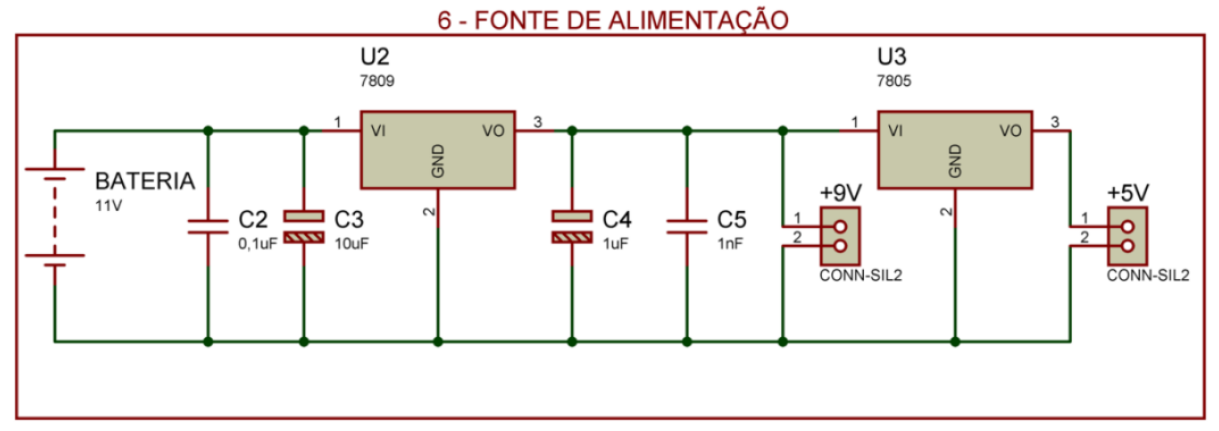

Figura 3.1-22: Módulo 6 do Circuito Principal

Fonte: Elaborada pelo autor

O módulo 6 apresenta a fonte de alimentação do sistema e este é mostrado na Figura 3.1-22 a seguir. O sistema é alimentado por uma bateria de 11Volts e passa por um regulador de tensão de $9 \mathrm{~V}$, indicado na figura por U2, para alimentar o circuito condicionador. Posteriormente a alimentação, é passada para um regulador de tensão 
de 5V, indicado na figura por U3, que faz a alimentação do circuito principal. Os capacitores indicados na figura por C2, C3, C4 e C5 são responsáveis por filtrar ruídos provenientes da alimentação do circuito.

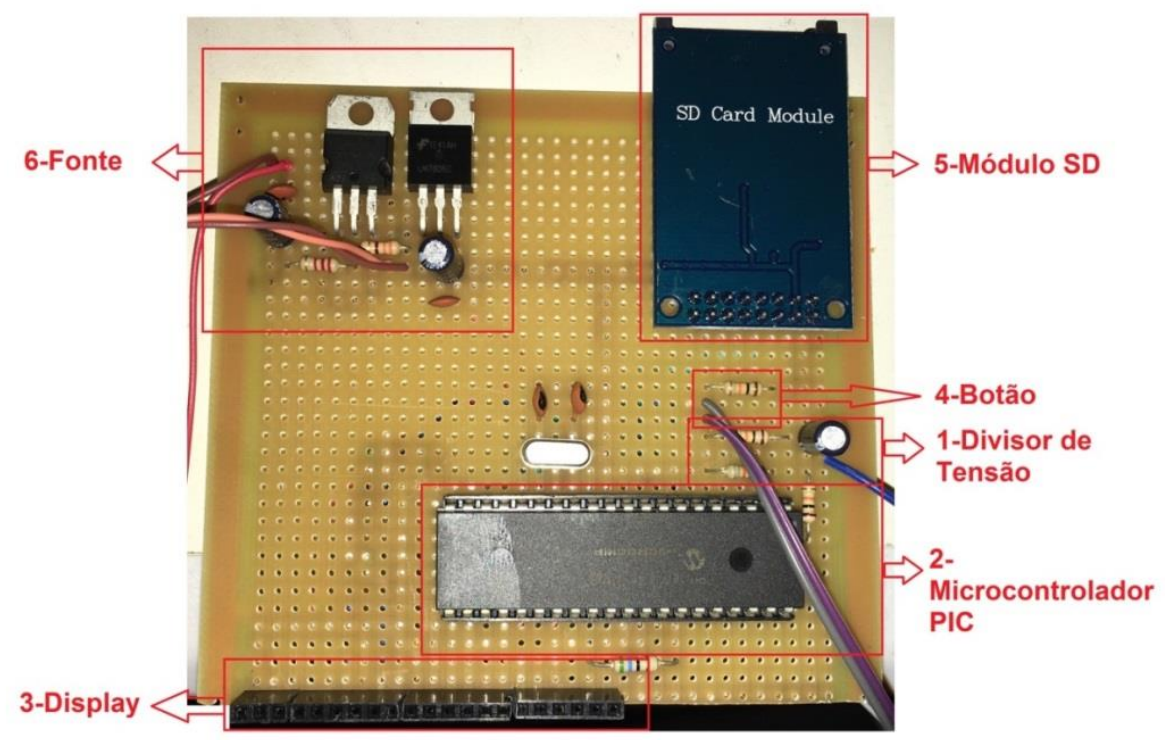

Figura 3.1-23:Placa de circuitos do Bloco 3

Fonte: Autor

É confeccionada uma placa de circuitos contendo todos os componentes do Bloco 3 do sistema proposto, que pode ser visto na Figura 3.1-23. A figura traz as identificações de cada módulo do circuito e sua correta localização na placa de circuitos.

\subsubsection{Código Fonte}

O código fonte em linguagem de programação $C$, apresentado no APÊNDICE A e programado no microcontrolador PIC, utiliza 3 bibliotecas externas, sendo a primeira a "_T6963C.h", responsável por fazer o controle do display gráfico, a segunda a "Imagens.c", por carregar as imagens de tela que serão utilizadas e a terceira, que corresponde como "Waveletfilter.h", encarregada de realizar o tratamento digital dos dados. Depois realiza-se a configuração dos pinos utilizados para controle do display e controle do cartão de memória do dispositivo. Em seguida, ocorre a definição das variáveis do código, onde a variável "Leitura" é empregada para armazenar os valores 
da amostragem do sinal, o vetor "Buffer" fica responsável por guardar os valores dos sinais após a amostragem, a variável "gravar" possui valor 0 ou 1 e é utilizada quando se deseja gravar o sinal no cartão de memória. As variáveis "i" e "cont" são empregadas apenas para rotinas de loop descritas na segunda parte do código.

A segunda parte do código traz as funções de utilização no sistema, onde a primeira função, "interrupt", é responsável por executar uma atividade específica quando uma interrupção externa for gerada e a segunda função é nomeada por "Main", sendo a função principal e a primeira a ser executada do sistema. Na primeira função do sistema em questão, é quando o usuário pressiona o botão para gravar o sinal mostrado no display, onde se altera a variável "gravar" para o valor "1", indicando que aquela tela deve ser salva no arquivo. Na segunda função, principal, primeiramente é feita a configuração dos pinos de entradas e saídas do microcontrolador PIC, no qual é configurado a entrada analógica que receberá os valores dos sinais provenientes do circuito condicionador do protótipo. Logo após é feita a inicialização do display e é aberta a comunicação com o cartão de memória e então são chamadas as telas de inicialização do sistema

A terceira parte do código é a seção da função "Main", que ficará sempre em loop enquanto o sistema estiver ligado. A primeira tarefa dessa seção é iniciar a aquisição do sinal por meio da biblioteca implementada, chamada de "WaveletFilter", que fará o tratamento digital do sinal. Essa biblioteca realiza a decomposição do sinal por meio da transformada discreta de wavelet, a remoção de ruídos por meio da aplicação de filtros passa altas e filtros passa baixas e a reconstrução do sinal, através da transformada wavelet inversa, retirando assim ruídos intrínsecos ao sinal. Para isso devem ser preenchidos os argumentos na chamada da função. O primeiro argumento a ser passado se refere a função de aquisição do sinal, representado no código por "ADC_read(0)", onde esta função retorna os valores na entrada analógica do microcontrolador. O segundo argumento representa a variação de valores possíveis na entrada analógica. O terceiro argumento se refere ao lugar onde o sinal será gravado, representado no código pelo vetor "Buffer". O quarto argumento se refere ao tamanho do buffer para gravação do sinal reconstruído. A segunda tarefa desta seção é mostrar no display gráfico 240 valores do vetor "Buffer" criado anteriormente, em que, para isso, 
é criado um loop que percorre todo o buffer e cada posição do buffer corresponde à localização no eixo x no display gráfico. A variação na vertical a ser mostrada no display, depende do valor inserido em cada uma das 240 posições do vetor criado. Como esses valores variam de 0 a 1023, totalizando 1024 valores, faz-se necessária uma divisão destes valores por 8, devido ao fato do display gráfico só possuir 128 pixels no eixo vertical. A impressão deste buffer, com o sinal já tratado, no display gráfico é feita através a função "T6963C_line". Logo após é feita a gravação do sinal em um arquivo no cartão de memória inserido no dispositivo. Para isso é feito um loop que percorre o buffer criado anteriormente e cada valor inserido gera um ponto no arquivo a ser criado. Para separar estes valores, é colocado um caractere ";" entre eles, formando assim um arquivo do tipo CSV, do inglês (Comma separated values) no interior do cartão de memória.

\subsubsection{Software Transmissor (BLOCO 4)}

Para realizar a transmissão do sinal é desenvolvido um software que fica responsável por realizar o envio do sinal cardíaco previamente gerado no circuito principal. Este software realiza a leitura do arquivo gerado, mostrando o arquivo sinal cardíaco que é gravado. Depois é gerada uma imagem desse sinal que é enviada, por email, ao médico responsável por diagnosticar o paciente em questão. A Figura 3.1-24 mostra de forma simples o diagrama de seu funcionamento.

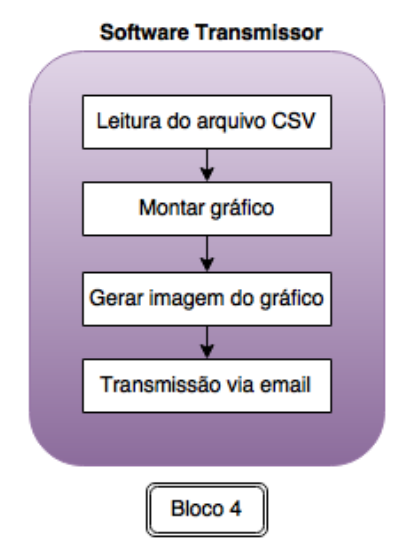

Figura 3.1-24: Diagrama de blocos Software Transmissor 
Fonte: Elaborada pelo autor

O software transmissor é divido em 4 etapas onde a primeira realiza a leitura do arquivo contendo o sinal cardíaco previamente gerado. Logo após é montado o gráfico do sinal cardíaco para a visualização pelo operador do software e então é gerado uma imagem do gráfico para ser enviada ao email do médico que fará o diagnóstico do sinal.

$\mathrm{O}$ arquivo gerado pelo circuito transmissor possui 240 valores separados pelo caractere ' $;$ '. O software criado lê cada um destes valores e monta um vetor contendo todos eles, onde cada um representa um ponto no gráfico a ser criado. Logo após é montado o gráfico utilizando cada ponto do vetor, dando origem ao gráfico do sinal cardíaco do paciente que está sendo analisado. Para a transmissão deste gráfico é utilizado um protocolo de transferência de email simples, chamado de SMTP (Simple Mail Transfer Protocol), que é o protocolo padrão para envio de e-mails através da internet, onde para seu correto funcionamento é necessário indicar o usuário e senha de um servidor de e-mail existente (POSTEL, 1982). O software transmissor gera uma imagem do gráfico apresentado e então anexa esta imagem ao email que será enviado. A Figura 3.1-25 mostra o software transmissor desenvolvido.

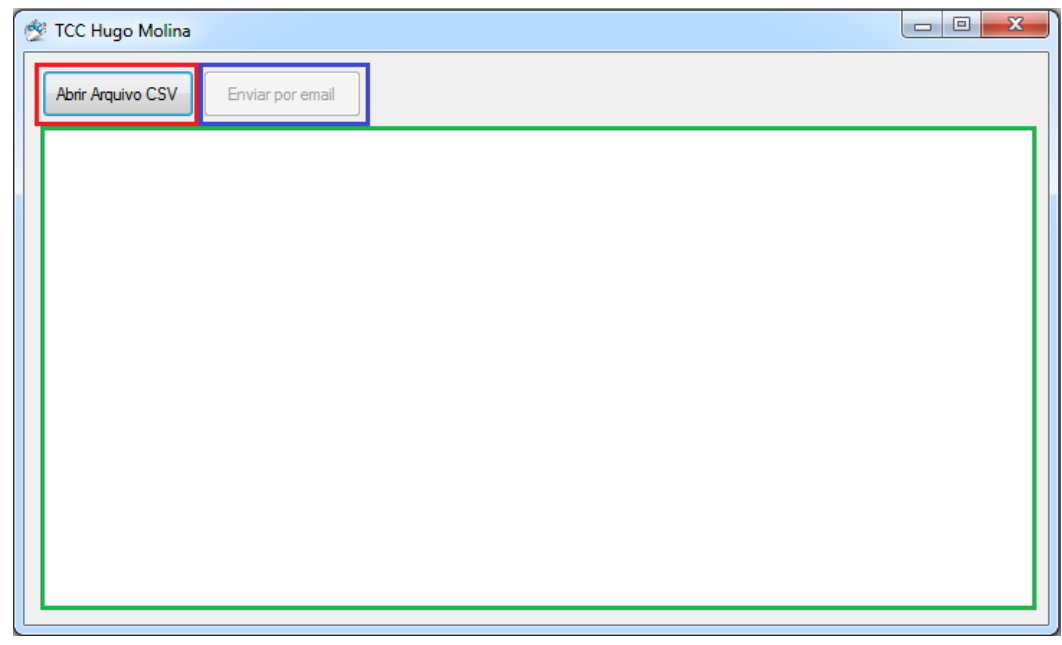

Figura 3.1-25: Software Transmissor Fonte: Elaborada pelo autor

Na Figura 3.1-25, o retângulo em vermelho demostra o botão responsável por 
localizar o arquivo gerado e depois montar o gráfico que será inserido no retângulo verde. Logo após ser montado o gráfico o botão indicado pelo retângulo azul é desbloqueado, permitindo, assim, que seja enviado a imagem do gráfico apresentado. Quando o botão para o envio é pressionado é aberta uma nova janela contendo os campos para o envio do e-mail. A Figura 3.1-26 mostra a janela da transmissão do email.

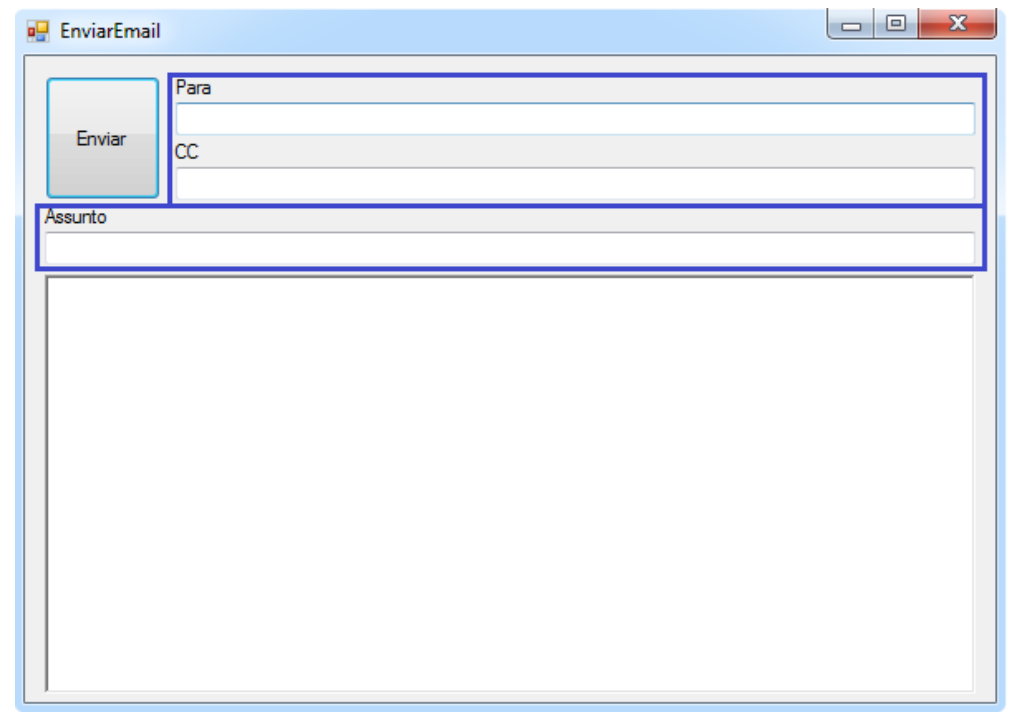

Figura 3.1-26:Envio do email Fonte: Elaborada pelo autor

Os campos em azul mostrados na Figura 3.1-26 devem ser preenchidos como os campos básicos de um email. No campo 'Para' é indicado o email do médico que receberá o gráfico do sinal cardíaco, o campo ' $C C^{\prime}$ deve ser preenchido somente no caso de existir algum outro email que deverá receber o sinal. O campo 'Assunto' será o assunto do email enviado. Após o preenchimento desses campos, o botão 'Enviar' abre a comunicação com o servidor de e-mails, passando todas as informações necessárias e anexando neste email a imagem do gráfico gerada.

\subsubsection{Código Fonte}

O código fonte, desenvolvido na linguagem C\# (CSharp), apresentado no Apêndice B e compilado utilizando software Visual Studio, é separado em 3 partes. A primeira parte do código refere-se a classe responsável por abrir o arquivo do tipo CSV, 
criado anteriormente pelo Bloco 3 do sistema. Inicialmente, nessa classe, é aberta uma janela onde se pode localizar o arquivo previamente salvo pelo protótipo, utilizando a função "OpenFileDialog", onde o caminho do arquivo fica salvo na variável "arquivo". Posteriormente, é declarada a variável "linha" do tipo String que, através da função "StreamReader", armazena todo o conteúdo do arquivo. Como os dados são separados pelo caractere ";", é criado uma rotina de repetição que retira todos os caracteres de separação e cada valor fica armazenado separado dentro do vetor nomeado por "LinhaSeparada"

A segunda parte do código é incumbida de receber o vetor "linhaseparada" e montar o gráfico do sinal previamente extraído. Primeiramente nesta parte do código é feita uma rotina de repetição que percorre todo o vetor, contendo os valores separados do arquivo, e então são colocados no vetor "dados" para montagem do gráfico. O gráfico é exibido através da função "gerarGrafico.Series.Add(sinal)". Posteriormente é gerada uma imagem do gráfico por meio da função "gerarGrafico.DrawToBitmap", que é salva no computador pela função "bmp.Save".

A terceira parte do código fica responsável por enviar o email contendo a imagem gerada do gráfico. Para a transmissão do gráfico é utilizado um protocolo de saída de emails (SMTP). Inicialmente é declarada a variável "local", que contém a localização da imagem gerada do gráfico e seguidamente é configurado os parâmetros do cliente SMTP por meio da função (smtp.PARAMETRO). Após a configuração do cliente de email é anexado o arquivo através da função "mail.Attachments.Add(attachment)", que anexa a imagem gerada junto ao email que será enviado. O email é enviado com a função "smtp.send". 


\section{CAPÍTULO 4 - TESTES E RESULTADOS}

Neste capítulo são apresentados os resultados dos testes realizados no projeto. Os quatro blocos definidos no capítulo 4 são avaliados de formas diferentes, respeitando suas funcionalidades e características. O primeiro bloco, referente aos eletrodos, é testado utilizando um osciloscópio digital. Este teste tem como objetivo observar o sinal captado antes da utilização de filtros analógicos e digitais. Para o Circuito condicionador, no segundo bloco, é testado a aplicação dos filtros analógicos e amplificador com objetivo de visualizar o sinal cardíaco na tela do osciloscópio e verificar a correta atuação destes componentes. No terceiro bloco, pertinente ao Circuito principal, é testado a aplicação do filtro digital, bem como a visualização do sinal no display gráfico do sistema proposto e a gravação do sinal no cartão de memória. Para o quarto e último bloco, é testada a importação do arquivo gerado, assim como o envio do email contendo a imagem do sinal previamente aberto no software.

Uma característica importante no projeto é o baixo consumo do dispositivo proposto. A corrente total do dispositivo é de $90 \mathrm{~mA}$, que alimentado em $11 \mathrm{~V}$ pela bateria do protótipo, obtém-se um consumo aproximado de $1 \mathrm{~W}$. Como é utilizada uma bateria com corrente máxima de $2200 \mathrm{~mA} /$ hora, dividindo-se a corrente máxima pela corrente do dispositivo, resulta-se em uma autonomia aproximada de 24 horas.

\subsection{Testes do BLOCO 1}

\subsubsection{Medição dos sinais sem filtros}

Os eletrodos são conectados no corpo humano e os sinais de saída dos eletrodos foram analisados com o auxílio de um osciloscópio digital DSO-X 3024A, da marca Agilent. A Figura 4.1-1 apresenta o sinal de saída sem nenhum tipo de tratamento do sinal. 


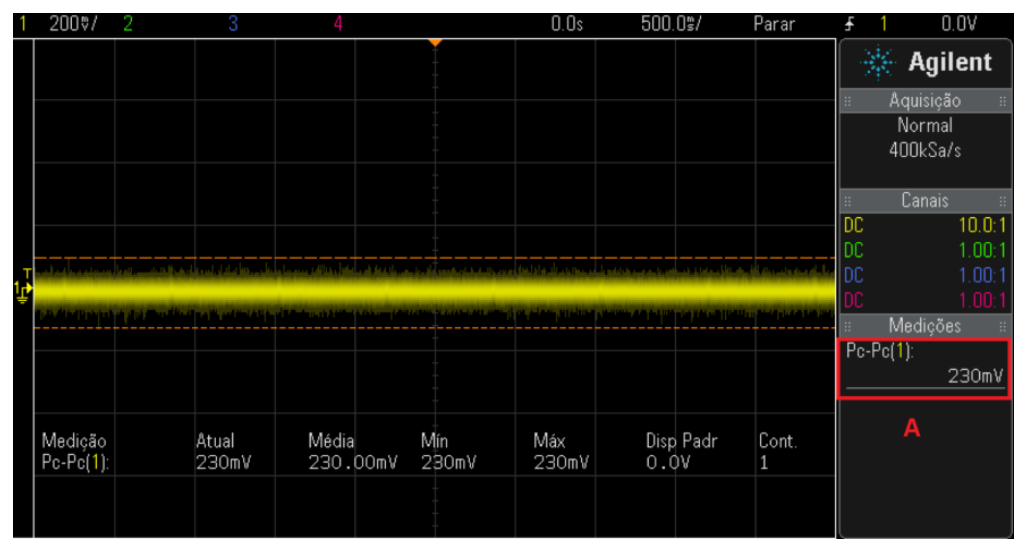

Figura 4.1-1: Sinal de saída dos eletrodos Fonte: Elaborada pelo autor

$\mathrm{Na}$ indicação em "A" da Figura 4.1-1 é possível perceber que a tensão do sinal exibido é de $230 \mathrm{mVpp}$, contudo, como apresentado no capítulo 2, a tensão de funcionamento dos impulsos elétricos do coração é na ordem de $1 \mathrm{mVpp}$. Este fato ocorre pela presença de outros sinais elétricos provenientes do corpo humano, além de ruídos externos advindos de causas diversas. A partir dessa constatação, vislumbra-se a impossibilidade de visualizar a captação dos sinais cardíacos do indivíduo de forma "limpa", ou seja, de uma maneira que mostre somente os sinais provindos do coração.

\subsection{Testes do BLOCO 2}

\subsubsection{Medição dos sinais com filtros analógicos e amplificador}

Com os eletrodos conectados ao indivíduo, o sinal é conectado ao circuito condicionador do dispositivo e seus sinais de saída conectados no osciloscópio digital. A Figura 4.2-1 a seguir mostra saída de sinais do circuito condicionador, bloco 2, do protótipo. 


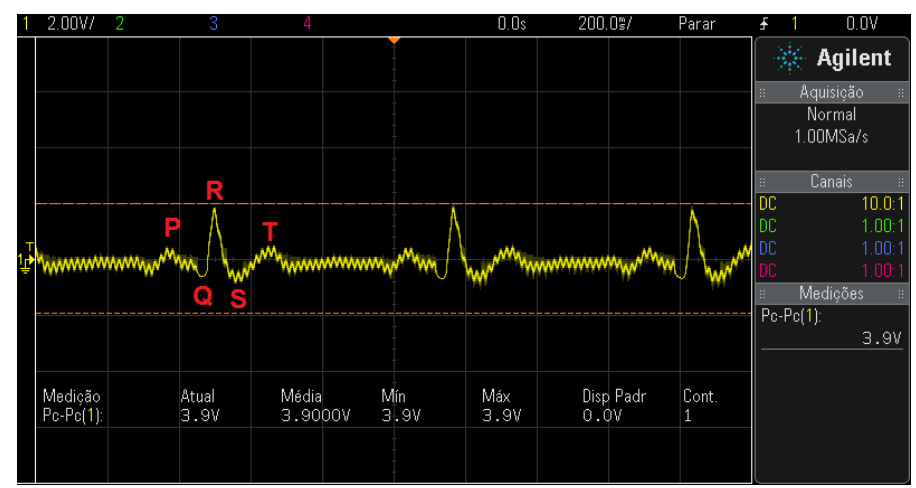

Figura 4.2-1: Sinal de saída do circuito condicionador Fonte: Elaborada pelo autor

No circuito condicionador, os sinais dos eletrodos passam por 3 estágios de filtros e um estágio de amplificação do sinal. Na Figura 4.2-1, torna-se possível a identificação da onda $\mathrm{P}$, complexo QRS e onda $\mathrm{T}$, conforme apresentado anteriormente no capítulo 2. O sinal exibido ainda possui uma série de influências externas, apresentado na figura pelo desnivelamento de sua linha.

\subsection{Testes do BLOCO 3}

\subsubsection{Sistema em funcionamento}

O sinal do circuito condicionador é conectado ao circuito principal que faz um filtro digital do sinal e apresenta este em sua tela de display gráfico. A Figura 4.3-1 refere-se a tela do circuito principal em fase de medição.

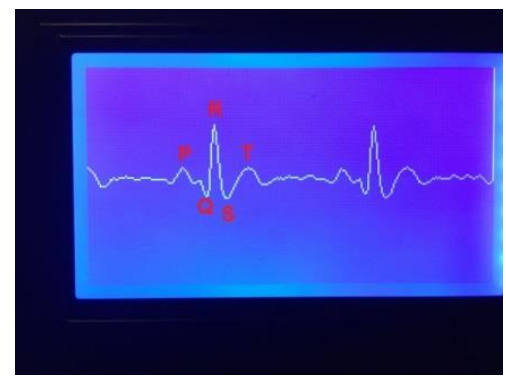

Figura 4.3-1: Foto do display gráfico do sistema Fonte: Elaborada pelo Autor 
No sistema principal, primeiramente é feita a aplicação do filtro digital e posteriormente a impressão do sinal no display gráfico do sistema. Na figura anterior é possível perceber a atuação do filtro pela linha mais retilínea apresentada na tela, evidenciando mais visivelmente as ondas características dos impulsos elétricos originados no coração, indicadas pelas letras em vermelho na figura, conforme visto anteriormente no capítulo 2.

\subsubsection{Teste de gravação do arquivo}

Para o teste de gravação do sinal no arquivo é gerado um gráfico na ferramenta Microsoft Excel e comparado ao sinal visualizado na tela principal do dispositivo. A Figura 4.3-2 mostra os resultados encontrados.
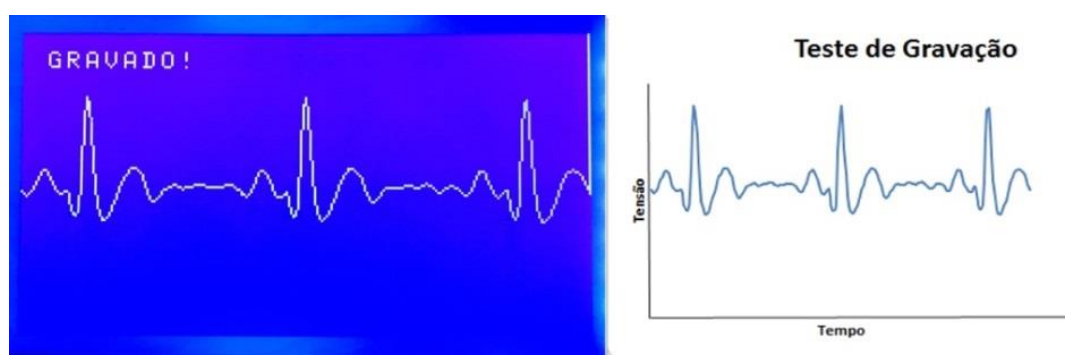

Figura 4.3-2: Comparativo sinal mostrado e arquivo gravado Fonte: Elaborada pelo autor

Na Figura 4.3-2, ao lado esquerdo, corresponde como uma foto da tela do protótipo com o sinal gravado e ao lado direito é mostrado o gráfico do arquivo gerado pelo protótipo, através do Microsoft Excel. Pode-se perceber que o protótipo gera um arquivo com o sinal muito semelhante ao sinal mostrado na tela do equipamento.

\subsection{Testes do BLOCO 4}

Para o teste do software transmissor, bloco 4, o arquivo gerado pelo circuito 
principal, bloco 3, é aberto pelo software, onde é feita a visualização do arquivo gerado. Depois é feito o teste de transmissão do email com a imagem do gráfico em anexo.

\subsubsection{Software em funcionamento}

Primeiramente é aberto, no software, o arquivo gerado no cartão de memória do dispositivo, no qual já é exibido o gráfico do sinal cardíaco. A Figura 4.4-1 mostra o software com o arquivo já aberto.

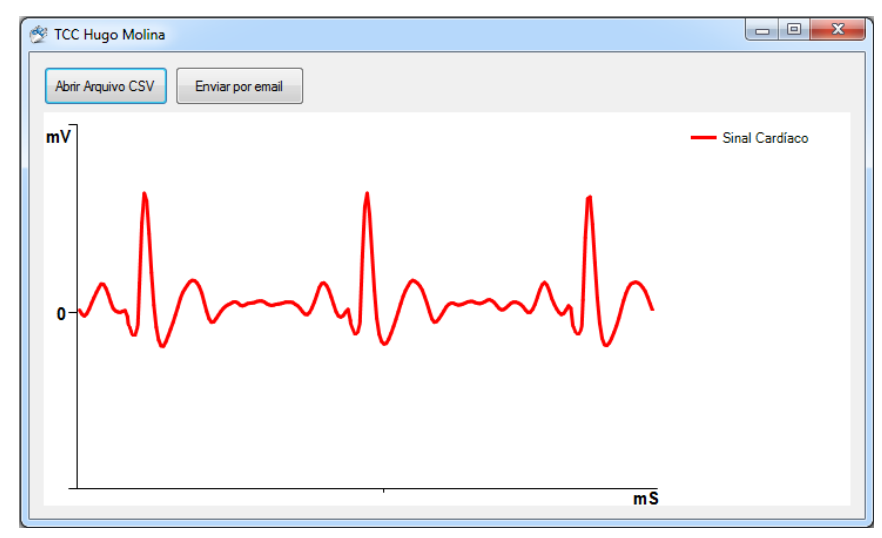

Figura 4.4-1:Software transmissor em execução Fonte: Elaborada pelo autor

A figura anterior mostra o software já com o sinal importado e a correta visualização do sinal cardíaco no gráfico gerado. Após a abertura do arquivo o botão "Enviar por email" é liberado para ser pressionado. A Figura 4.4-2 mostra a tela do software que faz a transmissão do gráfico exibido. 


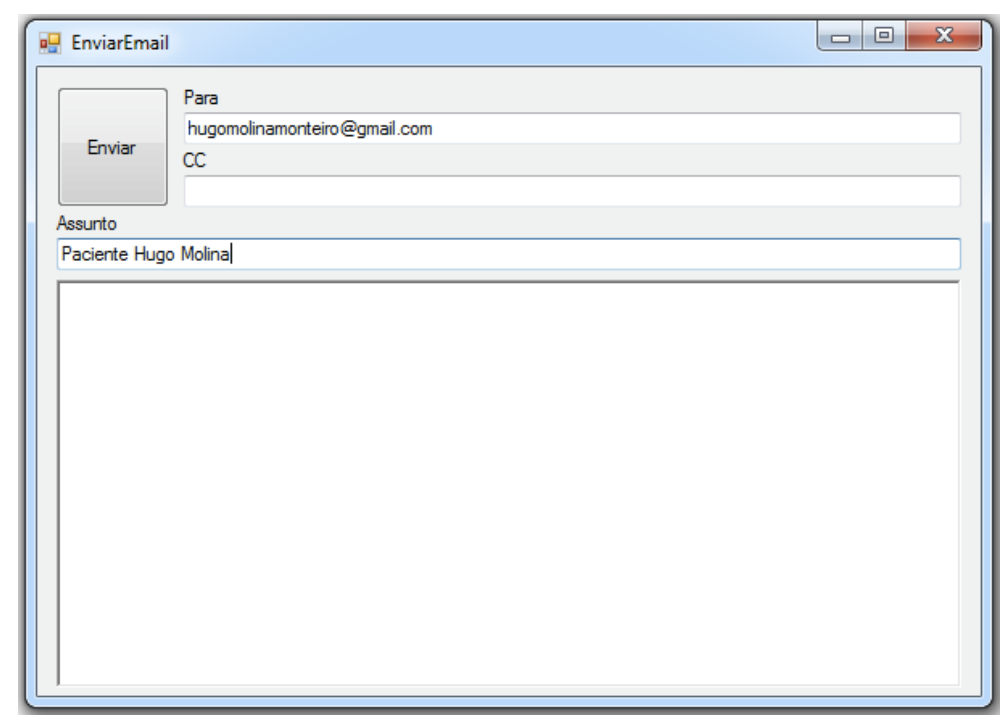

Figura 4.4-2: Transmissão do sinal via email Fonte: Elaborada pelo autor

Na figura anterior é preenchido o campo com um email que receberá o gráfico do sinal cardíaco e em seguida o email é enviado.

$$
\text { ecgtccfinal@gmail.com }
$$

para mim

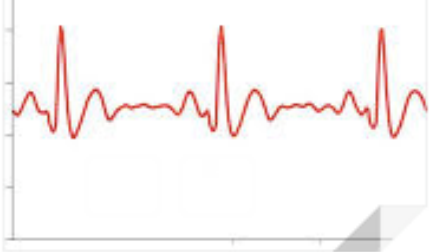

Figura 4.4-3: Recepção do email Fonte: Elaborada pelo autor

A Figura 4.4-3 mostra o email chegando com sucesso, trazendo como anexo o mesmo gráfico gerado na tela do dispositivo proposto.

\subsection{Testes comparativos}


Nesse teste é utilizado um eletrocardiógrafo profissional, contido no laboratório de fisiologia humana, no Centro Universitário de Brasília (UniCEUB), e comparado os valores de tensão com os recebidos pelo protótipo. Para que os sinais inseridos no eletrocardiógrafo profissional sejam idênticos aos conectados no dispositivo proposto é utilizado um equipamento simulador de sinais cardíacos de uso profissional para calibração de eletrocardiógrafos. A Figura 4.5-1 e a Figura 4.5-2 mostram o eletrocardiógrafo do UniCEUB e o equipamento de simulação de sinais cardíacos profissional utilizado.

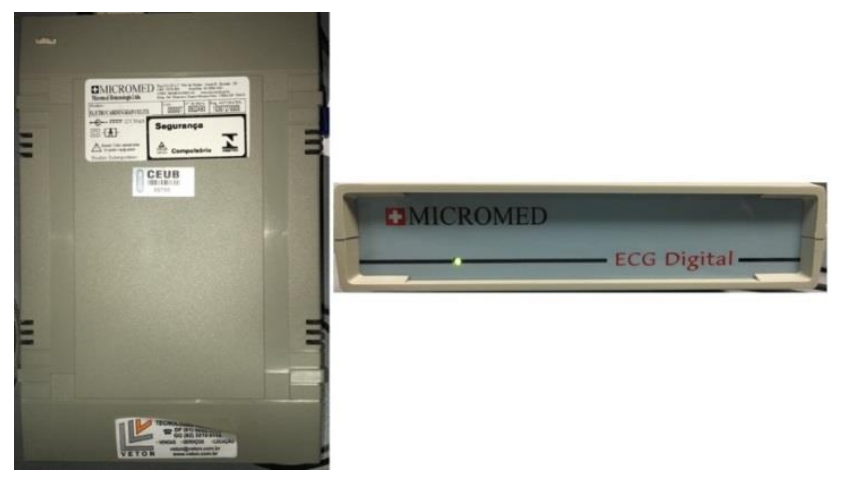

Figura 4.5-1: Eletrocardiógrafo profissional Fonte: Elaborada pelo autor

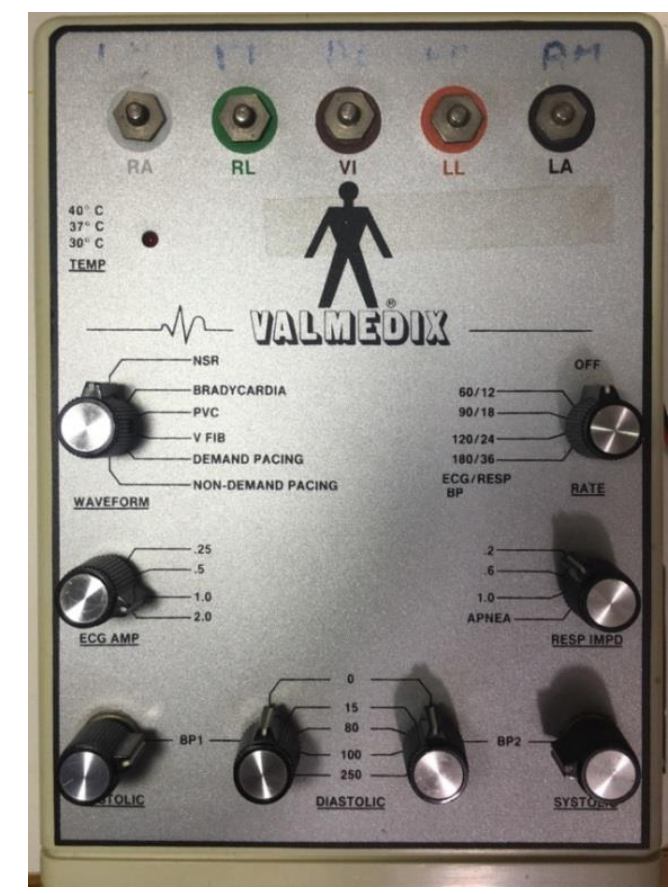

Figura 4.5-2: Simulador de ECG Fonte: Elaborada pelo autor 
A Figura 4.5-1 mostra o eletrocardiógrafo profissional, da marca Micromed e modelo Elite, existente no Uniceub. A Figura 4.5-2 mostra o equipamento simulador, da marca Valmedix, utilizado para gerar os sinais cardíacos.

Primeiramente é conectado o simulador de sinais cardíacos aos eletrodos do eletrocardiógrafo profissional e, em seguida, no software próprio do equipamento, é extraído o valor de tensão dos picos das ondas $P, R$ e T que serão comparados com os valores de tensão recebidos pelo dispositivo proposto. Posteriormente, com o mesmo gerador de sinais cardíacos conectados no protótipo, é gerado um gráfico de tensão, através do Microsoft Excel, com o valor de cada ponto de tensão das mesmas ondas. A Figura 4.5-3 mostra o resultado do comparativo entre os valores recebidos.
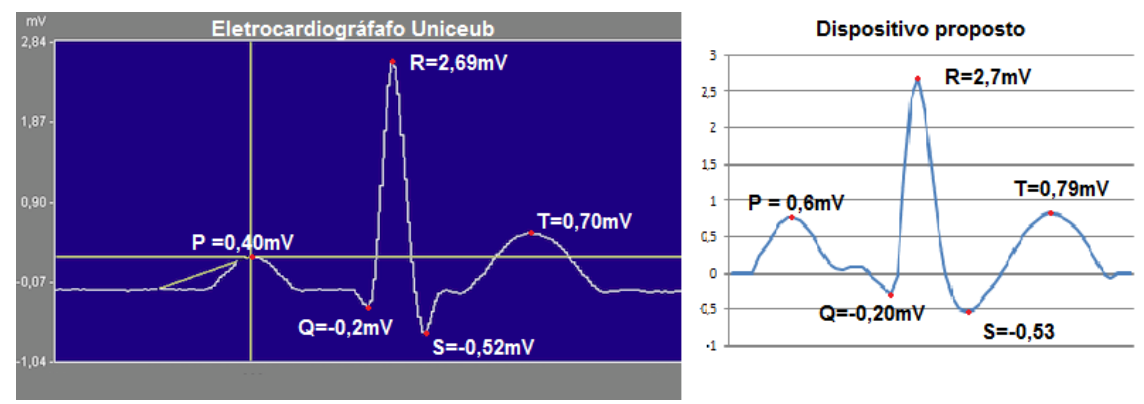

Figura 4.5-3: Comparativo Eletrocardiógrafo profissional x Dispositivo proposto Fonte: Elaborada pelo autor

Na figura anterior, o gráfico em azul, mostra os pontos de tensão para cada onda adquiridos pelo software próprio do eletrocardiógrafo profissional, o gráfico em branco mostra os pontos de tensão adquiridos do protótipo. O Quadro 4.5-1 apresenta o comparativo para cada ponto.

\begin{tabular}{|c|c|c|c|c|}
\hline Ponto & $\begin{array}{c}\text { Eletrocardiógrafo } \\
\text { Profissional }\end{array}$ & $\begin{array}{c}\text { Dispositivo } \\
\text { proposto }\end{array}$ & Erro absoluto & Erro relativo \\
\hline $\mathbf{P}$ & $0,40 \mathrm{mV}$ & $0,60 \mathrm{mV}$ & $0,20 \mathrm{mV}$ & $50 \%$ \\
\hline $\mathbf{Q}$ & $-0,20 \mathrm{mV}$ & $-0,20 \mathrm{mV}$ & $0,00 \mathrm{mV}$ & $0 \%$ \\
\hline $\mathbf{R}$ & $2,69 \mathrm{mV}$ & $2,70 \mathrm{mV}$ & $0,01 \mathrm{mV}$ & $0,37 \%$ \\
\hline
\end{tabular}




\begin{tabular}{|c|c|c|c|c|}
\hline $\mathbf{S}$ & $-0,52 \mathrm{mV}$ & $-0,53 \mathrm{mV}$ & $0,01 \mathrm{mV}$ & $1,92 \%$ \\
\hline $\mathbf{T}$ & $0,70 \mathrm{mV}$ & $0,79 \mathrm{mV}$ & $0,09 \mathrm{mV}$ & $12,86 \%$ \\
\hline
\end{tabular}

Quadro 4.5-1: Erro absoluto do protótipo

Fonte: Elaborado pelo autor

A diferença entre os valores adquiridos pelo protótipo e os obtidos pelo equipamento profissional deve-se ao motivo da utilização de componentes eletrônicos com valores de precisão em $10 \%$, normalmente encontrados em lojas comuns de eletrônica. Ajustes e a implementação de componentes eletrônicos de precisão serão realizados uma vez que será dado continuidade ao projeto junto com o professor Duque. Nesse cenário, a primeira resposta dada pelo protótipo é adequada diante da utilização de componentes eletrônicos sem precisão, onde é dada em equipamentos profissionais. O protótipo passará por uma nova fase de testes, acompanhada por professores das áreas de saúde do UniCEUB, tais como Medicina e Fisiologia.

Também é feito um comparativo entre as dimensões do eletrocardiógrafo profissional, contido no Centro Universitário de Brasília (Uniceub), e o protótipo criado. A Figura 4.5-4 mostra o comparativo em questão.

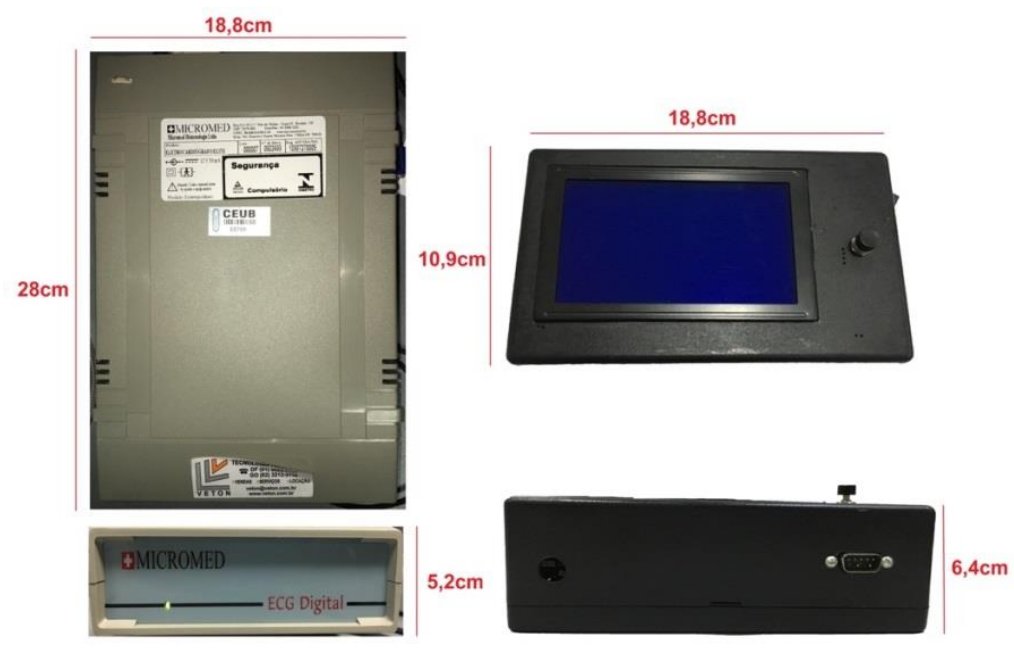

Figura 4.5-4: Comparativo de dimensões Fonte: Elaborada pelo autor

Na Figura 4.5-4 foram realizadas as medidas de dimensões entre o equipamento 
profissional e o dispositivo finalizado, gerando o Quadro 4.5-2 de dimensões.

\begin{tabular}{|c|c|c|}
\hline Dimensões & $\begin{array}{c}\text { Eletrocardiógrafo } \\
\text { profissional }\end{array}$ & Protótipo proposto \\
\hline Comprimento & $28,0 \mathrm{~cm}$ & $10,9 \mathrm{~cm}$ \\
\hline Largura & $18,8 \mathrm{~cm}$ & $18,8 \mathrm{~cm}$ \\
\hline Altura & $5,2 \mathrm{~cm}$ & $6,4 \mathrm{~cm}$ \\
\hline Volume & $2737,28 \mathrm{~cm}^{3}$ & $1311,49 \mathrm{~cm}^{3}$ \\
\hline
\end{tabular}

Quadro 4.5-2: Dimensões

Fonte: Elaborado pelo autor

Do quadro 4.5-2 verifica-se que o dispositivo proposto é menor que o equipamento profissional comparado. Este comparativo é realizado para se obter uma percepção das dimensões do protótipo final construído. 
A medicina compreende como um ramo essencial, de forma assistencialista, para a existência do ser humano. A sua evolução ao longo dos anos ocasionou uma maior qualidade de vida ao indivíduo, além de um alongamento da sua expectativa de vida. Dessa forma, emparelhou-se ao desenvolvimento tecnológico, utilizando as inovações, tanto de equipamentos eletrônicos como de softwares, para gerar diagnósticos mais eficientes de doenças e disfunções.

Um instrumento que possibilita a sua portabilidade garante maior facilidade na realização dos exames necessários em seu dispositivo. Assim como proposto neste projeto, essa portabilidade agiliza o processo de detecção de doenças cardíacas e podem ser aplicados em localidades desprovidas de recursos, enviando seus resultados remotamente a um especialista para que realize o diagnóstico devido.

Com isso, por ser um dispositivo portátil, sua principal vantagem é a de permitir que qualquer profissional da saúde possa manusear e realizar o exame, enviando seu produto via internet para um cardiologista. Esse especialista analisará o resultado, podendo sugerir ao paciente que se desloque a um centro médico, evitando, dessa maneira, maiores danos ao indivíduo consultado. A sua facilidade e a viabilidade de envio dos resultados podem salvar vidas, principalmente em locais remotos.

A proposta do projeto em questão, baseia-se na captação e transmissão dos sinais cardíacos do indivíduo para a análise por um especialista. A análise do sinal cardíaco é apresentada na tela do dispositivo e posteriormente transmitida.

Foram implementados filtros analógicos utilizando amplificadores operacionais, que eliminam grande parte de sinais e ruídos que não fazem parte do sinal cardíaco. Também é implementado um filtro digital por meio de uma biblioteca específica que, através da transformada wavelet, obtém-se um sinal mais limpo e claro. O display gráfico acoplado no sistema permite que o operador visualize o sinal cardíaco no local da realização da análise e o cartão de memória permite que o sinal seja gravado no local. Para a transmissão é desenvolvido um software que abre o arquivo previamente gravado e realiza a transmissão do gráfico via email para o especialista.

Duas linguagens de programação diferentes, C e C\#, são desenvolvidas com intuito de tornar o sistema prático e funcional, sendo agregado com a biblioteca Waveletfilter, que tem um papel fundamental para retirada de ruídos externos do sinal. 
Os objetivos no início do planejamento do projeto foram atingidos e o resultado dos testes comprovaram o correto funcionamento dos componentes envolvidos. Importante destacar que as dimensões e sua portabilidade é um diferencial se comparado aos equipamentos encontrados no mercado. O protótipo ainda encontra em fase de ajustes e desenvolvimento de novas funções, porém será produzido mais uma unidade do protótipo e o mesmo vai ficar para testes nos laboratórios de ciências do Uniceub (Labocien) pelos professores e alunos dos cursos de saúde.

\section{REFERÊNCIAS}

ABC.MED.BR. (15 de Fevereiro de 2013). Como é feito o eletrocardiograma. Acesso em 
16 de 03 de 2016, disponível em abc.med.br: http://www.abc.med.br/p/338024/como+e+feito+o+eletrocardiograma+para+que+ser ve.htm

COTRIM, A. (2009). Instalações Elétricas. Prince Hall.

DAUBECHIES, I. (1992). Ten Lectures on Wavelet. Mass: SIAM.

DINIZ, P. S., DA SILVA, E. A., \& NETTO, S. L. (2004). Processamento digital de sinais: Projeto e Análise de Sistemas. Porto Alegre: Bookman.

GESELOWITZ, D. B. (1989). On the Theory of the Electrocardiogram (Vol. 77). Proceedings of the IEEE.

GOLDMAN, M. J. (1973). Principles of Clinical Electrocardiography.

INSTITUTO FEDERAL DO ESPÍRITO SANTO. (s.d.). Instituto Federal do Espírito Santo. Acesso em 01 de Abril de 2016, disponível em ifes.edu.br: ftp://ftp.ifes.edu.br/cursos/Eletrotecnica/Pandolfi/Eletr\%F4nica\%20B\%E1sica/Amp\%2 0Op/AMPLIFICADOR_OPERACIONAL_E_555[1].pdf

JÚNIOR, A. P. (2003). Amplificadores Operacionais e Filtros Ativos (Vol. 6). Porto Alegre, RS: Bookman.

JOHNSON, H. (1991). Análise Básica de Circuitos Elétricos. MEXICO: Prentice Hall.

KAISER, G. (2004). A friendly guide to wavelets. Woodbine: Birkhauser.

KILPATRICK, D., \& JOHNSTON, P. (1994). Origin of the Electrocardiogram. IEEE Engeineering in Medicine and Biology (Vol. 1). Piscataway: IEEE.

MALLAT, S. (1999). A Wavelet Tour of Signal Processing. San Diego: Academic Press. MALVINO, A. P. (1985). Microcomputadores e microprocessadores. São Paulo, SP, Brasil: McGraw-Hill do Brasil. 
OLIVEIRA, H. M. (2007). Análise de Sinais para Engenheiros: Uma Abordagem via Wavelets. Recife: Brasport.

POSTEL, J. B. (1982). SIMPLE MAIL TRANSFER PROTOCOL. RFC 821. INTERNET STANDARD.

RANGAYYAN, R. M. (2002). Biomedical signal analysis: A case-study approach. Piscataway: IEEE Press / John Wiley \& Sons.

SOCIEDADE BRASILEIRA DE CARDIOLOGIA. (2003). Diretrizes de Insterpretação de Eletrocardiograma de Repouso (Vol. II). Arquivo Brasileiro de Cardiologia.

STRANG, G., \& NGUYEN, T. (1996). Wavelets and filter banks. Wellesley Cambridge.

TEXAS INSTRUMENTS. (MARÇO de 2001). Texas Instruments. Acesso em 1 de ABRIL de 2016, disponível em ti.com: http://www.ti.com/lit/ds/symlink/tlc274.pdf

TEXAS INSTRUMENTS. (JANEIRO de 2015). Texas Intruments. Acesso em 1 de ABRIL de 2016, disponível em ti.com: http://www.ti.com/lit/ds/symlink/Im124-n.pdf

WOLF, A. S. (2004). O CORAÇÃO E A ATIVIDADE ELÉTRICA CARDÍACA. Acesso em 16 de 03 de 2016, disponível em Divisão de Bibliotecas e Documentação: http://www2.dbd.puc-rio.br/pergamum/tesesabertas/0210429_04_cap_02.pdf 


\section{APÊNDICES}

\section{APÊNDICE A - CÓDIGO DO CIRCUITO PRINCIPAL}

/////////////////////////////////////////////////////////////////////////////

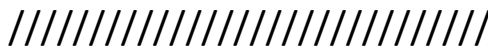

// Trabalho de Conclusão de Curso do Centro Universitário de Brasília // Ra: 21160644

// Aluno: Hugo Molina Monteiro

// Curso: Engenharia da computação

// Período: 07/2016

// Firmware do circuito principal do projeto, responsável por captar os dados // previamente filtrados pelo circuito condicionador, mostra-los em um display // gráfico e gerar um arquivo CSV contendo os sinais cardíacos captados.

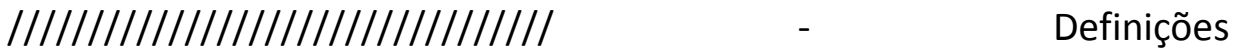

////////////////////////////////////////////////////////////

//Importa biblioteca responsável por gerenciar o display gráfico

\#include "_T6963C.h"

//Importar biblioteca responsável por gerecniar as imagens contídas no firmware \#include "Imagens.c"

$/ / / / / / / / / / / / / / / / / / / / / / / / / / / / / / / / /$-Definições de Pinos Display e LCD/////////////////////////////

//Pinos de controle do Display Gráfico

char T6963C_dataPort at PORTD;

sbit T6963C_ctrlwr at RC1_bit; // WR write signal

sbit T6963C_ctrlrd at RB3_bit; // RD read signal

sbit T6963C_ctrlcd at RB4_bit; / / CD command/data signal

sbit T6963C_ctrlrst at RB5_bit; $\quad$ // RST reset signal 
sbit T6963C_ctrlwr_Direction at TRISC1_bit; // WR write signal sbit T6963C_ctrIrd_Direction at TRISB3_bit; // RD read signal sbit T6963C_ctrlcd_Direction at TRISB4_bit; // CD command/data signal sbit T6963C_ctrlrst_Direction at TRISB5_bit; // RST reset signal

//Pinos responsáveis por controlar o Leitor de SD sfr sbit Mmc_Chip_Select at RCO_bit; sfr sbit Mmc_Chip_Select_Direction at TRISCO_bit;

//////////////////////////////////-Definições de Variáveis//////////////////////////////////////////////////

int i;

unsigned int Buffer[240];

unsigned char Buffermmc[480];

unsigned int Cont $=0$;

bit gravar;

unsigned long leitura $=0$;

//////////////////////////////////-Função de Interrupção/////////////////////////////////////////////////////

void interrupt()

\{

//Interrupção externa número 2

if (INTCON3.INT2IF == 1)

\{

//Seta Flag para gravação

gravar = 1;

//Limpa Flag de interrupção

INTCON3.INT2IF = 0;

\} 
void interrupt_low()

\{

\}//end interrupt_low()

//////////////////////////////////-Função

Principal-

/////////////////////////////////////////////////

void main() \{

//Inicia vetor no formato do arquivo no cartão de memória

char TXT[] = "0000;";

//Inicia vetor no formato do nome do arquivo que será gerado

char nome[] = "0.CSV";

//Desativa comparadores internos

$\mathrm{CMCON}=0 \times 07$;

//Ativa entrada de pino analógica na porta de conexão 2 - AN1

ADCONO $=0 \times 01 ;$

ADCON1 = 0x0E;

ADCON2 $=0 \times 05$;

//Define portas de entradas e saídas do sistema

TRISB = 0x64;

TRISC $=0 \times 00 ;$

PORTC $=0 \times 00$;

RCON.IPEN = 1; //Ativa nível nas interrupcoes

INTCON.GIEH = 1; //Ativa todas as interrupces de alta prioridade

INTCON.GIEL = 1; //Ativa todas as interrupces de baixa prioridade

INTCON3.INT2IE = 1; //Ativa interrupção externa na porta INT2

//Desliga BIT de gravação do sinal

gravar $=0$;

delay_ms(200); 
//Inicia display gráfico-tamanho $240 \times 128$

T6963C_init $(240,128,8)$;

T6963C_graphics(1);

T6963C_text(1);

T6963C_panelFill(0);

//Inicializa Cartão de memória

SPI1_Init_Advanced(_SPI_MASTER_OSC_DIV64,

_SPI_DATA_SAMPLE_MIDDLE,_SPI_CLK_IDLE_LOW, _SPI_LOW_2_HIGH);

//Mostra imagem do CEUB

T6963C_image(uniceub);

delay_ms(3000);

T6963C_image(desenvolvido);

delay_ms(5000);

//Mostra tela de inicialização

T6963C_image(menu);

T6963C_write_text("ELETROCARDIOGRAMA

PORTATIL",1,1,T6963C_ROM_MODE_XOR);

delay_ms(500);

T6963C_write_text("Inicializando...",1,4,T6963C_ROM_MODE_XOR);

delay_ms(300);

if (!Mmc_Fat_Init()) \{

// Reinicializa cartão de memória em uma maior velocidade

SPI1_Init_Advanced(_SPI_MASTER_OSC_DIV4, _SPI_DATA_SAMPLE_MIDDLE,

_SPI_CLK_IDLE_LOW,_SPI_LOW_2_HIGH);

//Verifica se cartão de memória está inserido

T6963C_write_text("Cartao SD Inserido!",1,5,T6963C_ROM_MODE_XOR);

\}else

T6963C_write_text("Cartao SD Removido!",1,5,T6963C_ROM_MODE_XOR);

delay_ms(10000);

T6963C_panelFill(0); 


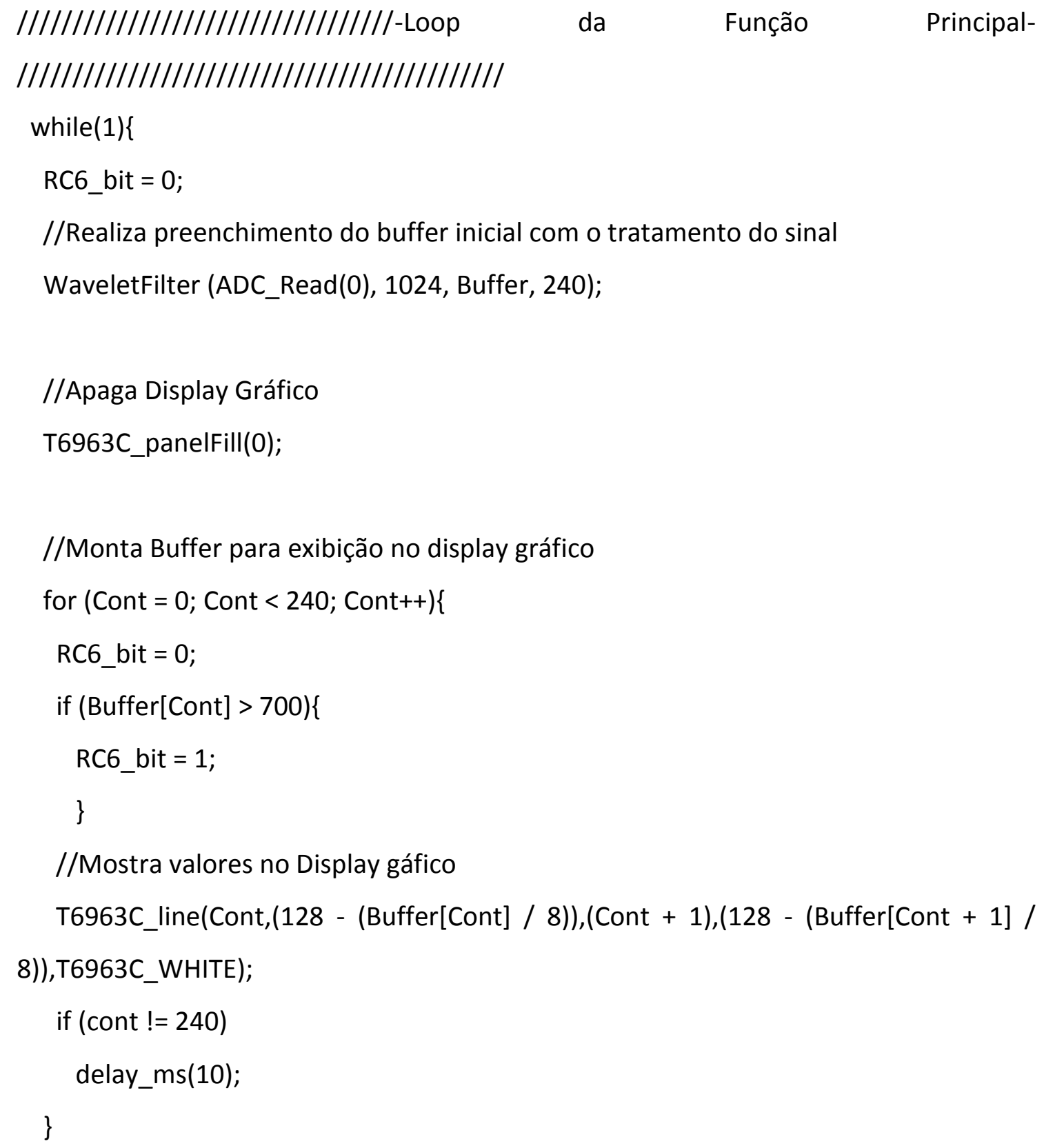




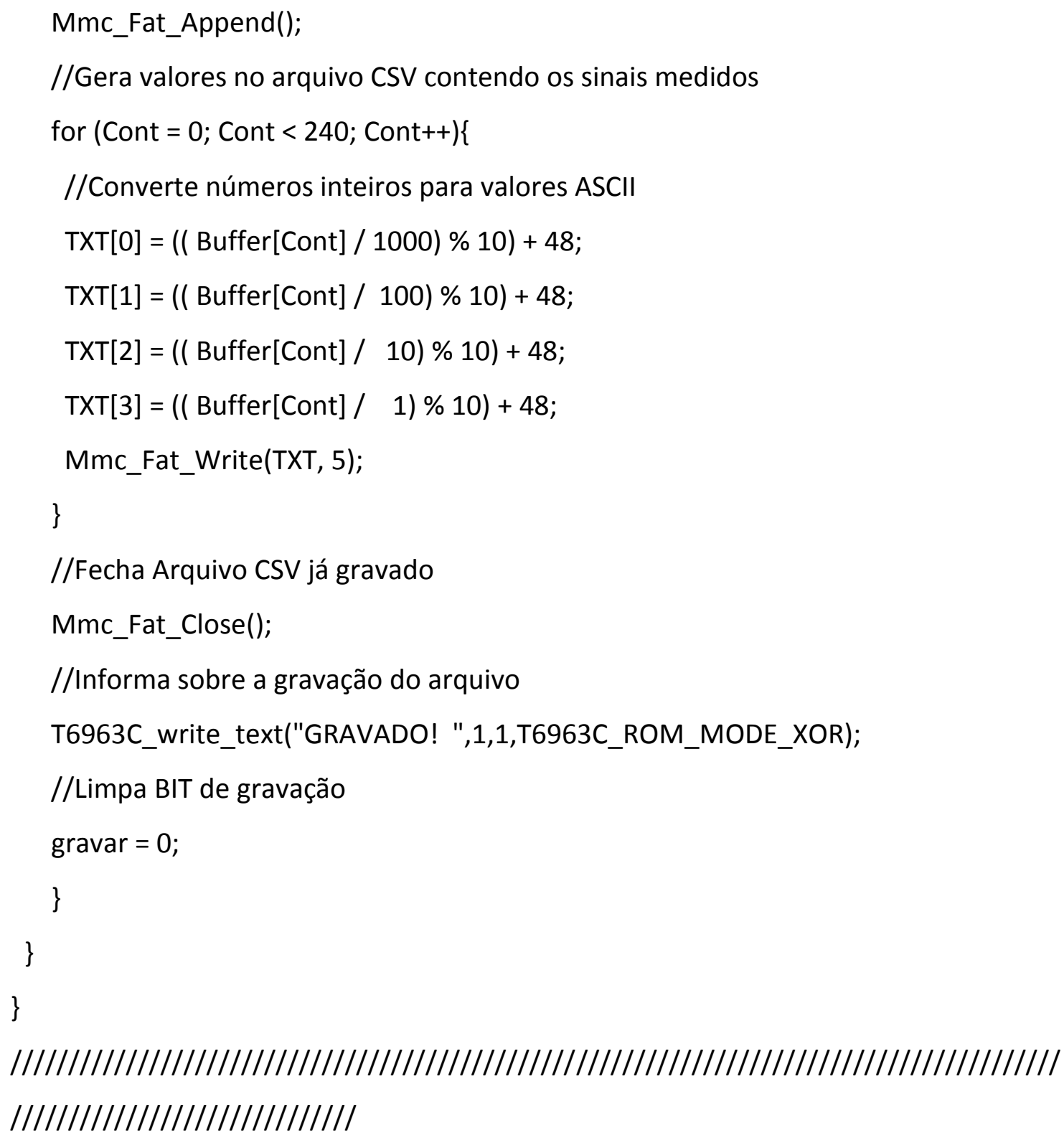


// Período: 07/2016

// Código fonte do software criado para transmitir os dados criados no dispositivo // portátil via email.

$/ / / / / / / / / / / / / / / / / / / / / / / / / / / / / /$ - Classe para ler arquivo ////////////////////////////////////////////

namespace LerCSV

\{

public class ArquivoCSV

\{

public string[] MetodoParaLerLinhaArquivo()

\{

string arquivo = "0";

OpenFileDialog openFileDialog = new OpenFileDialog();

\{

openFileDialog.Title = "Software Transmissor - Abrir";

openFileDialog.InitialDirectory = @"c: \Program Files";

openFileDialog.Filter $=$ "All files $\left.\left({ }^{*} .{ }^{*}\right)\right|^{*} .{ }^{*} \mid$ All files $\left.\left({ }^{*} .{ }^{*}\right)\right|^{*} .^{*}$;

openFileDialog.FilterIndex $=2$;

openFileDialog. RestoreDirectory = true;

if (openFileDialog.ShowDialog() == DialogResult.OK)

arquivo = openFileDialog. FileName;

\}

//Caminho onde se encontra o arquivo

StreamReader rd = new StreamReader(arquivo);

$/ /$ rd = arquivo;

//Linha completa do arquivo

string linha = null;

//Array do tipo string utilizado para adicionar o conteúdo da linha separado

string[] linhaseparada = null;

//realizo o while para ler o conteudo da linha 


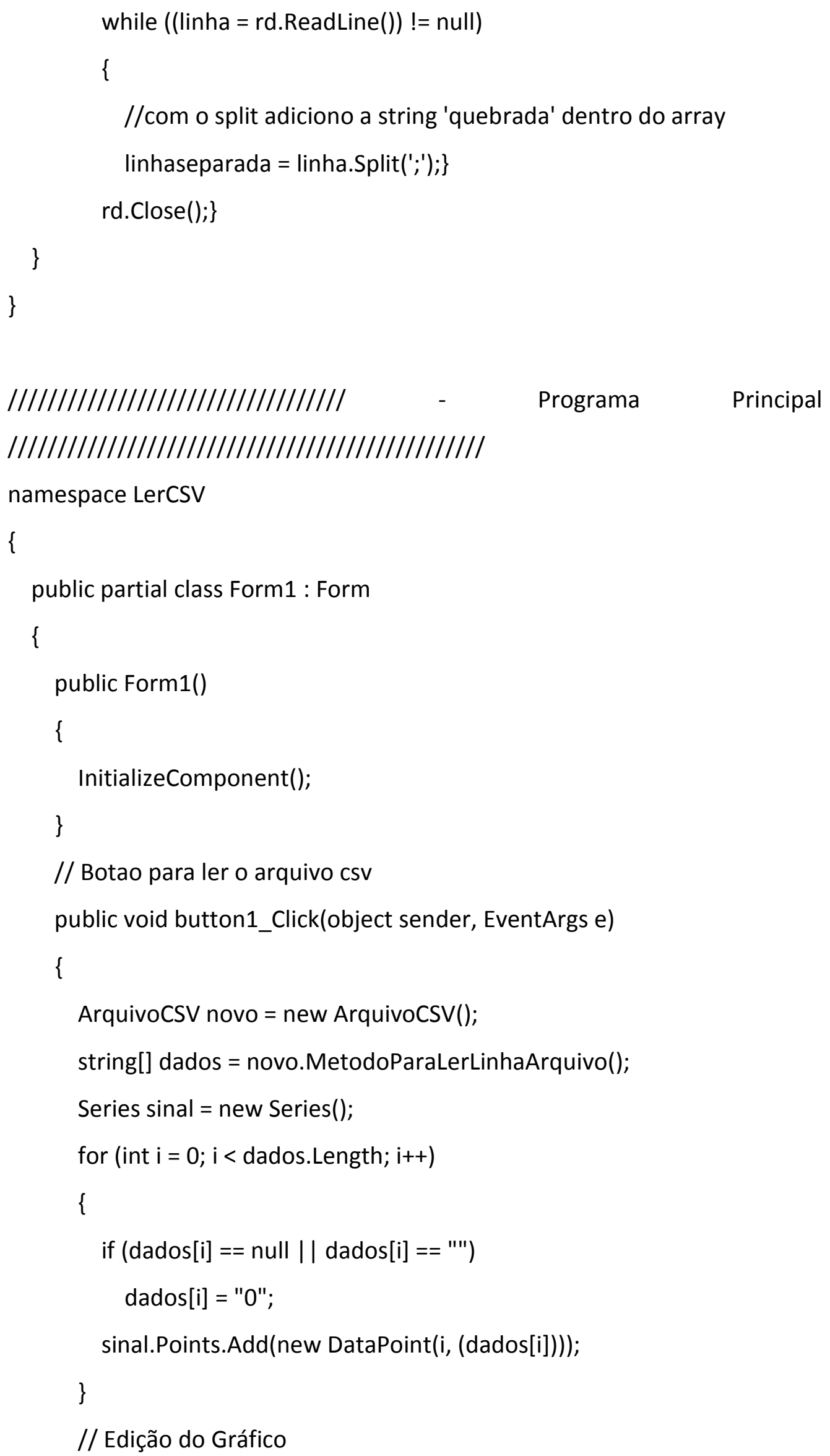


sinal.Color $=$ Color. Red;

sinal.ChartType = SeriesChartType.Line;

sinal.BorderWidth = 3;

sinal.Name = "Sinal Cardlaco";

gerarGrafico.ChartAreas["ChartArea1"].AxisX.MajorGrid.Enabled = false;

gerarGrafico.ChartAreas["ChartArea1"].AxisY.MajorGrid.Enabled = false;

gerarGrafico.ChartAreas["ChartArea1"].AxisX.LabelStyle.Enabled = false;

gerarGrafico.ChartAreas["ChartArea1"].AxisY.LabelStyle.Enabled = false;

// Mostra o sinal no Grafico.

gerarGrafico.Series.Add(sinal);

//Codigo que tira uma foto para ser enviado ao médico

var $\mathrm{bmp}=$ new Bitmap(gerarGrafico.Width, gerarGrafico. Height);

gerarGrafico.DrawToBitmap(bmp, new Rectangle(0, 0, bmp.Width, bmp.Height));

bmp.Save("Grafico.jpeg", System.Drawing.Imaging.ImageFormat.Jpeg);

bmp.Dispose();

MessageBox.Show("Ja foi tirada uma foto no mesmo local do Executavel!");

enviarEmail.Enabled = true;

\}

private void enviarEmail_Click(object sender, EventArgs e)

\{

EnviarEmail mostraCadastro = new EnviarEmail();

mostraCadastro.Show();

\}

\}

\}

$/ / / / / / / / / / / / / / / / / / / / / / / / / / / / / /$ - Classe para enviar email

///////////////////////////////////

namespace LerCSV 


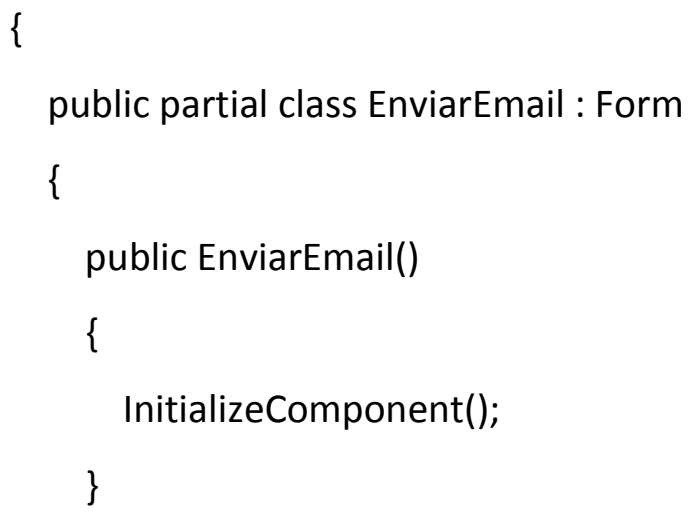

System.Net.NetworkCredential("ecgtccfinal@gmail.com", "Senha do email"); //Criando o SMPT cliente.

using (System.Net.Mail.MailMessage mail = new
System.Net.Mail.MailMessage())

\{

// Criando o Corpo do Email mail.From = new System.Net.Mail.MailAddress("ecgtccfinal@gmail.com"); if (!string.IsNullOrWhiteSpace(txtPara.Text))

\{ mail.To.Add(new System.Net.Mail.MailAddress(txtPara.Text)); \} else 


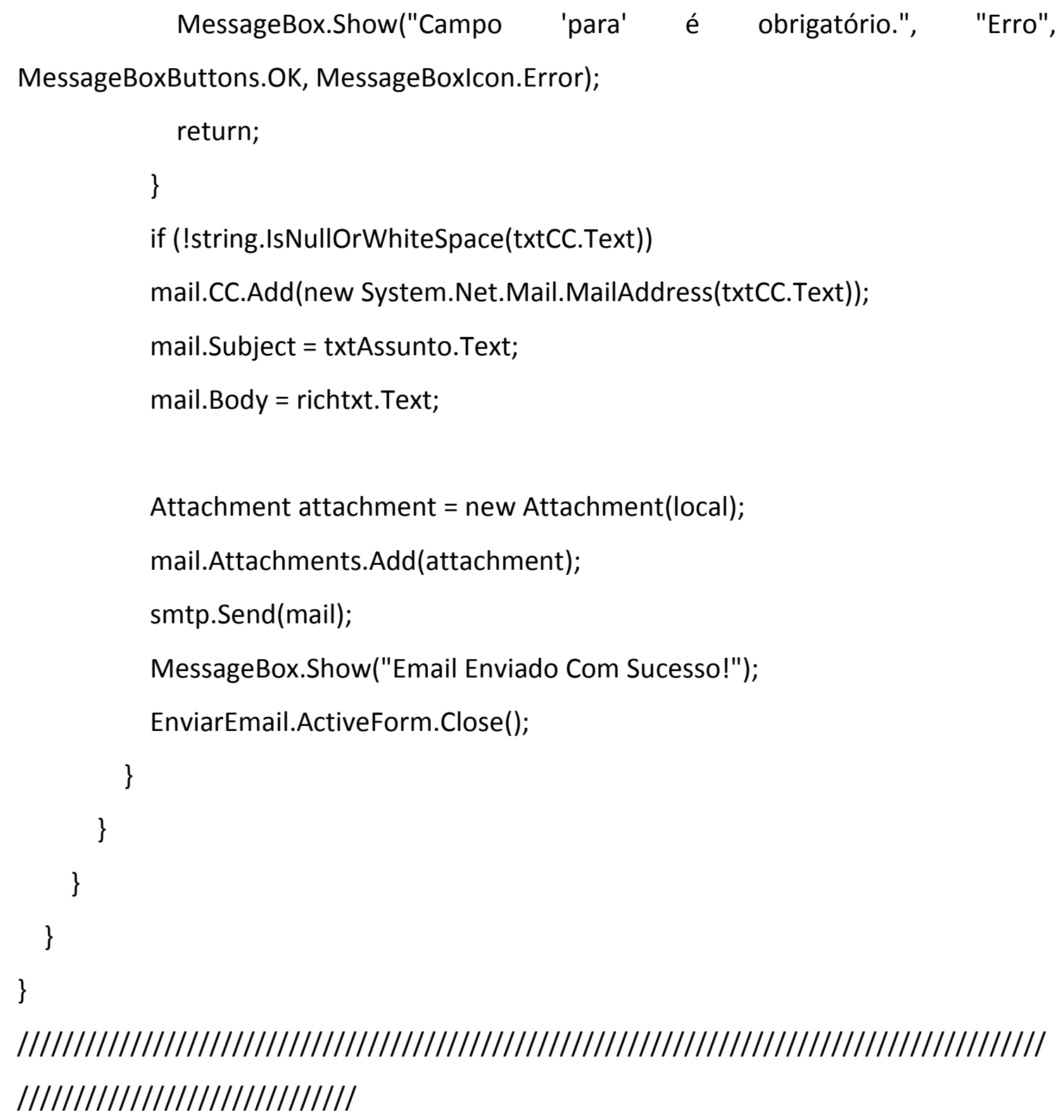

